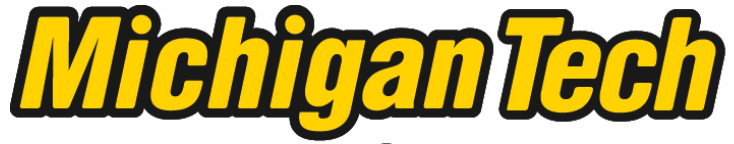 \\ Michigan Technological University Create the Future Digital Commons @ Michigan Tech
}

Dissertations, Master's Theses and Master's Reports - Open

Dissertations, Master's Theses and Master's

Reports

2015

DESIGN AND IMPLEMENTATION OF A MOBILE TEST CELL

Timothy J. Okkema

Michigan Technological University

Follow this and additional works at: https://digitalcommons.mtu.edu/etds

Part of the Automotive Engineering Commons

Copyright 2015 Timothy J. Okkema

\section{Recommended Citation}

Okkema, Timothy J., "DESIGN AND IMPLEMENTATION OF A MOBILE TEST CELL", Master's Thesis, Michigan Technological University, 2015.

https://doi.org/10.37099/mtu.dc.etds/995

Follow this and additional works at: https://digitalcommons.mtu.edu/etds

Part of the Automotive Engineering Commons 


\title{
DESIGN AND IMPLEMENTATION OF A MOBILE TEST CELL
}

By

Timothy J. Okkema

\author{
A THESIS \\ Submitted in partial fulfillment of the requirements for the degree of \\ MASTER OF SCIENCE \\ In Mechanical Engineering
}

MICHIGAN TECHNOLOGICAL UNIVERSITY

2015

(C) 2015 Timothy J. Okkema 
This thesis has been approved in partial fulfillment of the requirements for the Degree of MASTER OF SCIENCE in Mechanical Engineering

\author{
Department of Mechanical Engineering - Engineering Mechanics
}

\author{
Thesis Co-Advisor: Jeffrey Naber \\ Thesis Co-Advisor: Jeremy Worm \\ Committee Member: John Lukowski
}

Department Chair: William W. Predebon 


\section{Table of Contents}

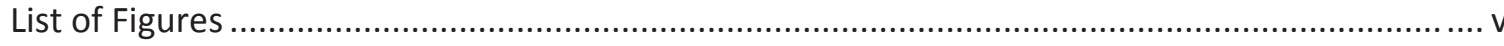

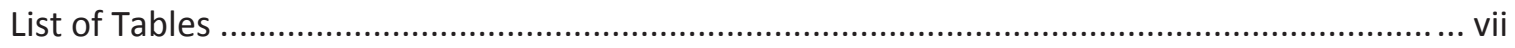

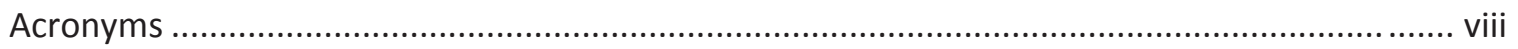

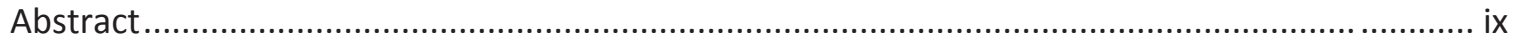

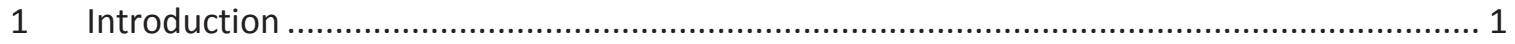

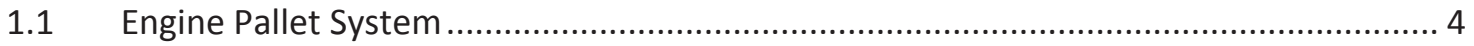

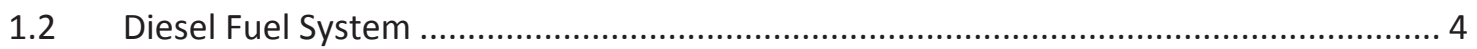

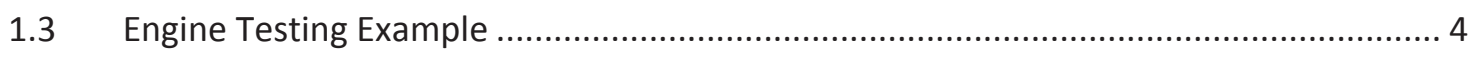

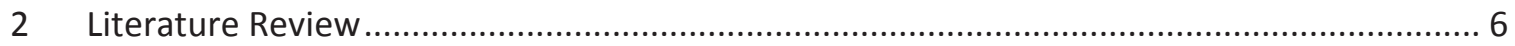

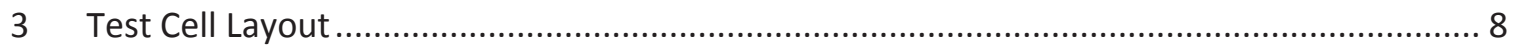

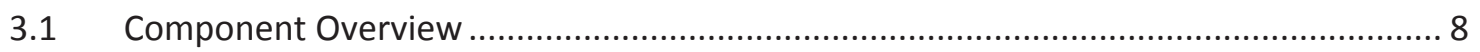

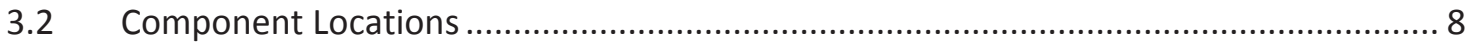

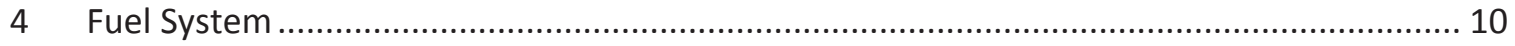

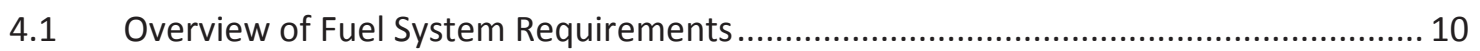

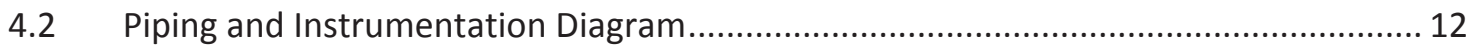

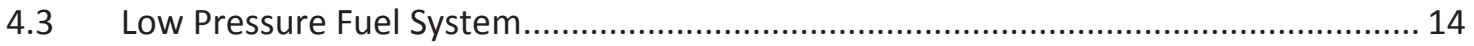

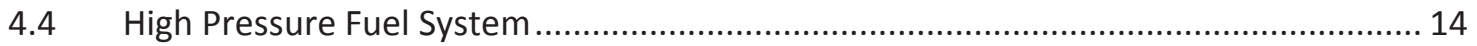

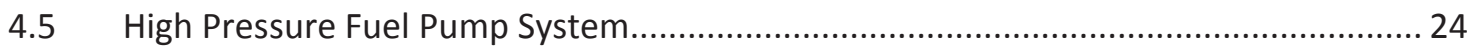

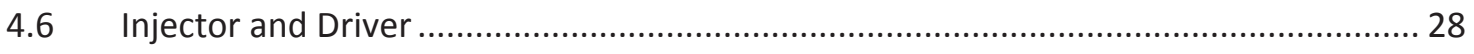

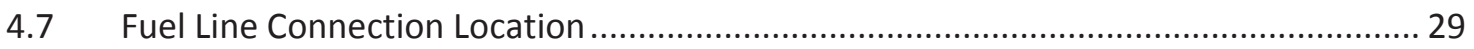

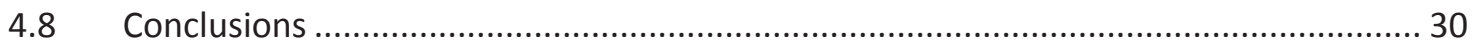

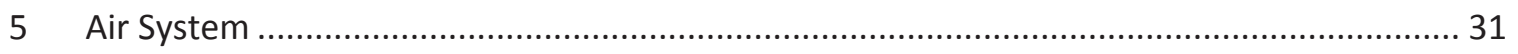

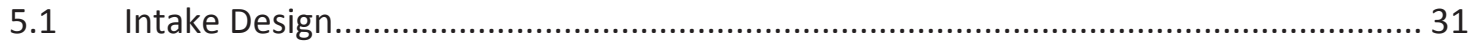

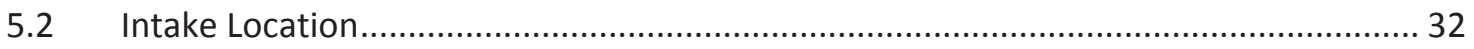

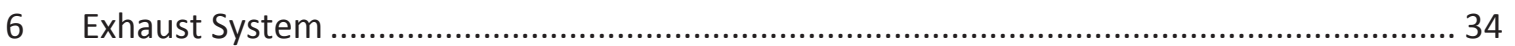

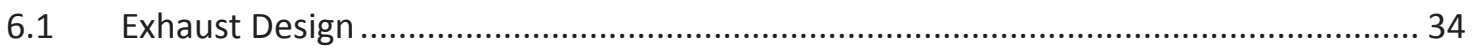

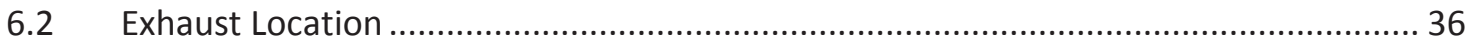

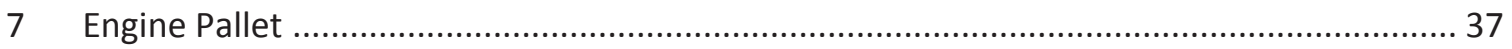

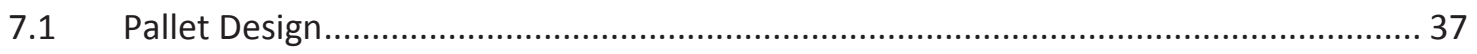




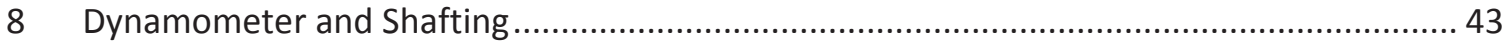

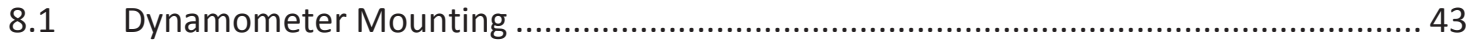

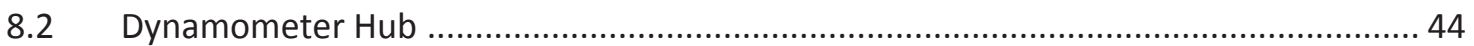

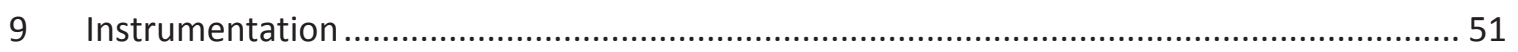

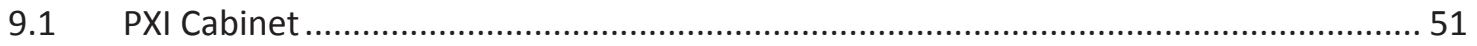

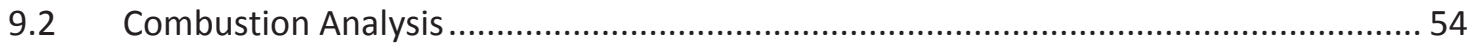

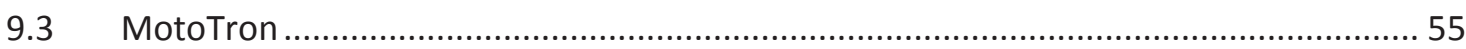

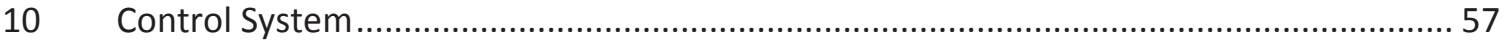

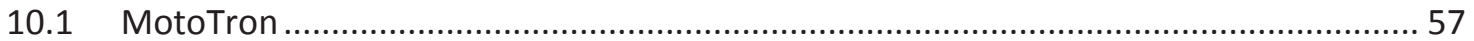

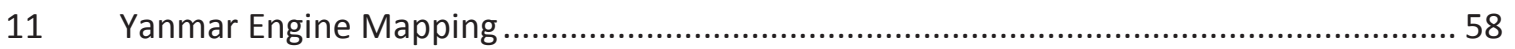

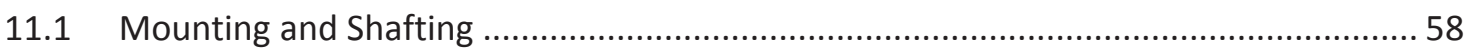

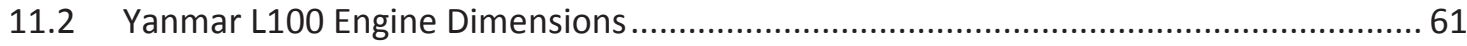

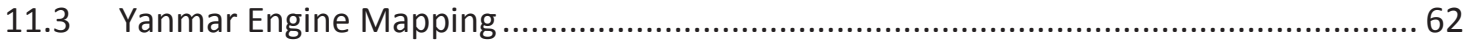

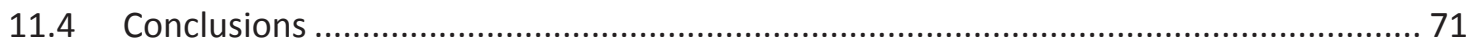

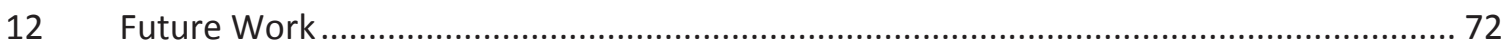

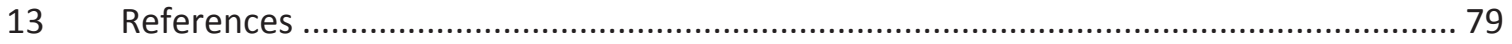




\section{List of Figures}

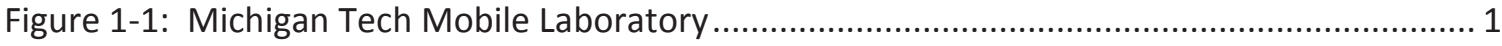

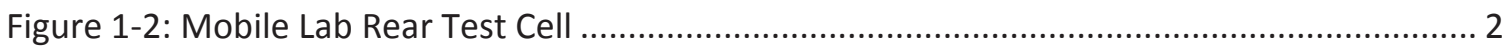

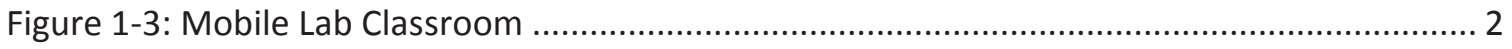

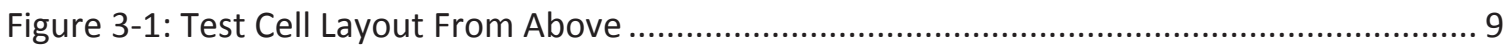

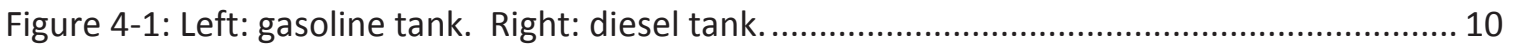

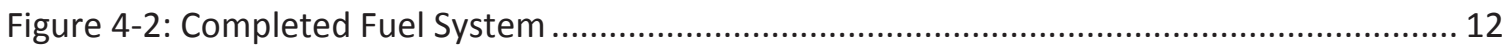

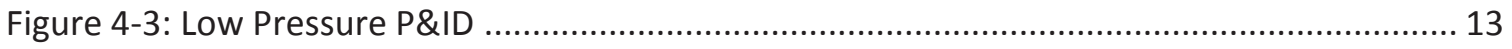

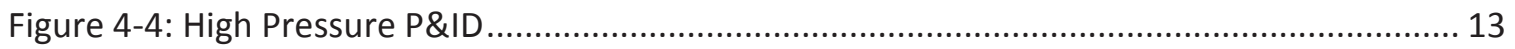

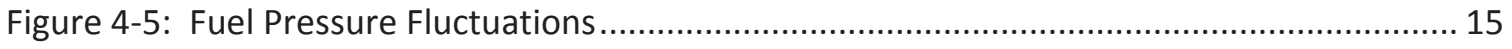

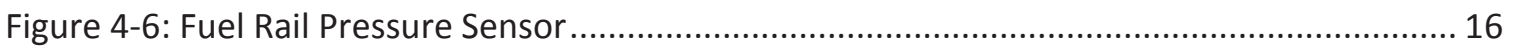

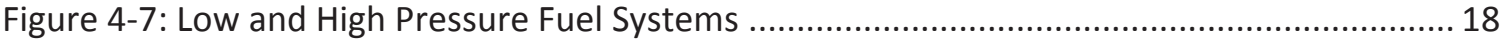

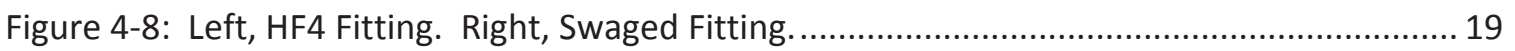

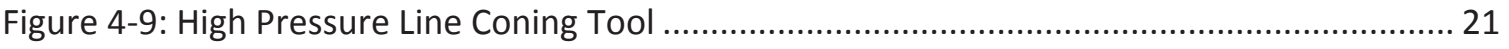

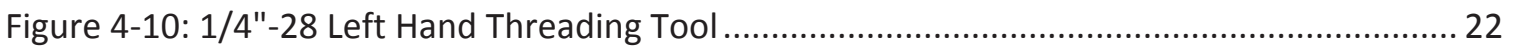

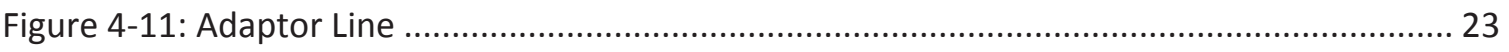

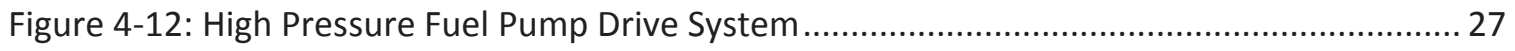

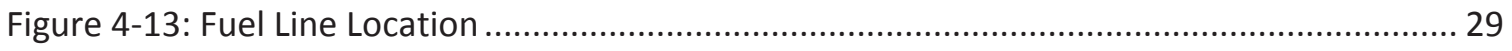

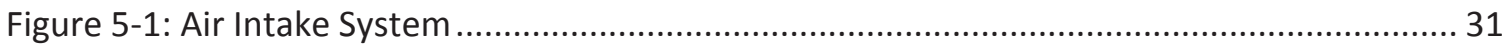

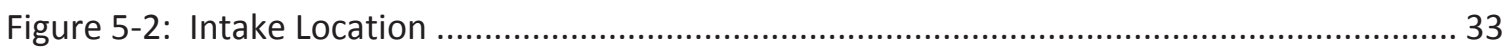

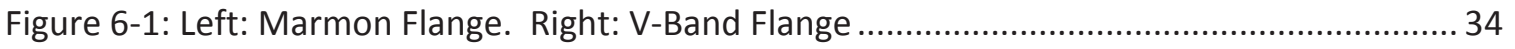

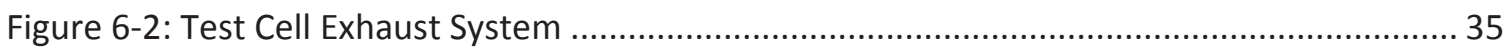

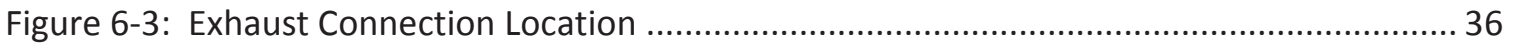

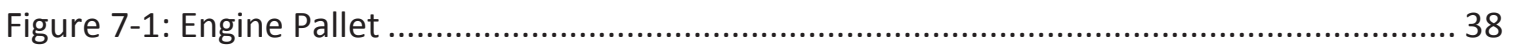

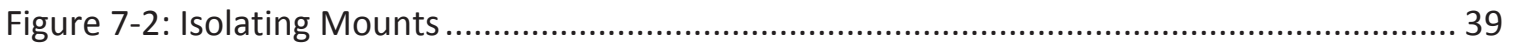

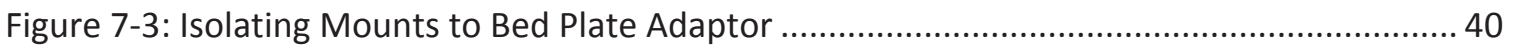

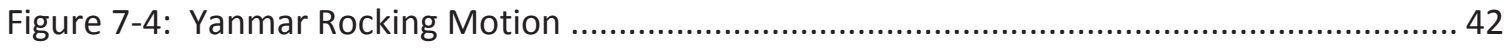

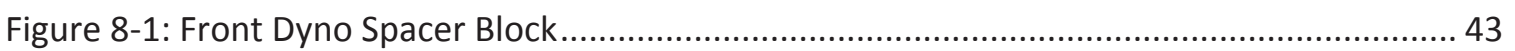

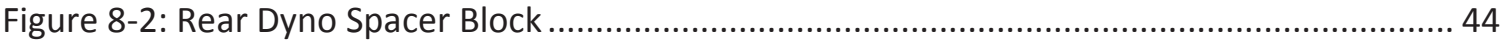

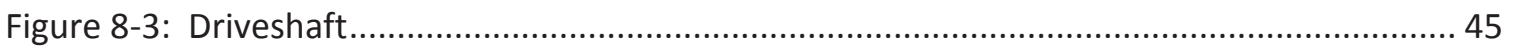

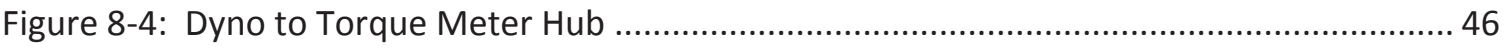

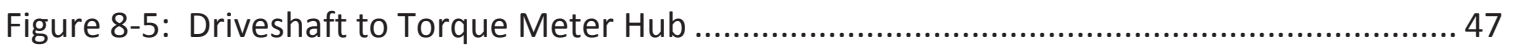

Figure 8-6: Dyno Hub Location and Isolating Mount Locations................................................ 48

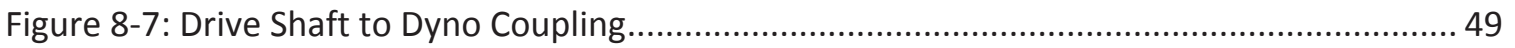

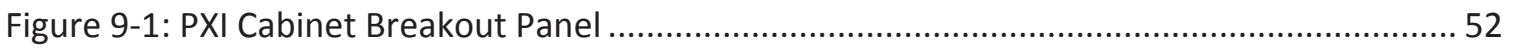

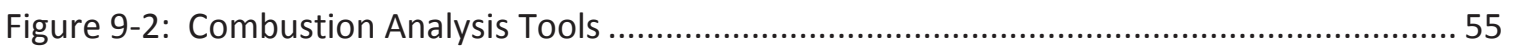

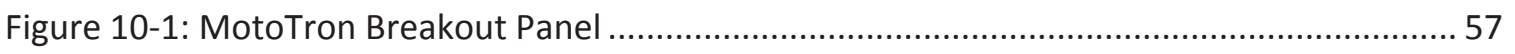

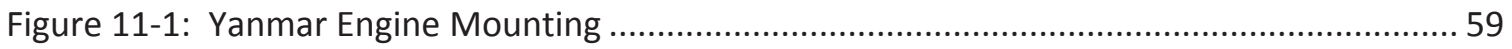




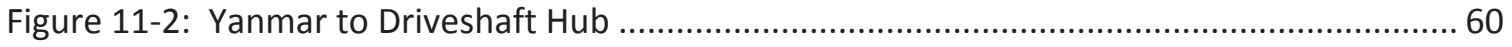

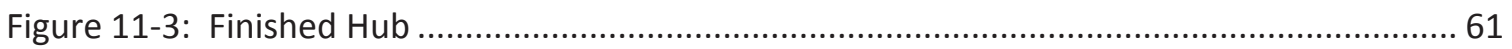

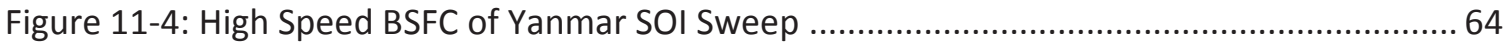

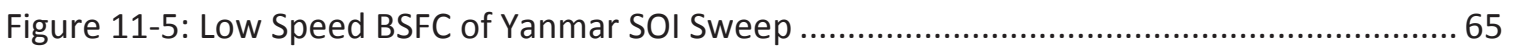

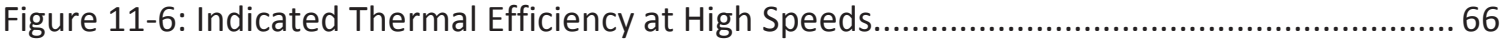

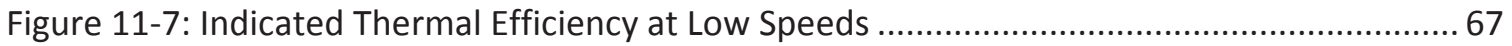

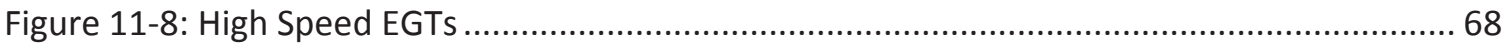

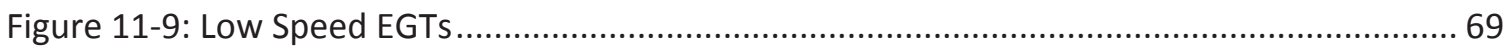

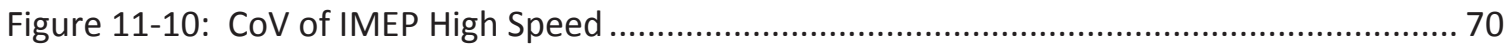

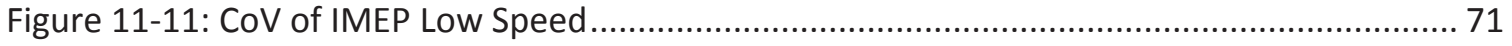

Figure 12-1: Bosch 7 Hole Common Rail Injector Spray Angle ..................................................... 73

Figure 12-2: Yanmar L100V 5 Hole OEM Injector Spray Angle ................................................... 74

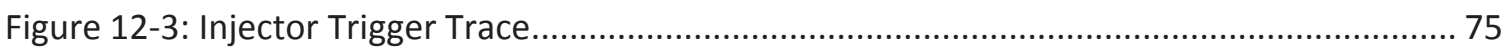

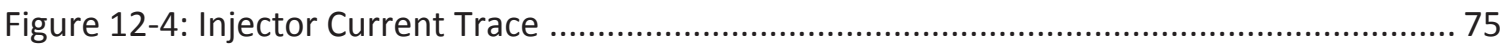

Figure 12-5: 1200RPM Injector Pulses vs High Pressure Pump Pulses ........................................ 77

Figure 12-6: 3600RPM Injector Pulses vs High Pressure Pump Pulses ........................................ 78 


\section{List of Tables}

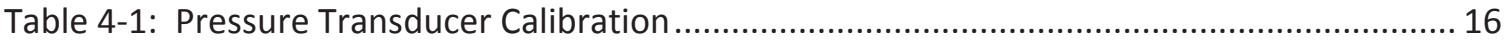

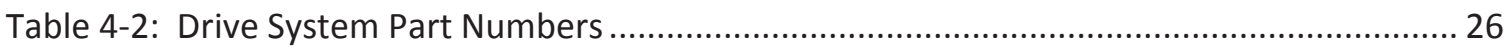

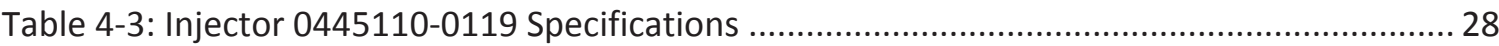

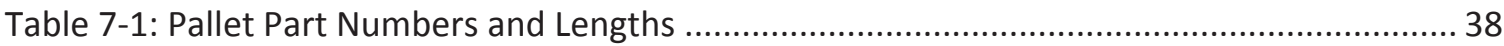

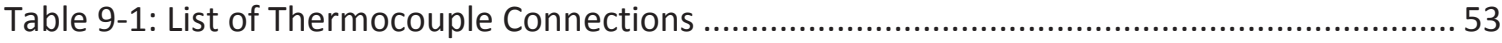

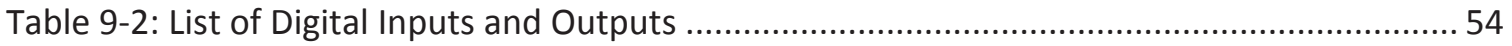

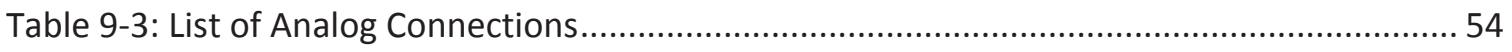

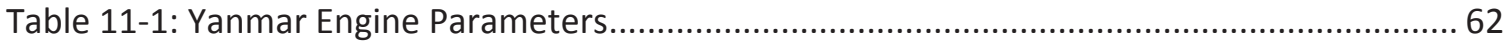

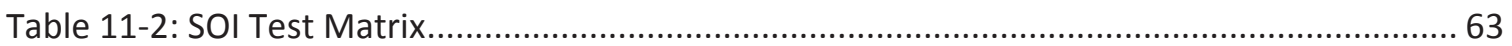




\section{Acronyms}

$\mathrm{AC}$ - Alternating Current

AVL- Anstalt für Verbrennungskraftmaschinen (Institute for Internal Combustion Engines)

BNC- Bayonet Neill - Concelman

CAD - Computer Aided Drafting

cDAQ - Compact Data Acquisition

ECU - Engine Control Unit

NEMA - National Electrical Manufacturers Association

OEM - Original Equipment Manufacturer

PXI - PCI Extensions for Instrumentation

RPM - Rotations Per Minute

SOI - Start of Injection

VAC - Voltage Alternating Current 


\begin{abstract}
In this thesis, a modular powertrain mounting and instrumentation system is developed to increase engine testing efficiency in the Michigan Technological University Mobile Laboratory (Mobile Lab). This method is specifically designed for use in an on-the-road application with limited space where traditional engine test cell designs are not practical. This system is made to be robust, but simple enough that it can easily be built by future powertrain test engineers. In addition, a wall mounted diesel system was developed to provide common rail injection pressures to add the ability for conversion of mechanical injected diesel engines. And finally, an engine was installed that uses all the test cell innovations covered in this thesis. Implementation of the system described in this thesis will help to increase the capabilities of the Mobile Lab for teaching courses and help to improve efficiency of engine testing.
\end{abstract}




\section{Introduction}

The Mobile Lab is an on-the-road teaching tool that is configurable for hands-on education. A picture of the lab is shown in Figure 1-1. The trailer contains a classroom space in the middle and two engine test cells on either end. These test cells can be used as teaching tools for powertrain development courses. The capabilities of these tests cells are on par with modern research test cells seen at many of the primary automotive manufacturers. To keep the test cells up to date, modifications are made so that they are representative of the latest innovations in powertrain testing. Figure 1-2 shows the rear powertrain test cell and Figure 1-3 shows the classroom space in the lab.

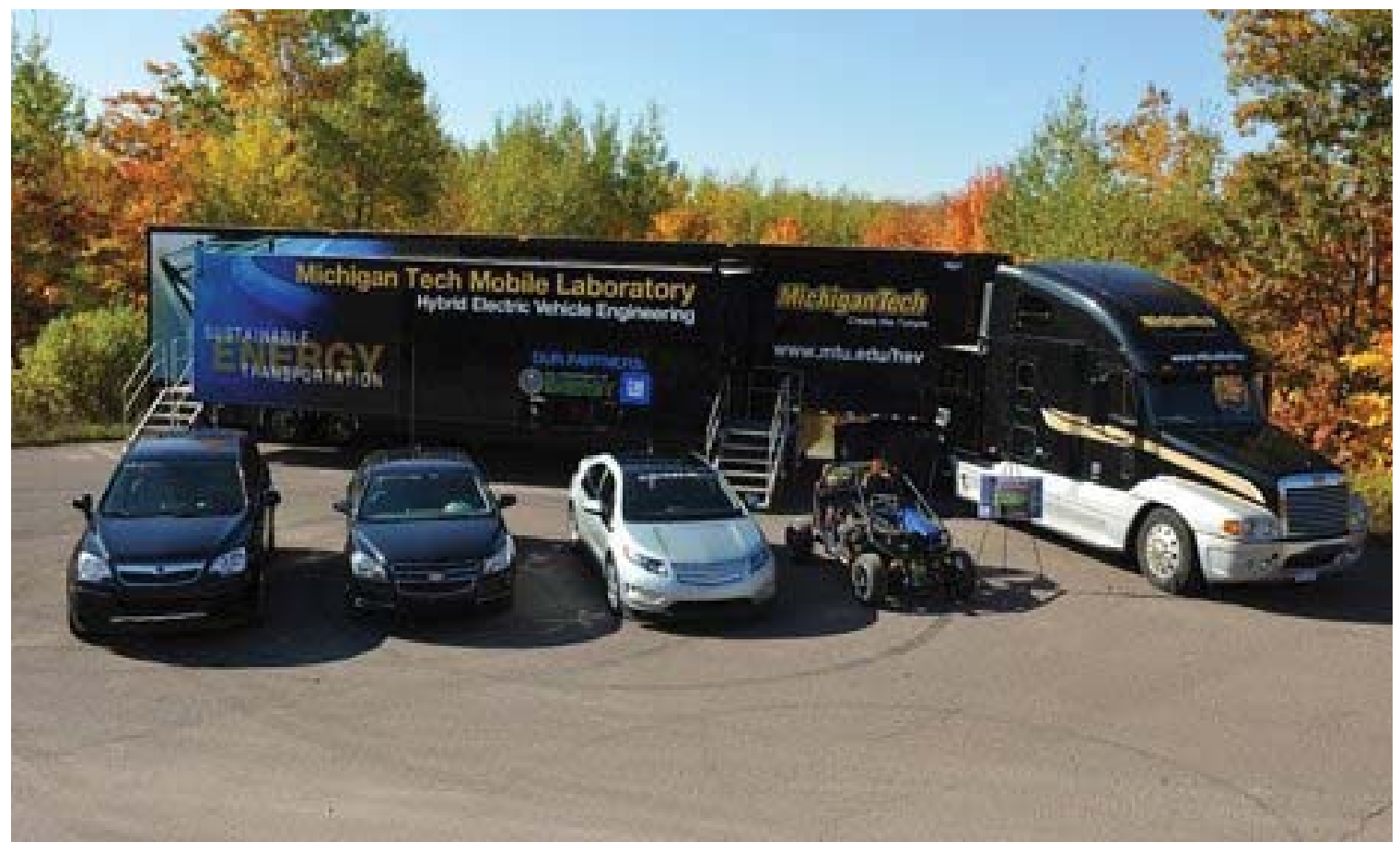

Figure 1-1: Michigan Tech Mobile Laboratory 


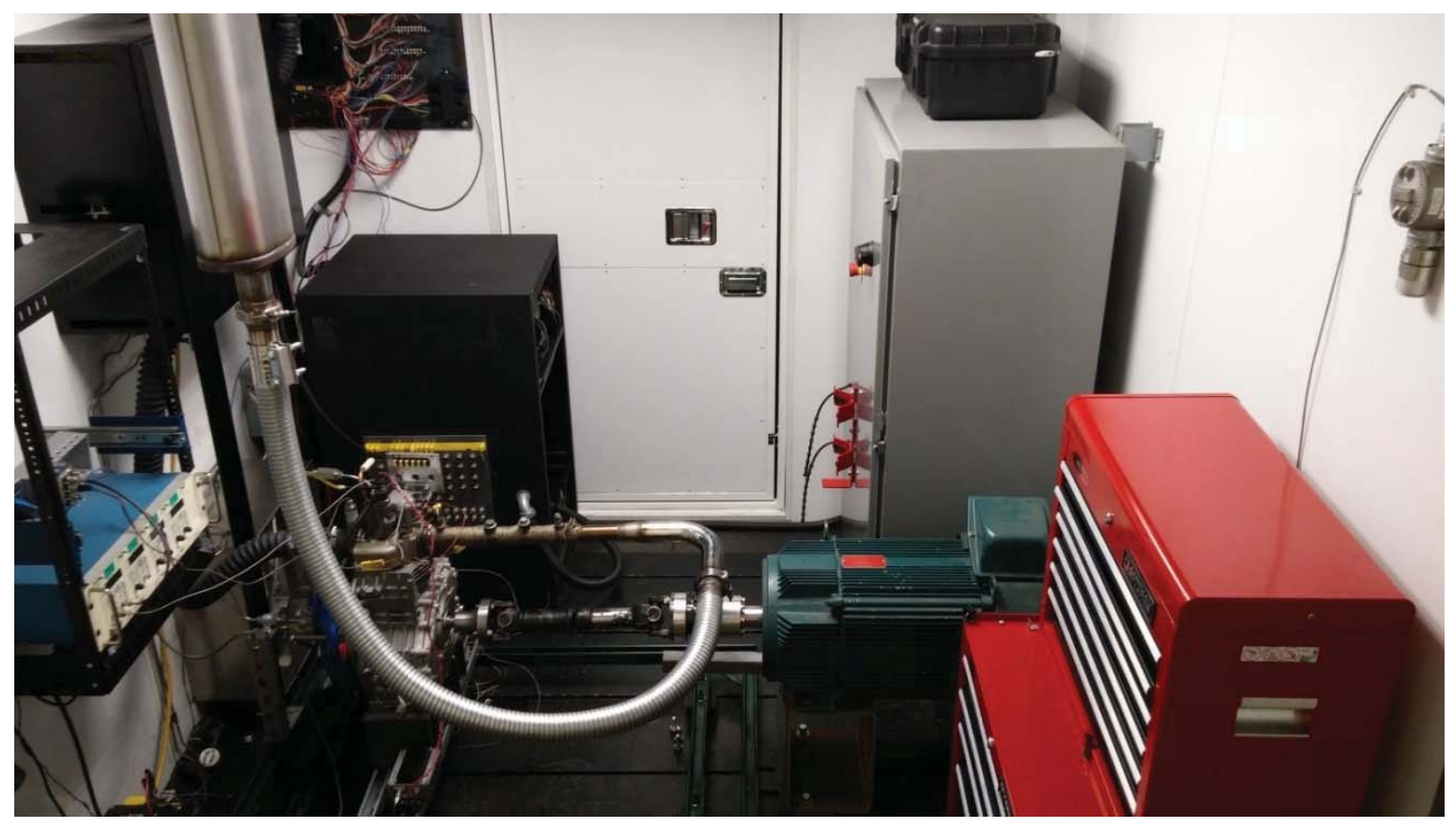

Figure 1-2: Mobile Lab Rear Test Cell

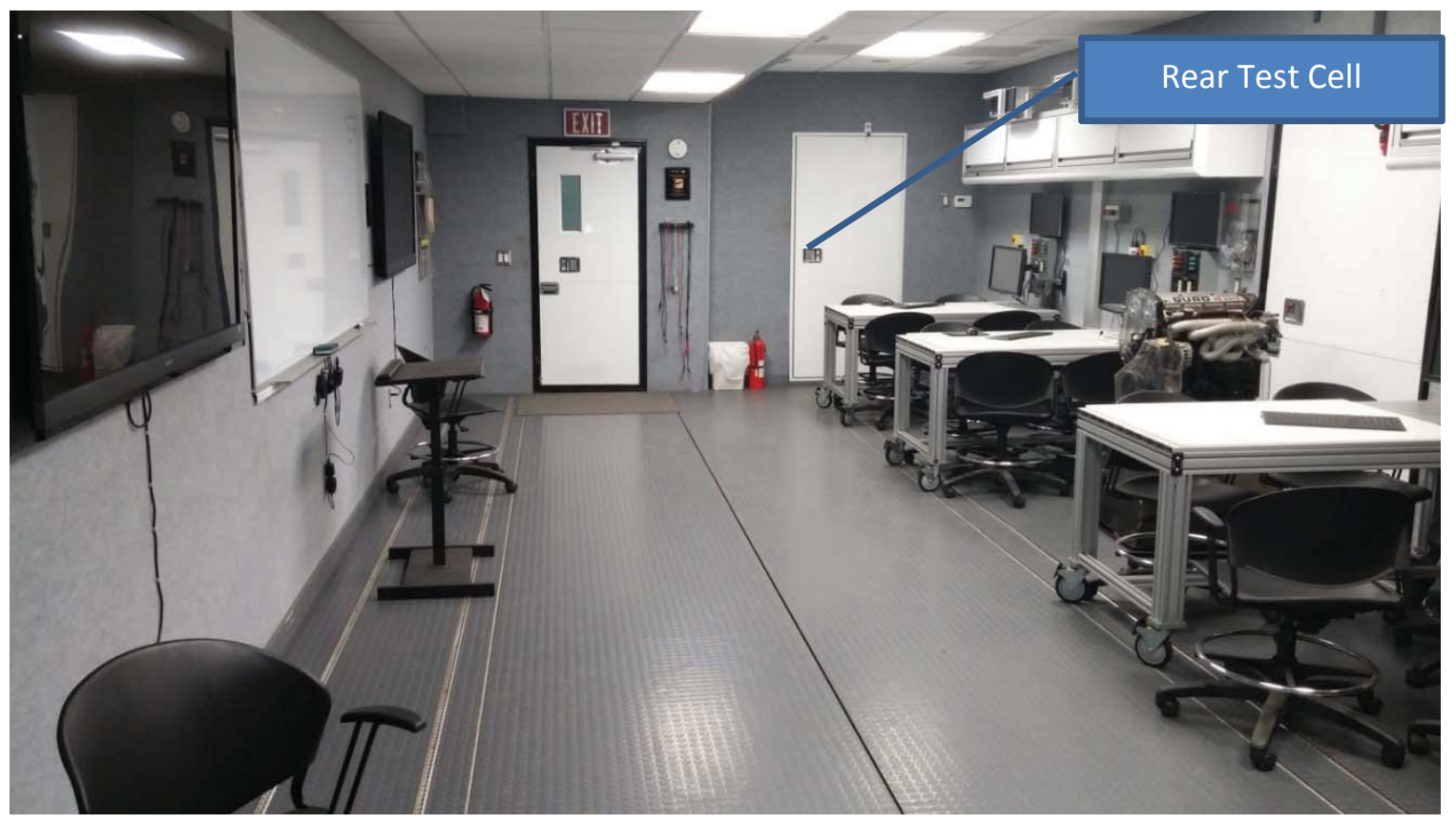

Figure 1-3: Mobile Lab Classroom

A fundamental constraint in powertrain testing is time on the dynamometer (dyno). Powertrain cells are expensive to install. To keep engine development costs low, the dyno needs to be utilized in the most efficient way possible. In a traditional 
powertrain testing environment, the engine is instrumented in the test cell itself. It is bolted directly to the bedplate of the test cell. Plumbing and wiring connections are made permanently to the engine. The engine becomes a part of the test cell, and subsystems are designed specifically for this engine. This ties up the dyno from being used for engine calibration testing, and therefore increases the cost of development for an engine.

In the past, innovations have been made to increase productivity of a test cell, such as having a through shaft dyno with a hub on either end. This is a double ended dyno and two engines can be set up at once on this type of dyno.

A significant innovation in saving time has been the development of a cart system that allows engines to be built up and instrumented outside of the test cell while testing is performed on other engines. This cart allows a single operator to roll an engine mounted to a heavy duty cart into a test cell, and connect it to the dyno in a short period of time

The Mobile Lab has a unique use for the cart system as well. Since many of the courses are short courses, and multiple courses might be taught back to back, the ability to use multiple engines in different parts of the courses brings a large amount of capabilities to the labs that can be offered.

The primary outcome of this project has been to develop a simple, yet effective system to quickly change engines in the Mobile Laboratory engine test cells for on the road education. The system incorporates many features seen in large scale test cells, while keeping everything small enough to fit in the smaller test cells used in the Mobile Lab. As a part of the pallet system, a wall mounted common rail diesel system was developed so that diesel engines could easily be integrated into the test cell. Finally, a single cylinder Yanmar that has been converted to common rail fuel injection was tested in the test cell. This demonstrated the instrumentation capabilities described in this thesis. 


\subsection{Engine Pallet System}

This thesis outlines the development of a pallet style system that allows engines to be switched in the Mobile Lab test cells quickly. The system is designed to be used in a small test cell environment, like that in the Mobile Lab, where there is no room for large rolling carts like those seen in large scale engine testing centers. By using components that can easily be purchased at general material suppliers listed later in this thesis, the pallet can be recreated easily by other researchers using the test cell.

In most engine testing centers, there is a large amount of space that can be utilized to store and build up engine carts. The Mobile Lab has a unique situation since it is an on-the-road trailer. The test cells are much smaller, and the ability to roll a cart in and out of the test cell is constrained. The pallet system was designed to allow the engine pallet to be easily lifted out and lowered to the ground outside the trailer. Isolating mounts in each of the four corners of the pallet are used as locating pins. As an engine is lowered onto the mounts, the pins will properly align the engine with the dyno. Connections such as exhaust, intake, fuel, instrumentation, and engine control are placed in pre-defined positions. This makes connection to the engine quick and simple. These systems are covered in Chapters 3-9.

\subsection{Diesel Fuel System}

As a part of the test cell development, a wall mounted diesel fuel system was developed that can output pressures high enough to run a common rail diesel injector, around 30,000 PSI. This system allows diesel engines to be tested, and gives control of injection timing and pressure to the test cell operator through MotoHawk rapid controls development software. With this system, common rail injection can be tested on engines that originally used mechanical injectors as well. This thesis covers the types of connections possible from this fuel system and the capabilities it adds to the test cell. This diesel system is covered in Chapter 4.

\subsection{Engine Testing Example}


The final step in the development of the engine cart system was to test an engine using the diesel system. A single cylinder diesel engine was used for this. A Bosch common rail injector was installed in place of the factory mechanical injector and connected to the wall mounted diesel fuel system. The engine was instrumented, and a test matrix was developed. The engine was run using the pallet system. Results are presented in Chapter 11. 


\section{Literature Review}

The design of the test cell is critical in making the engine testing process as efficient as possible. In many engine testing facilities, large investments have been made in separating the engine fixture and instrumentation procedure from the dynamometer test cell. This frees the test cell up for performing testing on other engines. For example, General Motors invested a significant amount of money in their Pontiac, MI test facility to reduce the time required to develop a new engine, and one of the main upgrades was an engine pallet system that allows operators to change engines within twenty minutes, without the use of any tools. In addition to eliminating ten weeks from the engine development process on average, this system was estimated to save $\$ 200$ million within the first year of use [1].

In [2], Thomas Sondey describes an engine delivery system used for full size engine test cells. This system uses a wheeled engine pallet assembly that moves the engine to the dynamometer room. The cart uses guide rails along with self-centering pins to properly locate the engine with the centerline of the dynamometer. Once the engine and pallet assembly has been moved to the proper location, multiple clamps are used to secure the cart to the test cell bed plate. This design increases efficiency of engine testing by freeing up the dyno room during engine fixturing. The cart system that Thomas describes is similar to the pallet system that is expanded on in this thesis. The pallet design is a smaller scale system.

To further increase the efficiency of the engine delivery system, Thomas Sondey, in [3], describes a modular fluid system that can be utilized differently for various engine applications. The manifold has multiple connections that an operator can configure for each particular engine being brought into the test cell. Quick connect fittings are used to connect the system to the engine. This is similar to the fuel system described in chapter 4 of this thesis, in that it allows for different connections depending on the desired test configuration. 
To further increase efficiency of the dyno room, all aspects should be modular. In a third paper, Thomas Sondey designs a modular system that includes standardizing exhaust, intake, and coolant systems for engines entering the test cell [4]. An engine cooling system is mounted to the bedplate, and connections are made to the engine quickly as the engine is brought into the test cell. In addition, the exhaust manifold is connected to the baseplate of the engine test cell, and an adjustable connection is provided for engines entering the test cell.

Franz Kienzl and Martin Wetzel design a pallet based system to increase testing efficiency in a test cell in [5]. This invention uses a pallet and pallet receptacle to separate the instrumentation process from the test cell. The pallet can be used with any powertrain component, and provides an alternate method of moving the component to be tested, rather than a cart that is rolled around on the ground by an operator. The design also calls for a gauge to be used outside the test cell to set the powertrain component to be tested in the correct position before bringing it into the test cell. This pallet based system is similar to that which is being implemented in the Mobile Lab test cell. In the Mobile Lab application, a size constraint plays a key factor in the design of the system described in this thesis. 


\section{Test Cell Layout}

\subsection{Component Overview}

In the Mobile Lab engine test cell, there are many different components that will be expanded upon further in this thesis. The main component is the dynamometer itself. In the Mobile Lab, this is a 75 horsepower $\mathrm{AC}$ dyno that is powered by three phase 480VAC. The dyno is manufactured by Baldor Electric, and further specifications can be found in [6]. This dyno has the capability to absorb up to 75 horsepower from an engine, or transmit torque to the engine. This allows for motoring tests, where the dyno turns the engine to determine parameters such as pumping losses in the engine.

Data logging is done through National Instruments equipment. A PXI cabinet is used for all thermocouple measurements, digital input/outputs, and analog connections. Full combustion analysis is supported by the test cell and this is done through a National Instruments cDaq chassis using AVL in-cylinder pressure transducers, a PCB signal amplifier, and a BEI encoder connected to the engine's crankshaft. This allows for full combustion analysis in the test cell, which is provided by micro DCAT software.

Engine control is done through a MotoTron ECU mounted in the test cell. This allows the use of MotoHawk and Simulink to build simple or complex control systems for the engines. When an engine change is made, the control algorithm for the new engine can be quickly flashed to the ECU. This also allows for set-point control of engines, allowing for start of injection (SOI), spark, lambda (air-fuel ratio), and other parameter sweeps.

\subsection{Component Locations}

Figure 3-1 shows an assembly CAD drawing of the components in the test cell from an aerial perspective. Figure 1-2 is a photograph of the same test cell. 


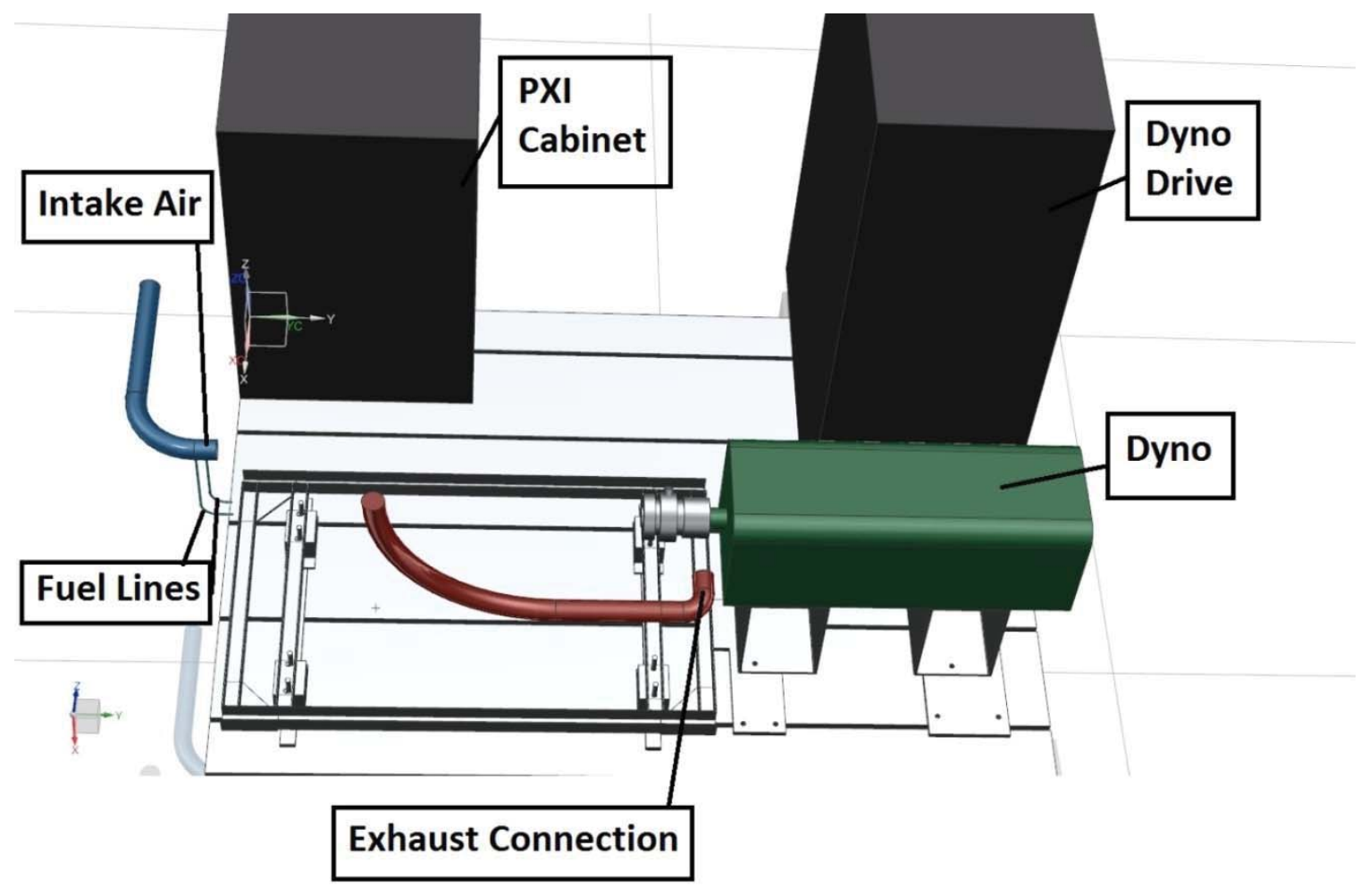

Figure 3-1: Test Cell Layout From Above 


\section{Fuel System}

\subsection{Overview of Fuel System Requirements}

The goal was to build a fuel system capable of supporting as many different engine configurations as possible. The Mobile Lab contains a dual fuel system that is plumbed to each of the test cells. There are two twelve gallon fuel cells, shown in Figure 4-1, that each have their own fuel pump and 100 micron filter. These cells are generally filled with gasoline and diesel fuel. The cells are located in the belly box of the Mobile Lab trailer so they are easily accessible for filling or changing.

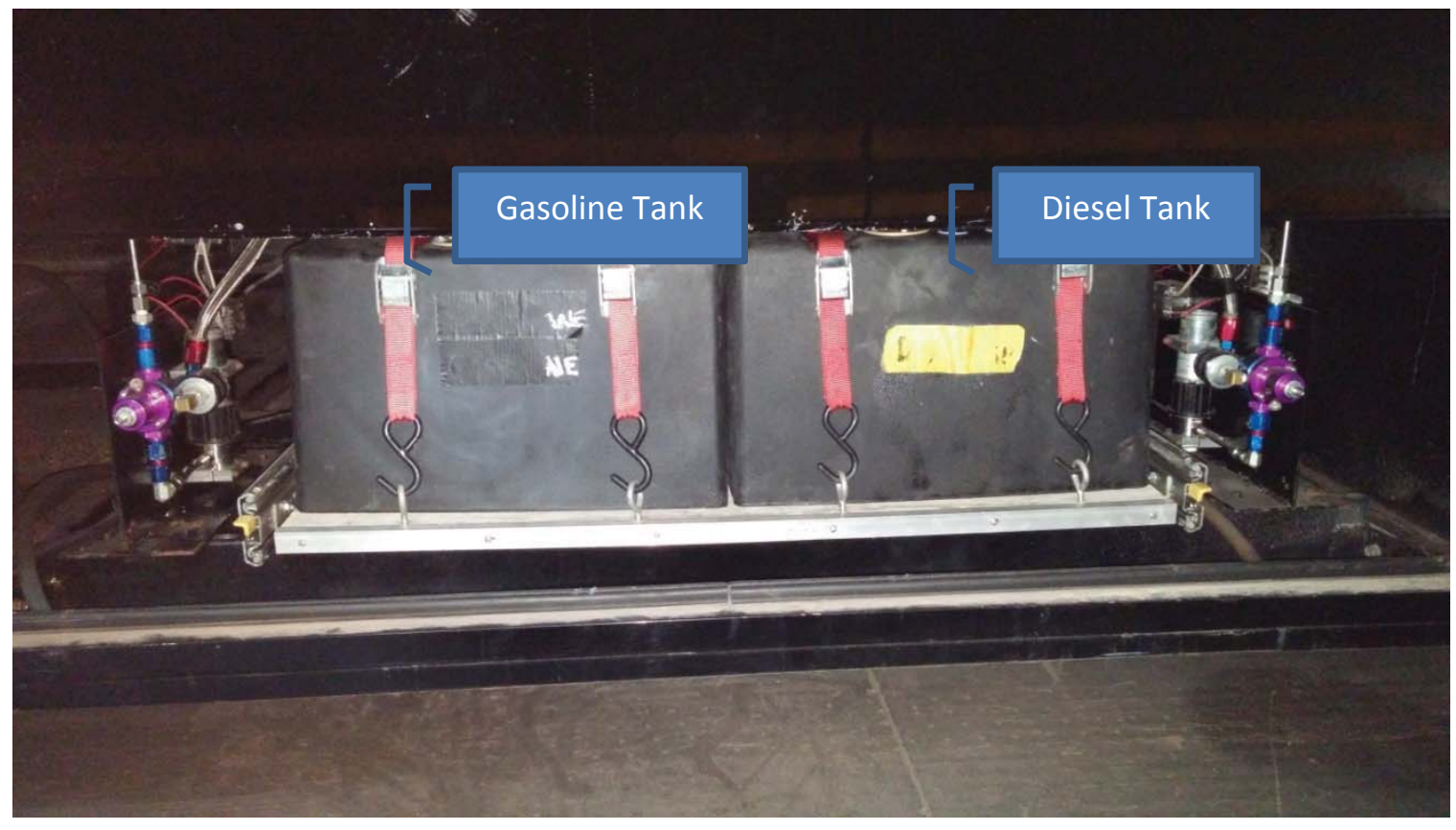

Figure 4-1: Left: gasoline tank. Right: diesel tank.

The fuel supply system from the belly box can be used as a lift pump for the high pressure diesel system or it can supply enough pressure for a port fuel injected gasoline engine. Both of these pressures are much lower than the pressure required for running a common rail diesel injector. In the case of the diesel engine tested and covered in chapter 11, there was no fuel pump or fuel rail for common rail injection installed on the engine, so the test cell fuel system needed to supply this pressure. 
Common rail fuel systems can vary in operating pressure. A Denso common rail system can supply up to $200 \mathrm{MPa}$, currently, with the intent to increase the supply pressure to $300 \mathrm{MPa}$ [7]. Bosch's common rail system provides pressures between 110 and $220 \mathrm{MPa}$ depending on the application [8]. This is a huge increase from the requirements of a standard fuel injected gasoline, which only requires around $400 \mathrm{kPa}$ of pressure [9].

In addition to much higher pressures, diesel common rail systems require fine filtration. For example, a Parker fuel filter used in on the road diesel applications provides filtration ranges from 30 microns to as small as 2 microns [10]. Larger particles could easily clog, or partially clog the injector which can lead to skewed testing results as well as completely stop the engine from running.

Supporting components for the extreme high pressures and fine filtration required in diesel common rail systems are difficult to find, and expensive. This section of the thesis covers the way the fuel system in the Mobile Lab addresses these concerns and can be used for both gasoline and diesel engines with outlet pressures ranging from $7 \mathrm{kPa}$ to $160 \mathrm{MPa}(180 \mathrm{MPa}$ if the pressure relief valve is changed). The completed system mounts to the wall of the test cell, and is contained in a steel NEMA box that separates the mechanical drive system from the plumbing system. This separation protects each subsystem from the other in the case of a failure such as a broken belt or burst fuel line. An overview of the fuel system is shown in Figure 4-2. The low and high pressure fuel systems are both shown in the NEMA box. Piping and identification diagrams are shown for both the low pressure and high pressure system in Figure 4-3 and Figure 4-4. 


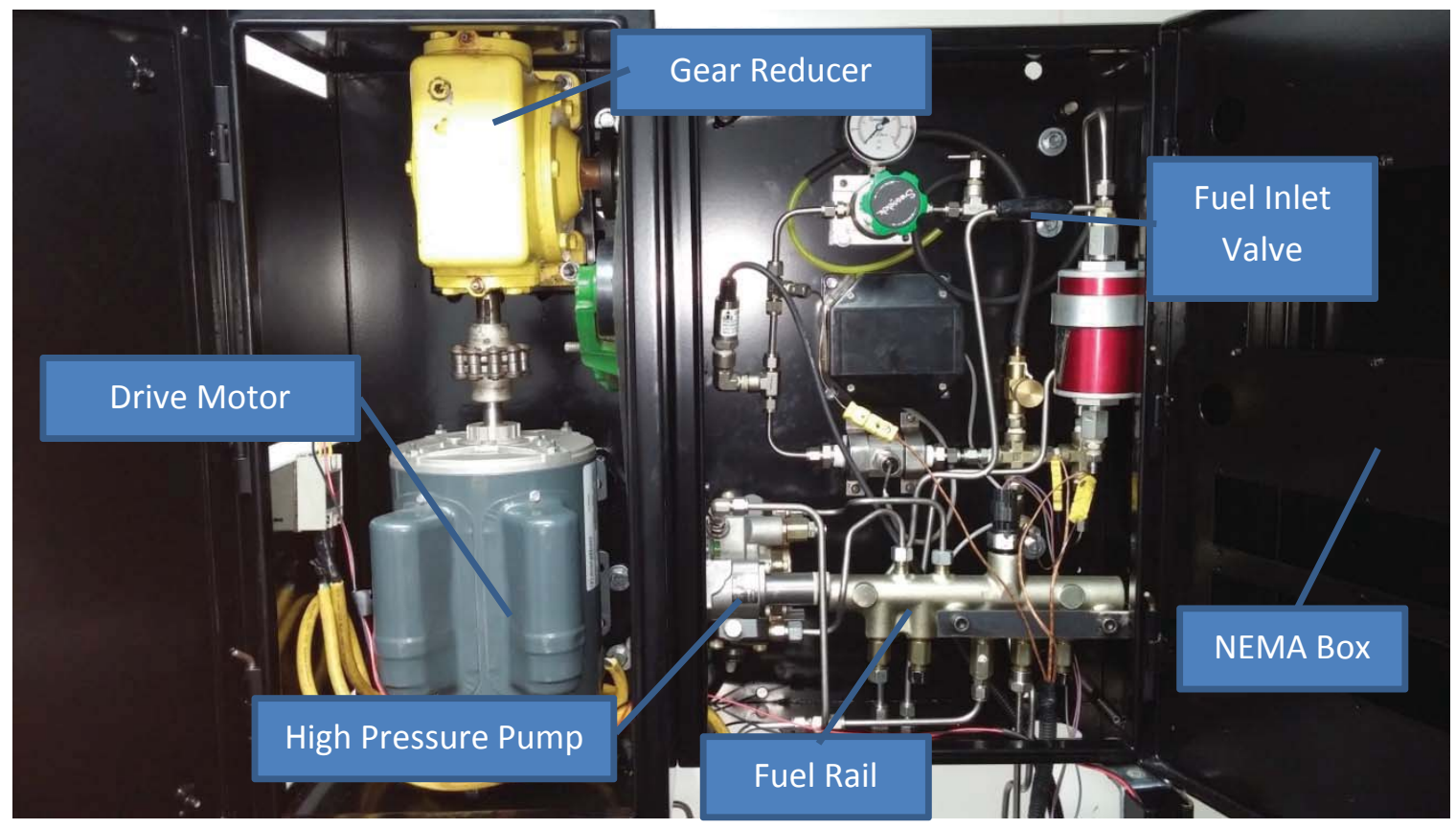

Figure 4-2: Completed Fuel System

\subsection{Piping and Instrumentation Diagram}

This diagram shows the routing of the fuel system from the inlet tube of the wall mounted fuel system to the engine. The diagram in Figure 4-3 is the P\&ID diagram for the low pressure fuel system. Figure 4-4 shows the high pressure system P\&ID diagram, including the low pressure cooling and return lines of the high pressure system. Further details on these systems are covered in sections 4.3 and 4.4. 


\section{Low Pressure Fuel System P\&ID}

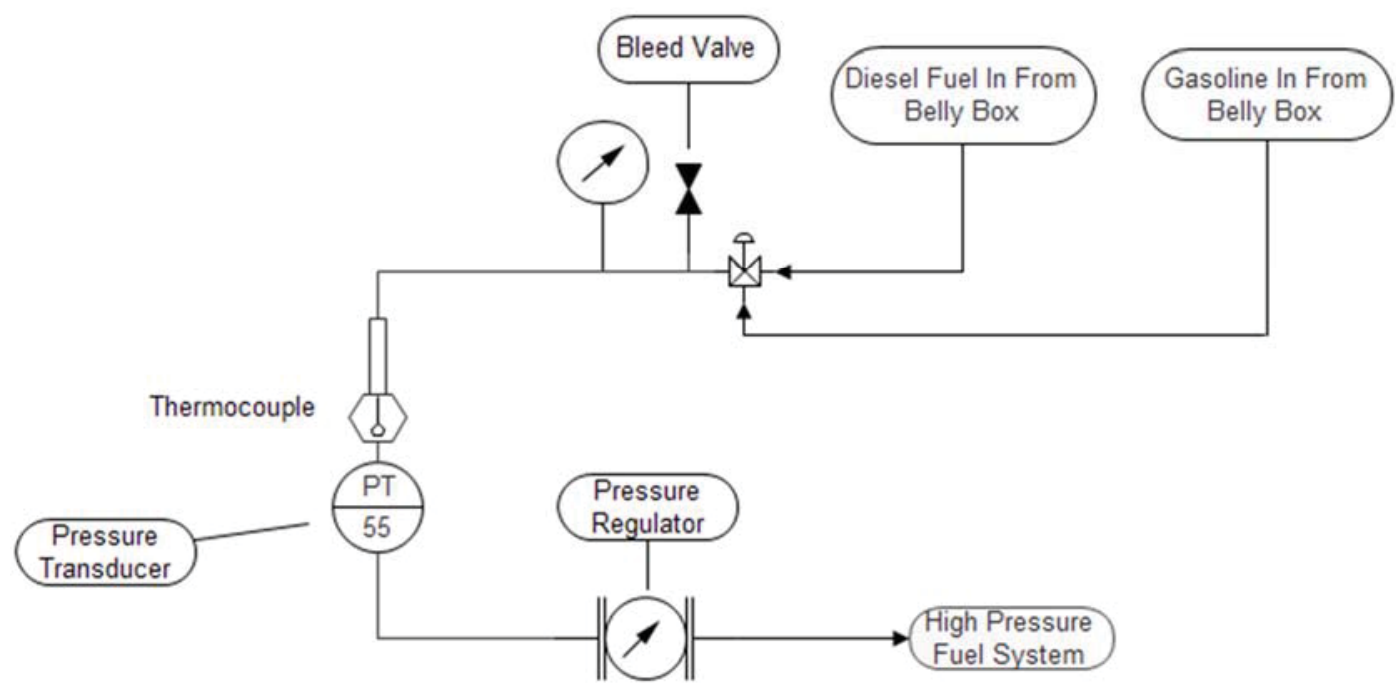

Figure 4-3: Low Pressure P\&ID

\section{High Pressure Fuel System P\&ID}

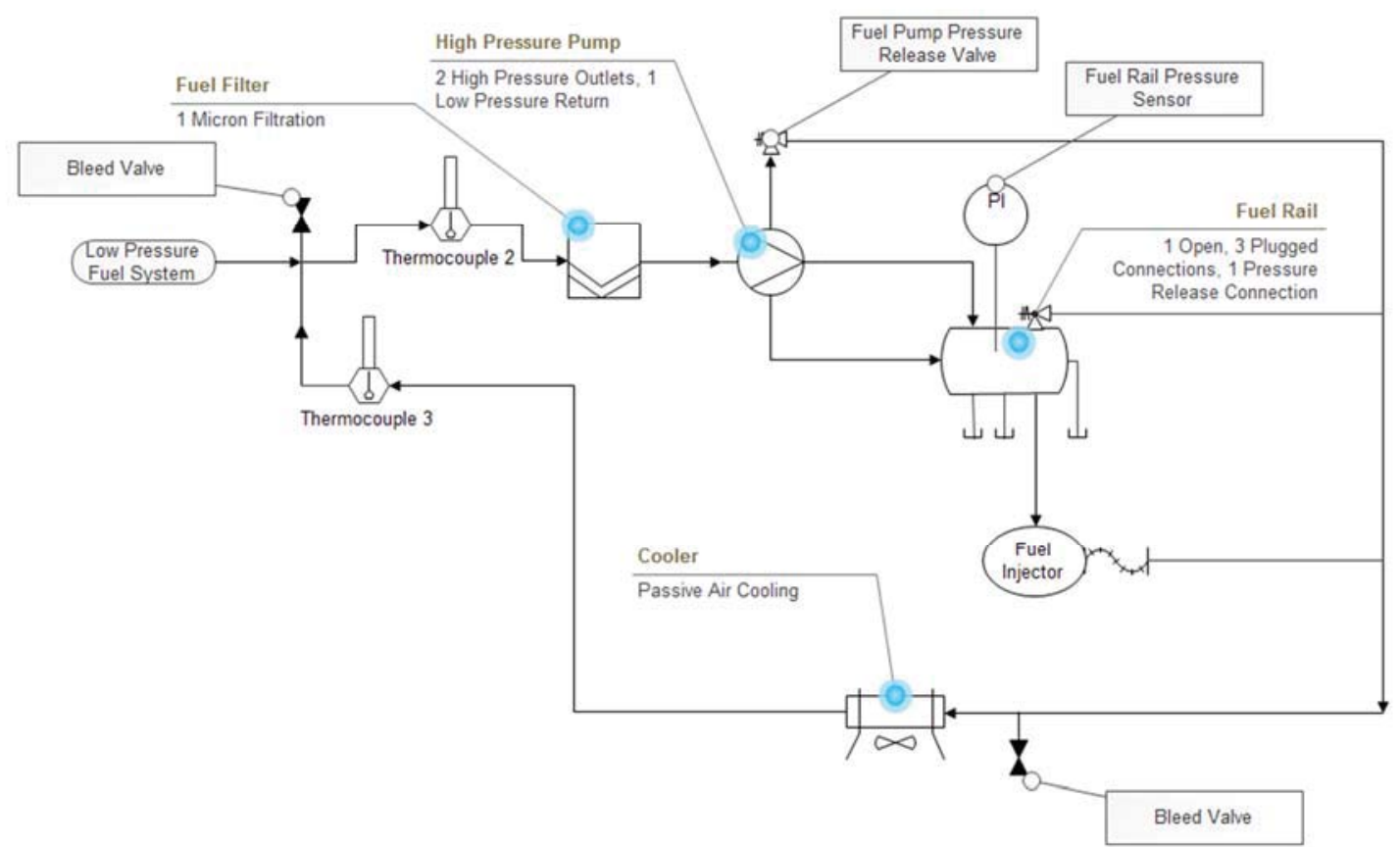

Figure 4-4: High Pressure P\&ID 


\subsection{Low Pressure Fuel System}

The first section of the fuel system will be called the low pressure side for the purpose of this report. This system contains everything up to and including the flow meter. Pressure for this fuel system is provided by the fuel pump in the belly box tank shown in Figure 4-1. Diesel and gasoline fuel are routed to a three way valve. The user can switch between fuels depending on the engine being brought into the test cell. Fuel is routed through a regulator and can be set to the required pressure either for the engine the user is planning to run, or set to $45 \mathrm{kPa}$ for use with the high pressure fuel system. After flowing through the regulator, a pressure transducer and thermocouple send readings to the PXI cabinet. Fuel passes through a Flow Technologies flow meter before going either to the engine or to the high pressure pump. The part number is FTO-1NIXSBLHC-5. The flow meter has a range of 0.002 to 0.02 GPM with an accuracy of $\pm 0.25 \%$ [11]. The serial number for the flow meter installed in the rear test cell is: $120621 \mathrm{M} 13985$.

\subsection{High Pressure Fuel System}

After fuel exits the flow meter in the low pressure system, it enters what will be considered a part of the high pressure fuel system. Fuel flows through an inline fuel filter before going to the high pressure pump. The filter is manufactured by Canton Racing, and provides filtration up to 1 micron. The fittings on either end of the filter are M16x1.5 female fittings. A replacement filter can be purchased through Summit Racing Equipment [12].

The next element in the fuel system is the high pressure fuel pump. This is a Denso HP3 fuel pump that was originally used on a large diesel engine. An example can be found on the John Deere tractor at the Keweenaw Research Center (KRC). The pump is design to be operated at pressures of $180 \mathrm{MPa}$. This pump should never be used with gasoline fuels. Only diesel fuel is to be used in this pump. Output on the pump is $0.9 \mathrm{~mL}$ per rotation. This pump has two pressure pulses per revolution. A service manual for the Denso HP3 pump can be found on the Mobile Lab Google Drive or in reference [13]. 
Fuel flows from the two outlet ports on the pump to a matching fuel rail that supports up to four outlets. The fuel rail contains a pressure sensor, the pin-out is provided in Figure 4-6 along with the calibration in Table 4-1. Fuel pressure is controlled via a solenoid on the fuel pump. This is solenoid is controlled by MotoTron, so the user can set optimal fuel pressure. The proportional-integral-derivative (PID) control loop set for the fuel pressure solenoid allows fluctuations in fuel pressure $+/-3500 \mathrm{kPa}$. This fluctuation causes the amount of fuel sprayed from one cycle to the next to change for a set injector dwell. This could be refined by further tuning of the PID loop, or changing the pump system as mentioned in Chapter 12. The fuel pressure pulsations as the injector is fired for a $55,000 \mathrm{kPa}$ set point can be seen in Figure $4^{-5}$.

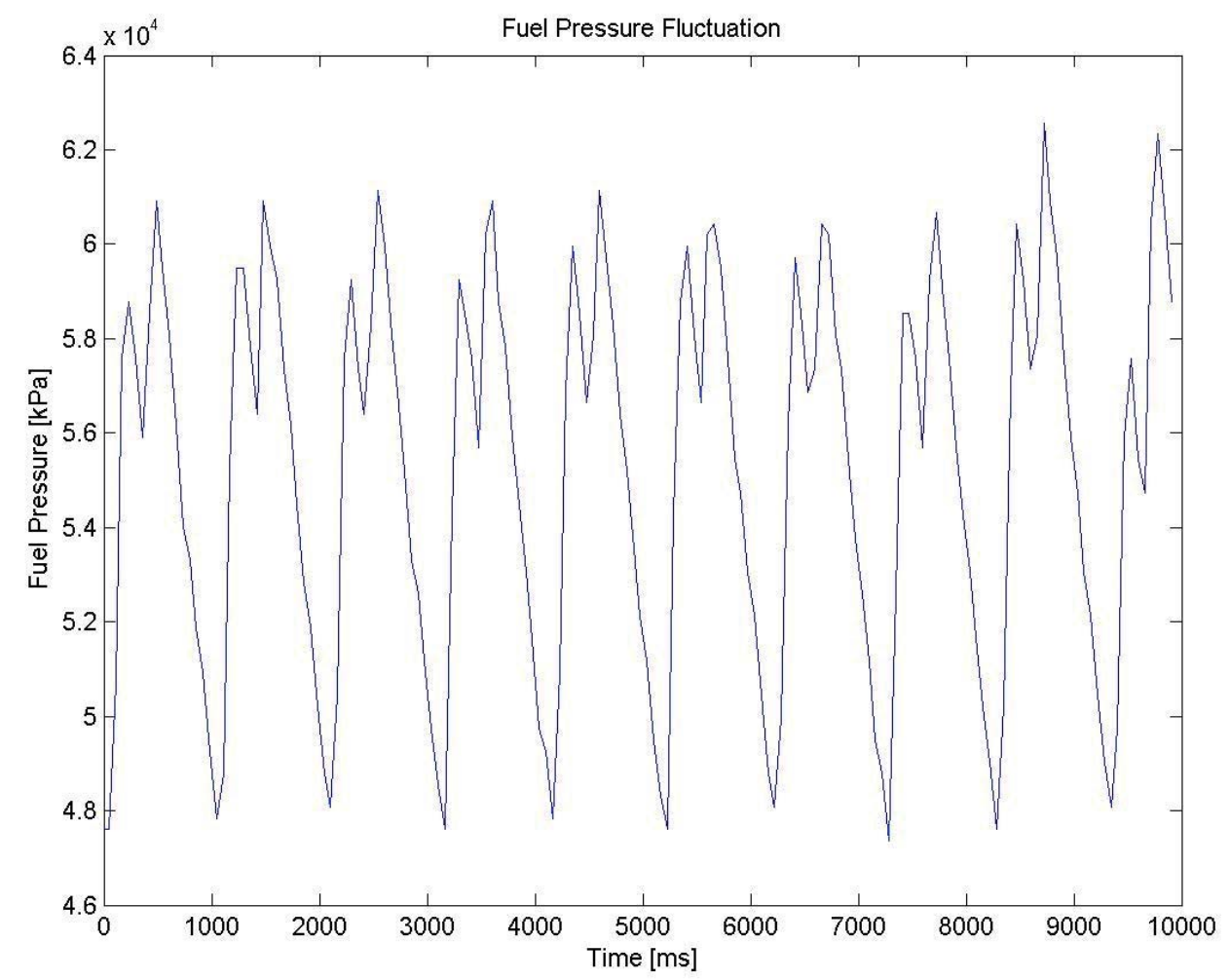

Figure 4-5: Fuel Pressure Fluctuations 


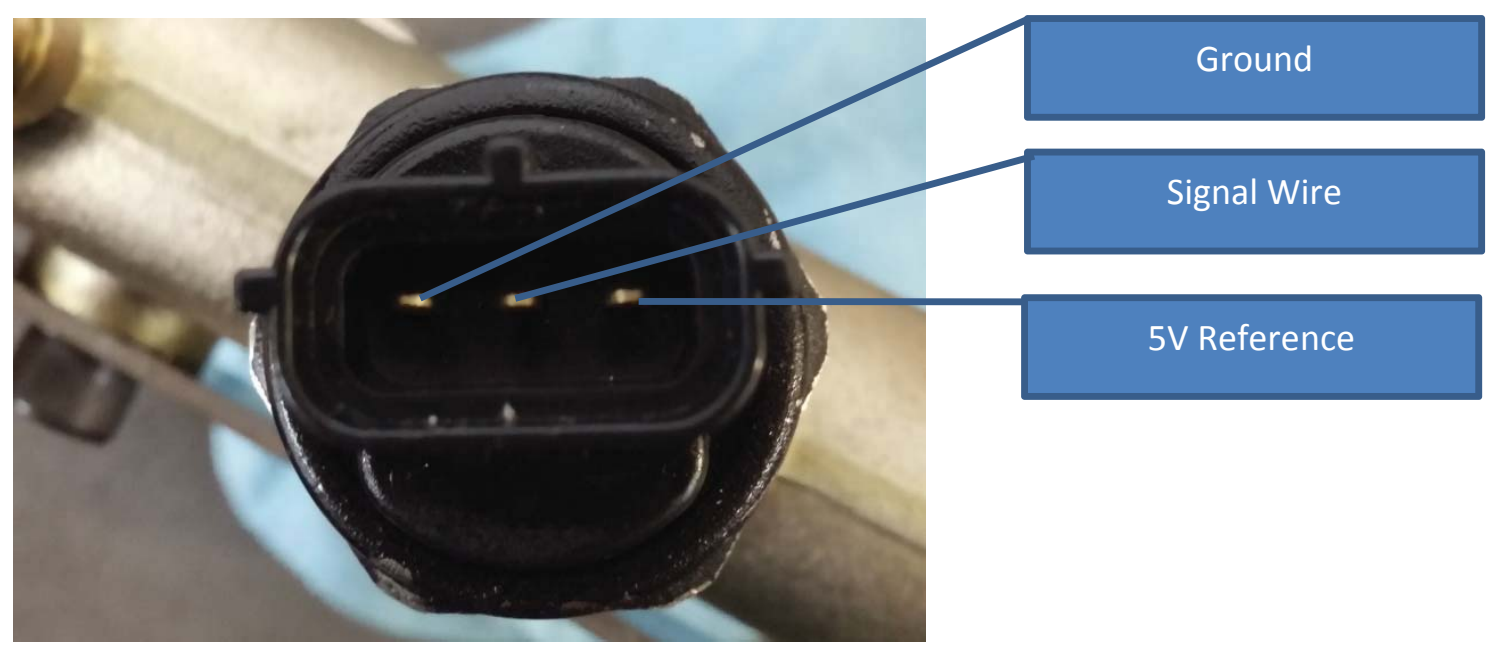

Figure 4-6: Fuel Rail Pressure Sensor

Table 4-1: Pressure Transducer Calibration

\begin{tabular}{|r|r|}
\hline Pressure (Mpa) & Voltage \\
\hline 0.0 & 1.029 \\
\hline 1.7 & 1.064 \\
\hline 3.4 & 1.100 \\
\hline 3.8 & 1.107 \\
\hline 47.6 & 1.965 \\
\hline 67.2 & 2.371 \\
\hline 96.5 & 2.970 \\
\hline 113.1 & 3.307 \\
\hline
\end{tabular}

The high pressure fuel lines up to the fuel rail are OEM lines from the John Deere application the pump and fuel rail were originally used on. The lines use M14 nuts with a 60 degree swaged end. The lines are sized with a $6 \mathrm{~mm}$ outer diameter with a $2 \mathrm{~mm}$ inner diameter. The outlet line from the fuel rail to the termination end that an incoming engine would connect to is a custom line ordered from Columbus Diesel Supply [14]. This line is constructed of a $1 / 4$ " outer diameter, has a 60 degree swaged end that matches the fuel rail, and has an M14 nut on the end that threads onto the fuel rail outlet port. Columbus Diesel Supply can provide diesel lines of any length, with pre swaged ends. These lines can be bent using a heavy duty $1 / 4$ " tubing bender to any application. The Michigan Tech Alternative Energy Research Building (AERB) 
located in Hancock, MI has a Swagelok 1/4" tubing bender that works for this application.

Shown in Figure 4-7 is the assembled fuel system. This includes the low pressure and high pressure system. Also seen in this picture are two bleeder valves that can be used to purge the system when changing from diesel to gasoline, or used to make sure there is no air in the system when using the diesel system. There is an additional purge point at the connection to the cooler. 


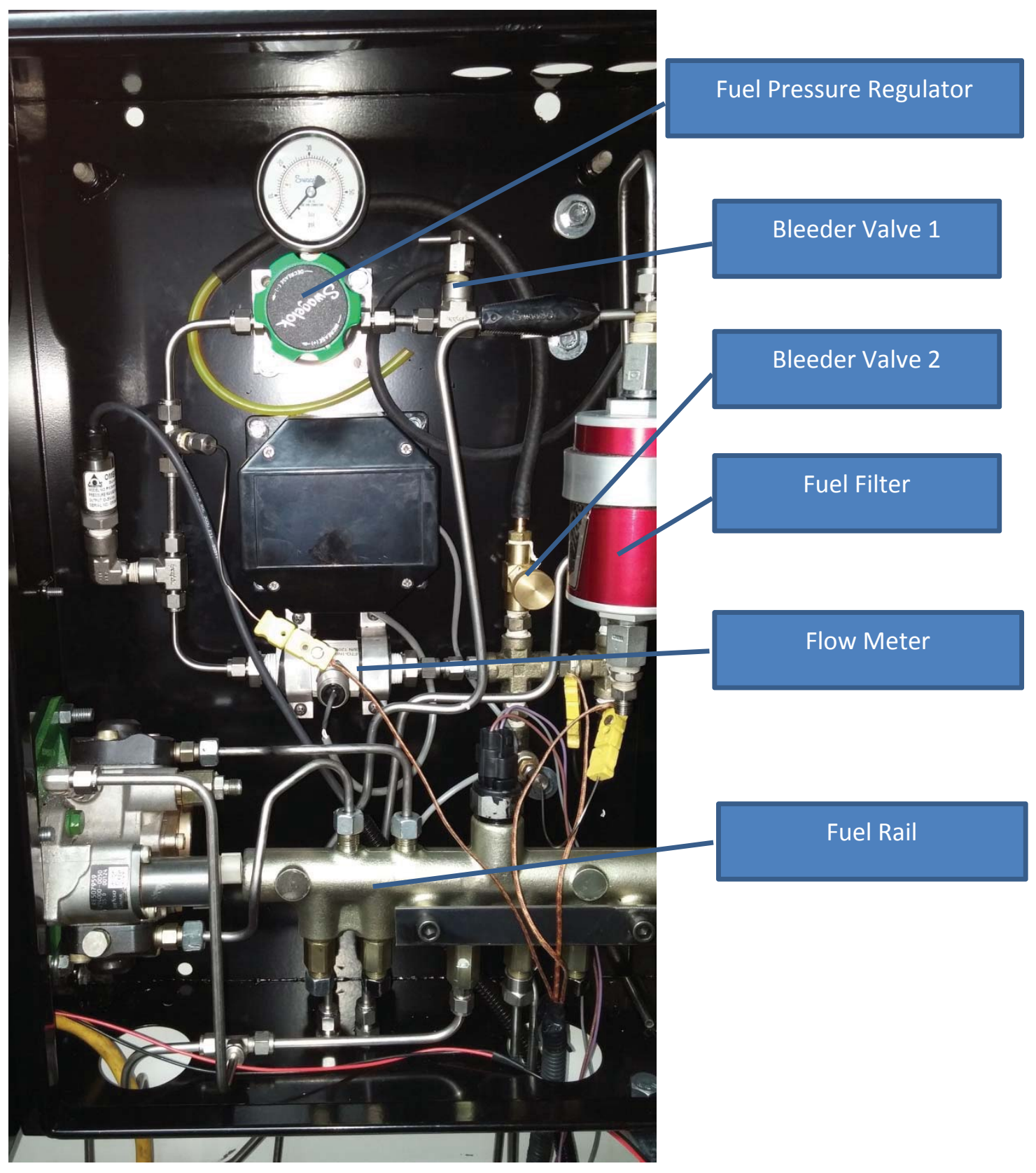

Figure 4-7: Low and High Pressure Fuel Systems

In a traditional diesel engine, the high pressure pump and fuel rail are both solidly mounted to the engine, so the only flexible fuel line needed is in the low pressure section of the system. In the Mobile Lab application, the fuel system is wall mounted, while the engine is on rubber isolators that allow movement. Because of this, running 
a straight fuel line from the fuel rail directly to the engine could cause fatigue issues in the line over time, and potentially could end in a dangerous situation if the high pressure line bursts. One option would be to purchase a short flexible line that would run from the diesel line termination point to the engine cart, and this line would absorb all the vibrations from the engine. Because the pressures are well above standard operating pressure for a heavy duty hydraulic hose, which is generally around $35 \mathrm{MPa}[15]$, this is not a safe option. One supplier has been found that can supply flexible line that supports pressures up to $320 \mathrm{MPa}$, and is safe to use with diesel fuel. More details on specific applications can be found on the Spir Star website [16]. Spir Star can also fabricate the lines made with a variety of fittings, including the HF4 style of fitting that Michigan Tech has the tools to make lines to mate with. Figure 4-8 compares an HF4 fitting with a swaged diesel fitting.

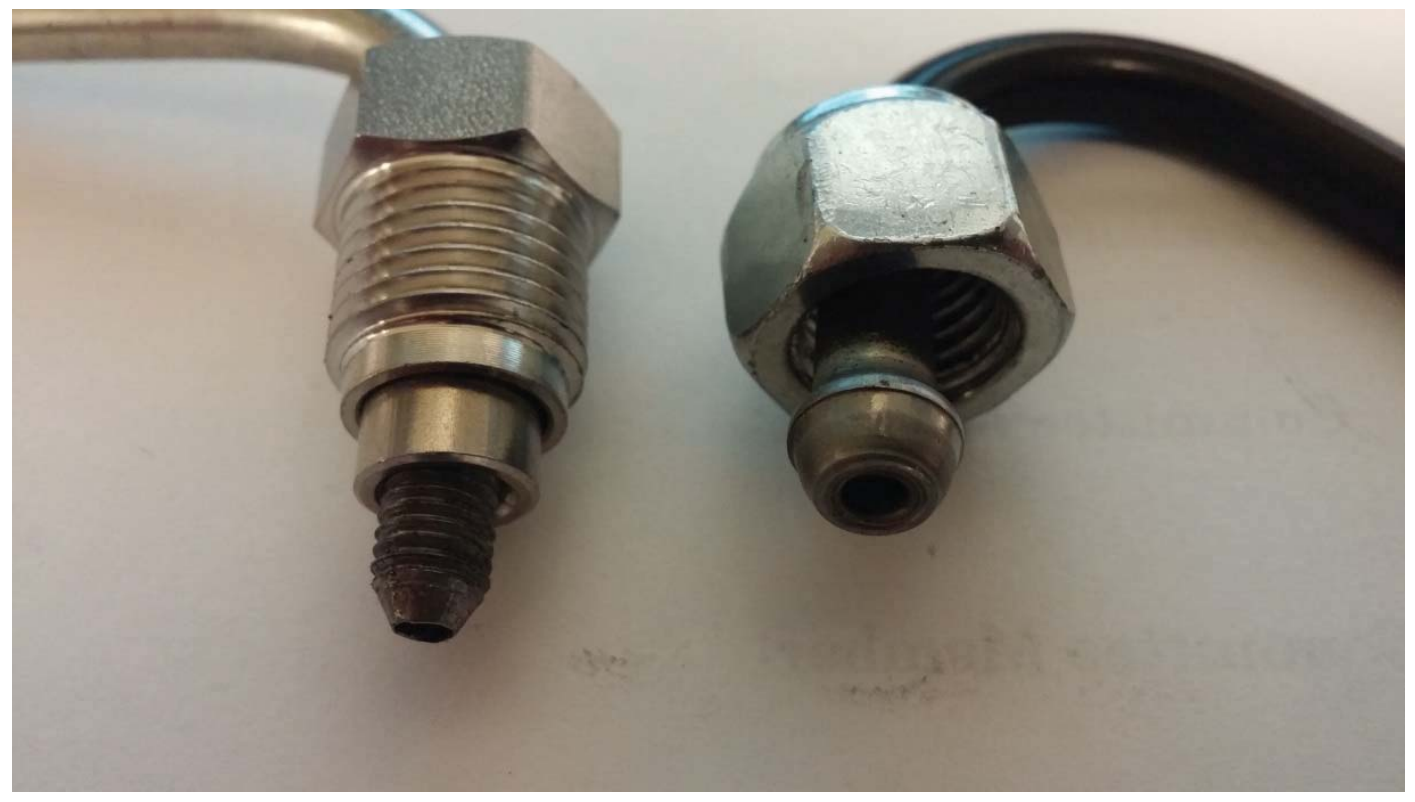

\section{Figure 4-8: Left, HF4 Fitting. Right, Swaged Fitting.}

In the Mobile Lab application, an alternative method was used to account for engine vibrations. Using excess fuel line coming from the fuel rail, the fuel line was coiled around a 6 inch pipe to form a spring like shape. This is similar to the way brake lines were coiled in older vehicles to absorb vibrations. 
The terminating end is an HF4 style of fitting, this style of fitting is shown in Figure 4-8. Fittings and fuel line for this style of fitting can be purchased from High Pressure Equipment Company (HiP). This style of fitting uses a $1 / 4$ " line, so the same line that was purchased from Columbus Diesel supply with a swaged end could be threaded and coned for used with HF4 style fittings. Dimensions for this type of fitting can be found on HiP's website [17].

Having an HF4 style terminating end simplifies the process of making new lines for additional ends. Swaging tools are cost prohibitive for use in the Mobile Lab shop, however tools for making HF4 style fittings are readily available within the APS Labs at the AERB along with a document describing how to use them. The coning tool is a steel sleeve with a brass insert that centers the tool on the fuel line. A 60 degree cutter inside the tool cones the end of the line when used with a drill. This tool can be seen in Figure 4-9. The threading tool is similar in design, but is custom made for use with a hand tool. A steel sleeve fits two 1" outer diameter and 0.25 " inner diameter ball bearings that center the tool on a fuel line. A 1/4"-28 left hand thread die sits inside the tool. A typical hand threading tool can attach to the back side of the die assembly and be used to cut the threads on the outside of the fuel line. This tool can also be seen in use in Figure 4-10. An assembled drawing can also be found on HiP's website [18]. 


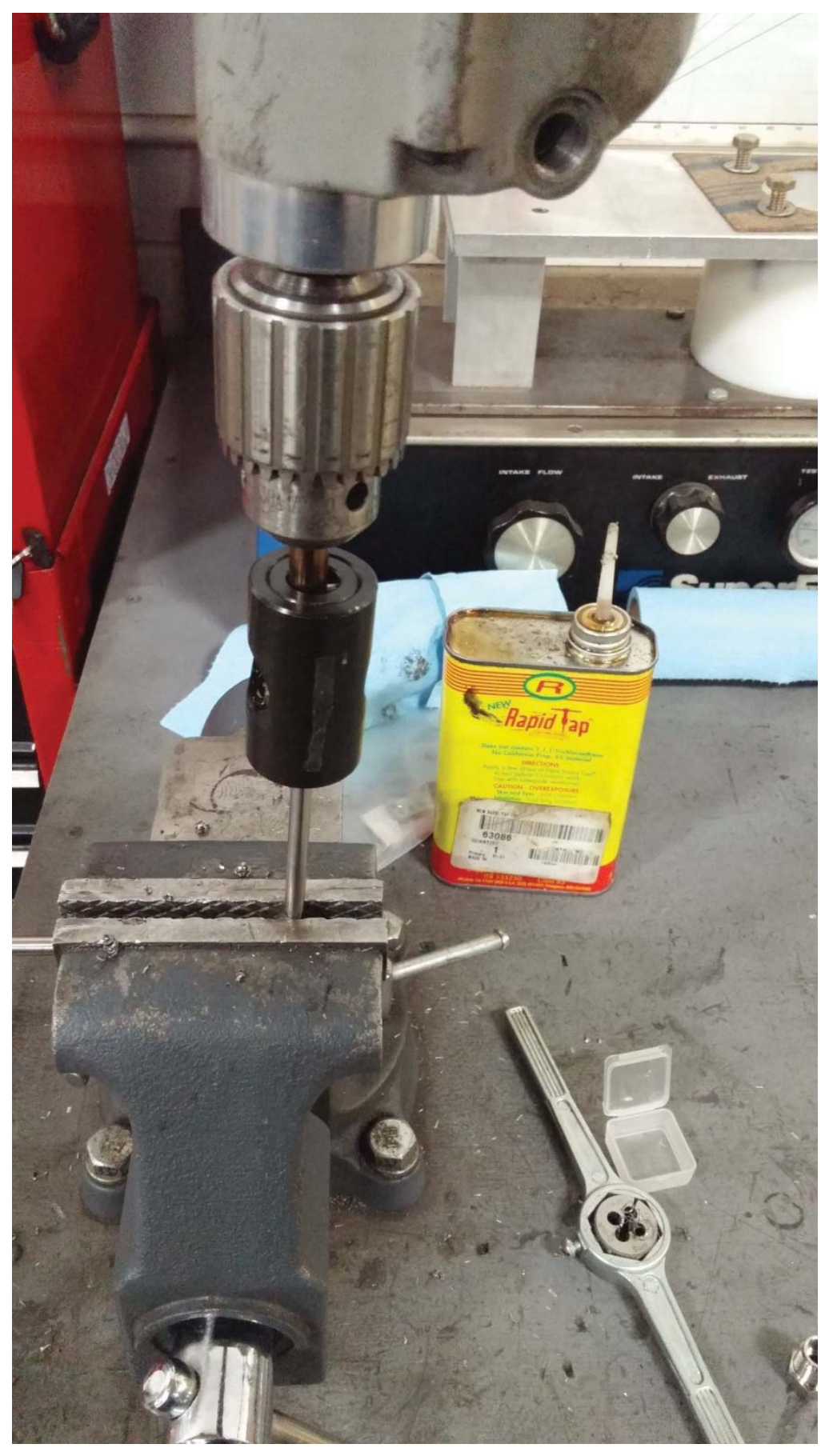

Figure 4-9: High Pressure Line Coning Tool 


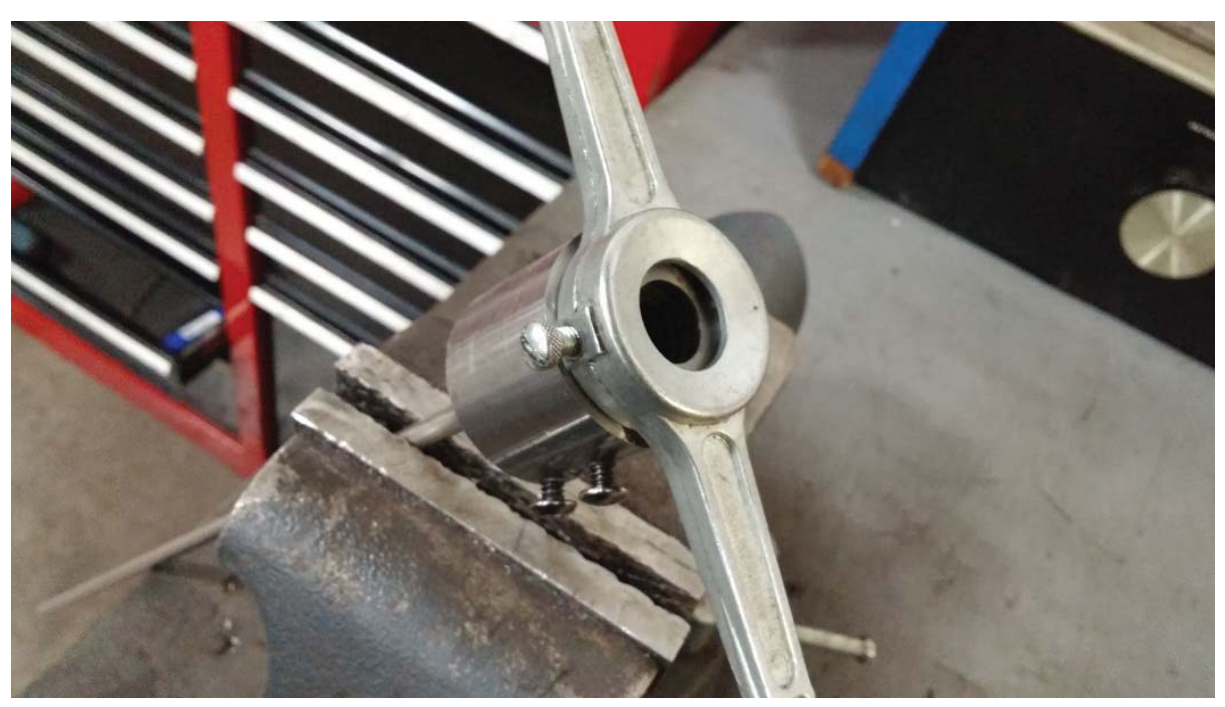

Figure 4-10: 1/4"-28 Left Hand Threading Tool

The terminating end of the high pressure line is a female fitting currently (HF4), but other options are available depending on the application. Other options are available as well, depending on the application. If a larger or smaller fuel line was needed, HiP has adapters that would thread onto the HF4 fuel line coming out of the fuel rail, and have output sizing in either $1 / 8$ " tubing or $3 / 8$ " tubing. Alternatively, an adaptor line is available in the test cell tool box that terminates in a traditional swaged end, shown in Figure 4-11. This line can be used with either M12 or M14 nuts depending on what is required by the user. 


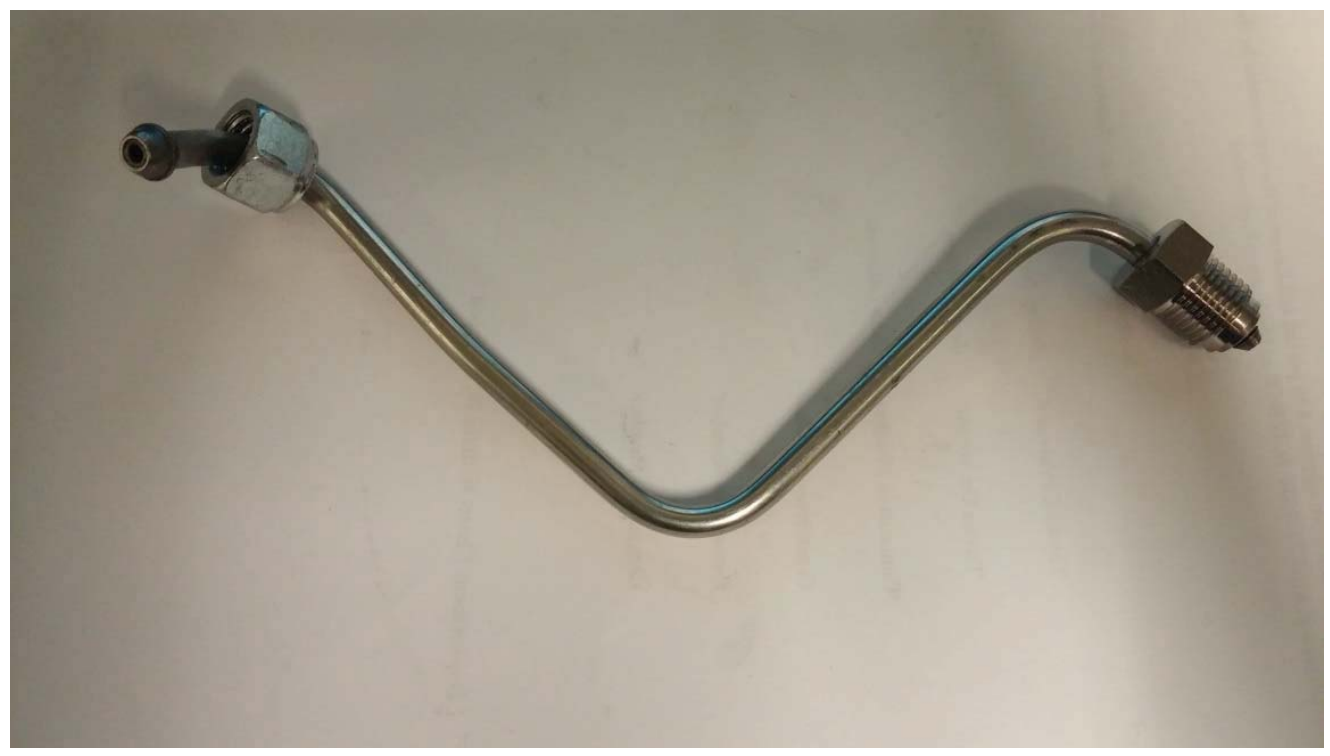

\section{Figure 4-11: Adaptor Line}

The HP3 high pressure fuel pump also has a low pressure return line. In a typical, on-the-road application, this line would return to the fuel tank. To maintain accurate fuel flow measurements in the Mobile Lab test cell, the system must be a return less system. The fuel system must be fully bled for accurate fuel flow measurements. Because the fuel pump is rated for much larger engines than the Mobile Lab test cell can support, it will deliver more fuel than the engine will use. With constant recirculation, this may cause overheating of the fuel which can lead to vapor lock. To help battle this issue, the fuel is not routed directly from the outlet of the pump back to the inlet. Instead, it is routed through a small finned aluminum cooler that is located in front of the ventilation inlet to the test cell.

In addition to the low pressure return from the fuel pump, there is a pressure release valve on the fuel rail that will release at pressures of $160 \mathrm{MPa}$. The pressure release valve and the fuel pump low pressure return are tied together along with the low pressure return from the injector. All of these systems pass through the cooler before returning to the inlet of the injection pump and connecting with the inlet from the low pressure fuel system. A thermocouple has been installed in the return line from the cooler as well as the line that runs to the high pressure fuel pump to monitor 
temperatures and estimate the effectiveness of the cooler. Another option would be to slow down the rotation speed of the fuel pump. This will be covered in section 4.5.

\subsection{High Pressure Fuel Pump System}

As mentioned in section 4.1, the mechanical system has been separated from the fuel lines for safety. Each system is in a separate NEMA box and the two are bolted together. This is shown in Figure 4-7. A broken belt or other catastrophic failure of the mechanical system could result in a fuel line being broken if the two systems were in the same box. Steel plates have been welded into the mechanical box. Studs are threaded into the plates to mount both the electric motor, and the gear reducer.

General duty AC electric motors usually run at 1800 RPM. Although it was attempted to run the fuel pump at this speed, it required more power than could be provided with 120VAC motors. This would also run the pump at a much higher speed than would be required for use with the small engines in the Mobile Lab. In a large scale version of the fuel system, running a direct drive coupled electric motor would be recommended to provide sufficient fuel for large engines. In standard OEM applications, the pump would run at half the crankshaft speed [7].

To calculate the maximum flow rate the pump would be used at in the Mobile Lab application, the power of the dyno should be used as the maximum that should be seen in the test cell. The dyno has a maximum power of $75 \mathrm{hp}$, or $56 \mathrm{KW}$. Diesel has a lower heating value of $42.8 \mathrm{MJ} / \mathrm{kg}$. It is assumed that the engine's efficiency would be $30 \%$. Using these numbers, the flow rate of diesel required to support $56 \mathrm{~kW}$ can be calculated as shown in Equation 4-1.

\section{Equation 4-1: Flowrate from Maximum Engine Power}

$$
\text { Flowrate }\left(\frac{\mathrm{kg}}{\mathrm{s}}\right)=\frac{\frac{P(\mathrm{~kW})}{\eta}}{\operatorname{LHV}\left(\frac{\mathrm{MJ}}{\mathrm{kg}}\right)}=\frac{\frac{56(\mathrm{~kW})}{0.30}}{42.8 * 10^{3}\left(\frac{\mathrm{Kg}}{\mathrm{s}}\right)}=0.0044\left(\frac{\mathrm{kg}}{\mathrm{s}}\right)
$$


Based on this flowrate, the maximum power required to turn the pump can be calculated based on Equation 4-2, where "q" is the flowrate of the fluid through the pump calculated in Equation 4-1. "P" is the output pressure of the pump. In the case of the diesel pump, the desired output pressure is $180 \mathrm{MPa}$.

\section{Equation 4-2: Pump Input Power}

$$
\operatorname{Power}(k W)=\frac{q\left(\frac{m^{3}}{h}\right) * P(P a)}{3.6 * 10^{6}}=0,98(k W)
$$

Using the pump's output of $0.9 \mathrm{~mL}$ per rotation and the flow rate of diesel required to support $56 \mathrm{~kW}$, the speed of the pump should be 296RPM. Using this speed and the $0.98 \mathrm{~kW}$ required to run the pump, the torque required is $31.7 \mathrm{Nm}$.

To both slow down the pump speed and increase the torque available to turn the motor, a 20:1 gear reducer was installed. The output speed of the gear reducer is 90RPM when used with the current 1800RPM motor installed. The drive motor is a $1.5 \mathrm{hp}$ motor with a $56 \mathrm{H}$ style frame. Dimensions for this style of frame can be found on a NEMA motor frame chart [19].

Attached to the output shaft of the gear reducer is a 26 tooth cogged pulley. This pulley is attached with a 1" bore, P1 style quick disconnect (QD) bushing that can be purchased at McMasterCarr, part number 9859T3. Further documentation, including dimensioned drawings can be found online [20]. The fuel pump currently has a 20 tooth pulley on it which puts the final drive speed at 117 RPM.

The fuel pump main shaft has a 1:10 taper with a keyway on it. To replace this pulley with another with a different tooth count, the bore of the pulley would need to be custom made. It is recommended to do this with a CNC lathe (available at Minerals and Materials Engineering Building) to make sure the taper is done properly. A tensioner is also a part of the system. With the current pulley configuration, an 84 tooth belt is being used, Gates part number $420 \mathrm{H} 100$ [21]. The pulleys and belt are 1" width by $1 / 2$ " pitch. Table 4-2 lists the part numbers and suppliers for the different pulleys currently used in the system. 
Table 4-2: Drive System Part Numbers

\begin{tabular}{|l|l|l|l|l|}
\hline & Notes & Price & Part Number & Supplier \\
\hline Belt & 420H & $\$ 33.89$ & $6484 \mathrm{~K} 177$ & McMaster-Carr \\
\hline Drive Pulley & 26 Tooth, P1 Style & $\$ 90.04$ & $26 \mathrm{HP} 100$ & MotionIndustries \\
\hline Pump Pulley & 20 Tooth, Requires machining & $\$ 59.41$ & $6495 \mathrm{~K} 46$ & McMaster-Carr \\
\hline QD Bushing & P1 Style, 1" Shaft & $\$ 18.87$ & $9859 \mathrm{~T} 3$ & McMaster-Carr \\
\hline
\end{tabular}

The fully assembled drive system is shown in Figure 4-12. On the left side of the box is the $40 \mathrm{amp} \mathrm{AC}$ relay that is used to turn the pump system on. The yellow transmission on top is the 20:1 gear reducer. As shown in the picture, the pump itself mounts on the opposite side of the drive box wall, with a hole cut for the pulley to fit through. 


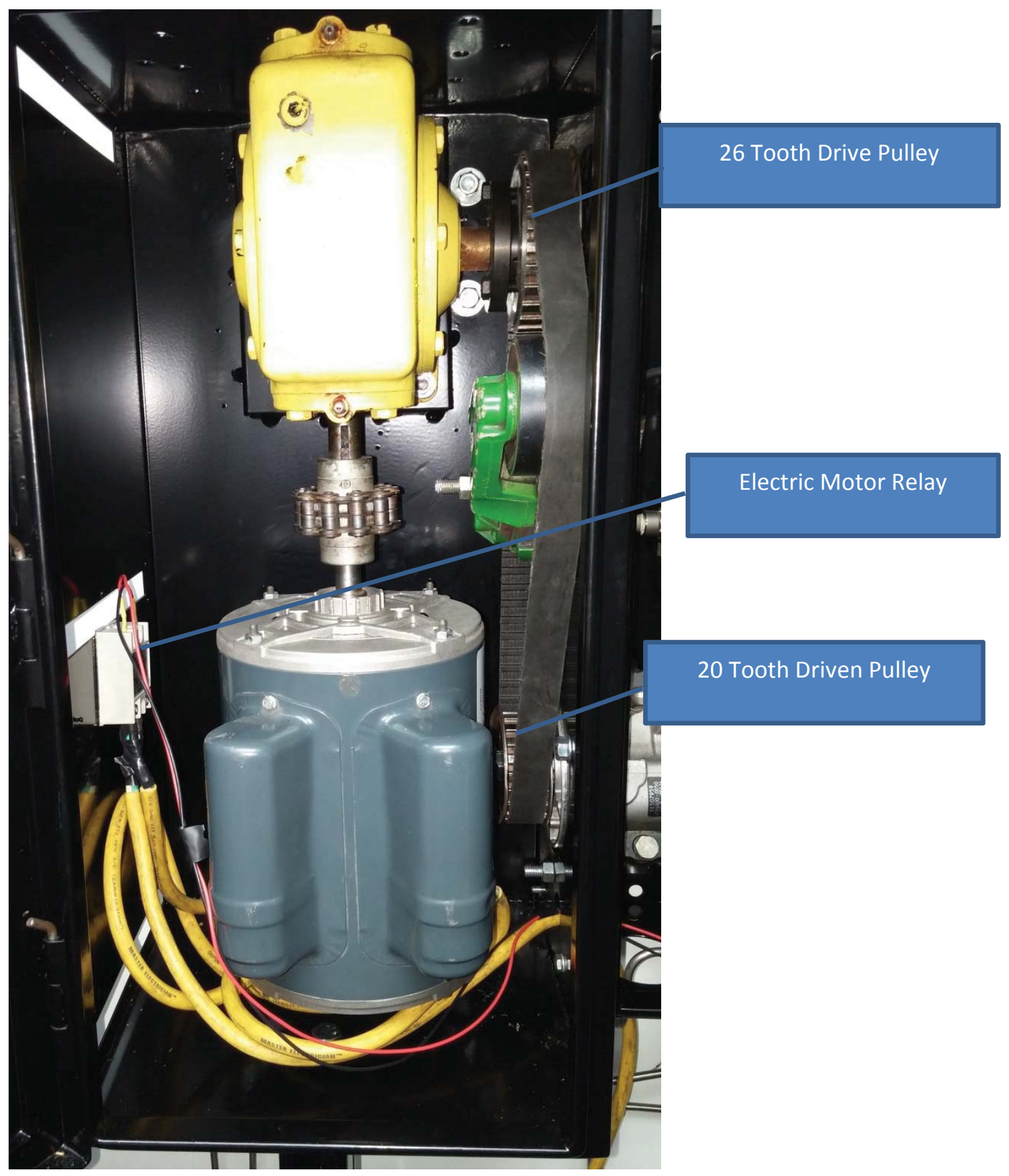

Figure 4-12: High Pressure Fuel Pump Drive System

Using the current pulley configuration, the speed of the fuel pump is 117 RPM. As mentioned in 4.1 , the fuel pump outputs $0.9 \mathrm{~mL}$ per rotation. This puts the maximum 
fuel flow rate at $1.755 \mathrm{~mL} / \mathrm{second}$ with the current configuration. The advantage to the pulley drive system using a QD bushing is the availability of other pulleys, and the simplified process to change them. If a smaller engine is being tested, it would be recommended to change the output pulley on the gear reducer to a smaller size to slow down the rotation speed of the pump.

\subsection{Injector and Driver}

When using the common rail injection system, most common rail injectors will work. The engine tested in 11 uses a Bosch common rail injector. The solenoid on nearly all Bosch injectors is the same; however injector tip design will vary between injectors. The current injector is part number 0445110119 and the OEM use is the 1.9L Fiat and Alpha Romeo JTD series of engines. The corresponding nozzle part number is 0433175 386. Further information on this injector can be found in Table 4-3. Spare Bosch injectors can also be found in the Hybrid Electric Humvees in the Mobile Lab vehicle storage area. Removal of these injectors is difficult, and it's recommended that an injector puller is bought or made to remove them. The threads on the injector head are M27x1.0 pitch. Alternatively, replacement Bosch injectors can be ordered from Europe, from suppliers such as [22].

Table 4-3: Injector 0445110-0119 Specifications

\begin{tabular}{|r|l|l|l|l|}
\hline $\begin{array}{l}\text { Injector Hole } \\
\text { Diameter[mm] }\end{array}$ & $\begin{array}{l}\text { Included } \\
\text { Spray Angle }\end{array}$ & $\begin{array}{l}\text { Spray angle } \\
\text { offset }\end{array}$ & $\begin{array}{l}\text { Number } \\
\text { of Holes }\end{array}$ & $\begin{array}{l}\text { Flow Number[cc/30sec } \\
\text { at 100bar. Room Temp] }\end{array}$ \\
\hline 0.139 & 155 & 25 & 77 & 440 \\
\hline
\end{tabular}

The Bosch injector uses the same swaged diesel style fitting as the fuel rail, however the nut is an M12 rather than M14. A short length of $1 / 4$ " line is attached to the injector that terminates in an HP4 style fitting. This adaptor line can be reused on additional diesel engines used in the test cell so the only new required line uses HP4 fittings, which can be made in the Mobile Lab shop using the tools borrowed from the AERB.

The injector is driven off of a capacitor bank connected to a $12 \mathrm{~V}$ power source, currently a car battery. The capacitor bank has an output of $48 \mathrm{~V}$ as required for an 
injector. Each injector will require its own driver if more than one injector is used with the current configuration. The box was built by Applied Tesla Technologies, located in Conroe, Texas.

\subsection{Fuel Line Connection Location}

When using the high pressure fuel system, the connection location in relation to the pallet is critical. As mentioned in section 4.4, different terminating ends are offered. The additional length added by these connections is not included in this terminating end. The final terminating end is an HF4 fitting and dimensions are shown in Figure 4-13 in relation to the engine test bed.

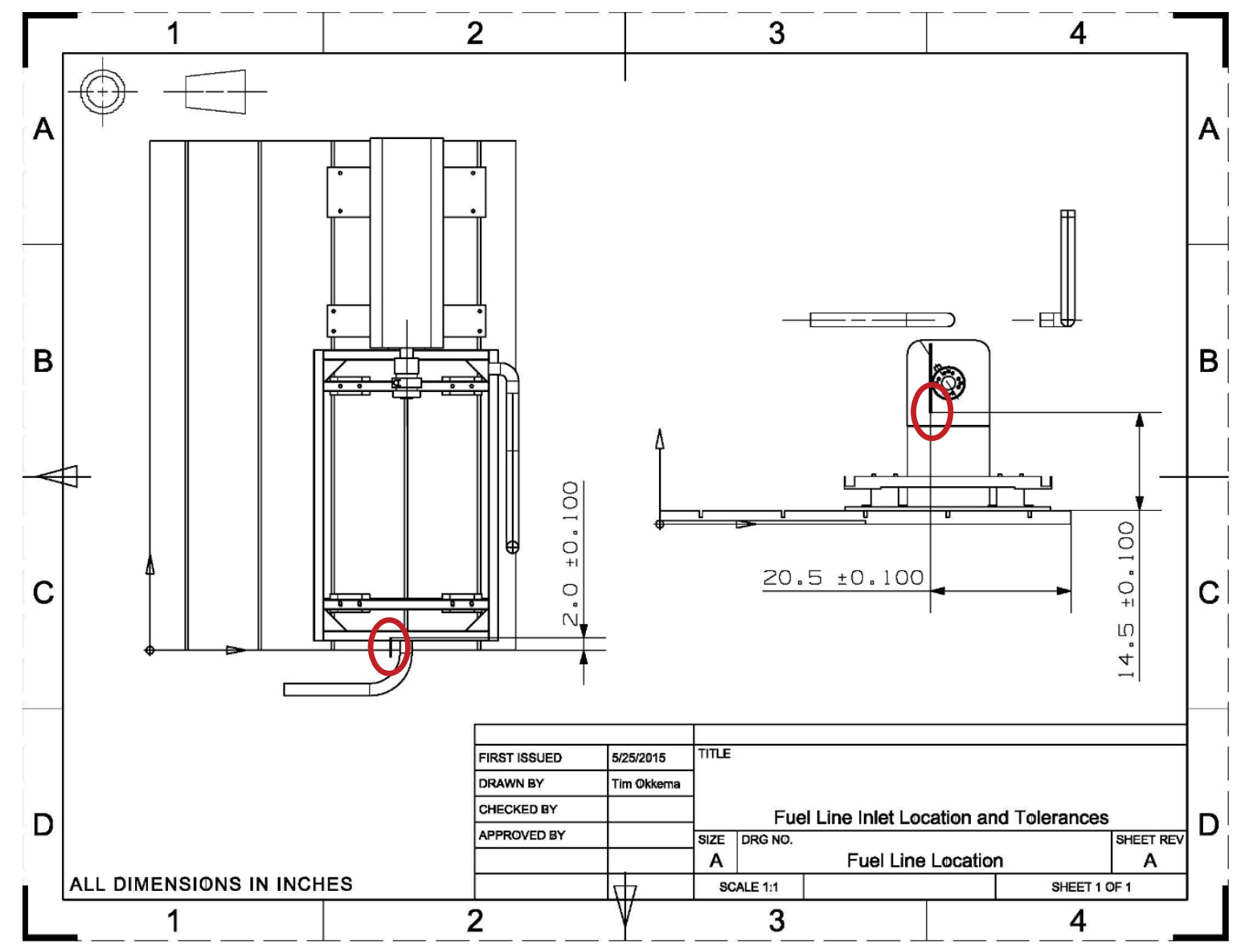

Figure 4-13: Fuel Line Location 


\subsection{Conclusions}

In conclusion, this fuel system provides many different options for engines in the test cell. This allows for switching between different engines quickly and efficiently. The Mobile Lab is used for teaching short courses, and with the fuel system capabilities, gasoline and diesel engine courses can now be taught with little down time in between. Different fuels can be run simply by changing the three way valve at the inlet of the low pressure system. A valve at the end of the low pressure system can be used to change between using the high pressure system or running directly off the low pressure system.

With the high pressure fitting style, and spare parts available, many different configurations can be run in the test cell. Fuel lines can be made in house, which makes converting engines to common rail injection economical in the Mobile Lab test cell. This could allow for courses showing the differences between mechanical injection to common rail injection. With the ease of switching between gasoline and diesel in the rear test cell, gasoline engine courses can be taught back to back with diesel engine courses. 


\section{Air System}

\subsection{Intake Design}

The air intake system is mounted to the wall near the ventilation system and routes along the wall to the engine intake. Included in this system is a shutoff valve that cuts off the air flow to the engine in the case of an emergency. This is critical when running diesel engines, and can be utilized if the diesel engine starts to run on its own lube oil supply. The valve is just inside the doorway of the test cell, and is used as an emergency shut off for the engine. Using the emergency stop buttons in the lab will cause the dyno to output its maximum torque to slow the engine speed down to zero. If shutting off the fuel, and using the dyno to slow the speed of the engine down does not work, the air valve can be used. Figure 5-1 shows an image of the intake system.

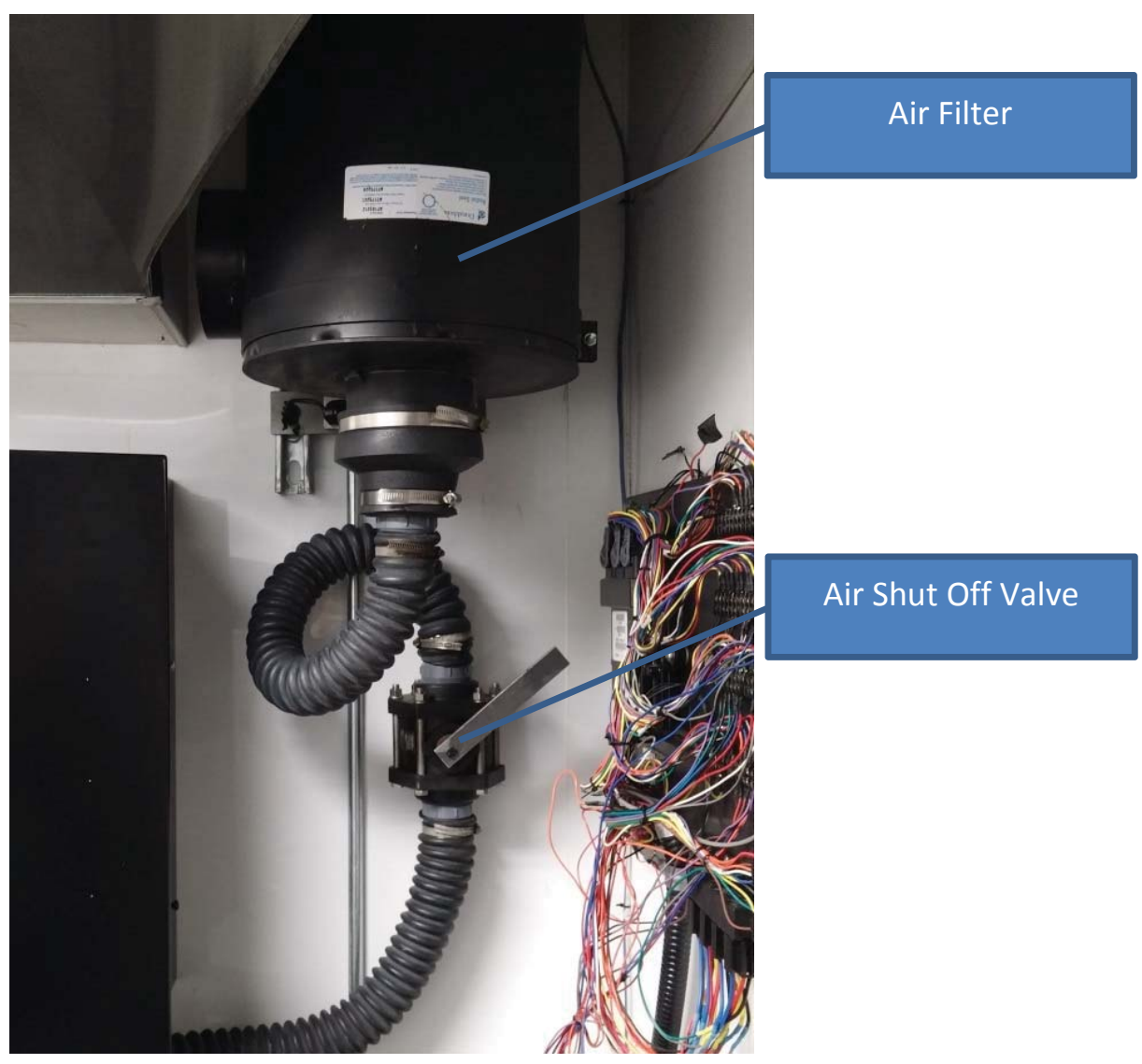

Figure 5-1: Air Intake System 
The air filter is from a large diesel engine and is oversized for this application. This helps to reduce noise, while still providing plenty of air flow. The filter is mounted upside-down so that the intake can be tied into the test cell fresh air intake in the future. The disadvantage to the upside-down mounting is that the dust collector is at the top of the air filter. In the Mobile Lab test cell, this shouldn't be an issue since very little dust enters the test cell.

At the inlet of the air filter, there is a thermocouple measurement. There is also a pressure transducer installed at the exit of the air filter. In the OEM application, this would be used to determine when the pressure drop across the air filter was too large, and the filter needs changing.

\subsection{Intake Location}

The intake tubing is flexible, and allows for a lot of variability in the intake location of the engine to be brought in, while keeping the connection quick and simple. The standard connection location has been determined for the intake. Figure 5-2 shows the dimensions of the intake location and the tolerances allowed for connecting engines. This connection is made by a hose clamp around the rubber intake hose, and fits a two inch diameter intake tube. 


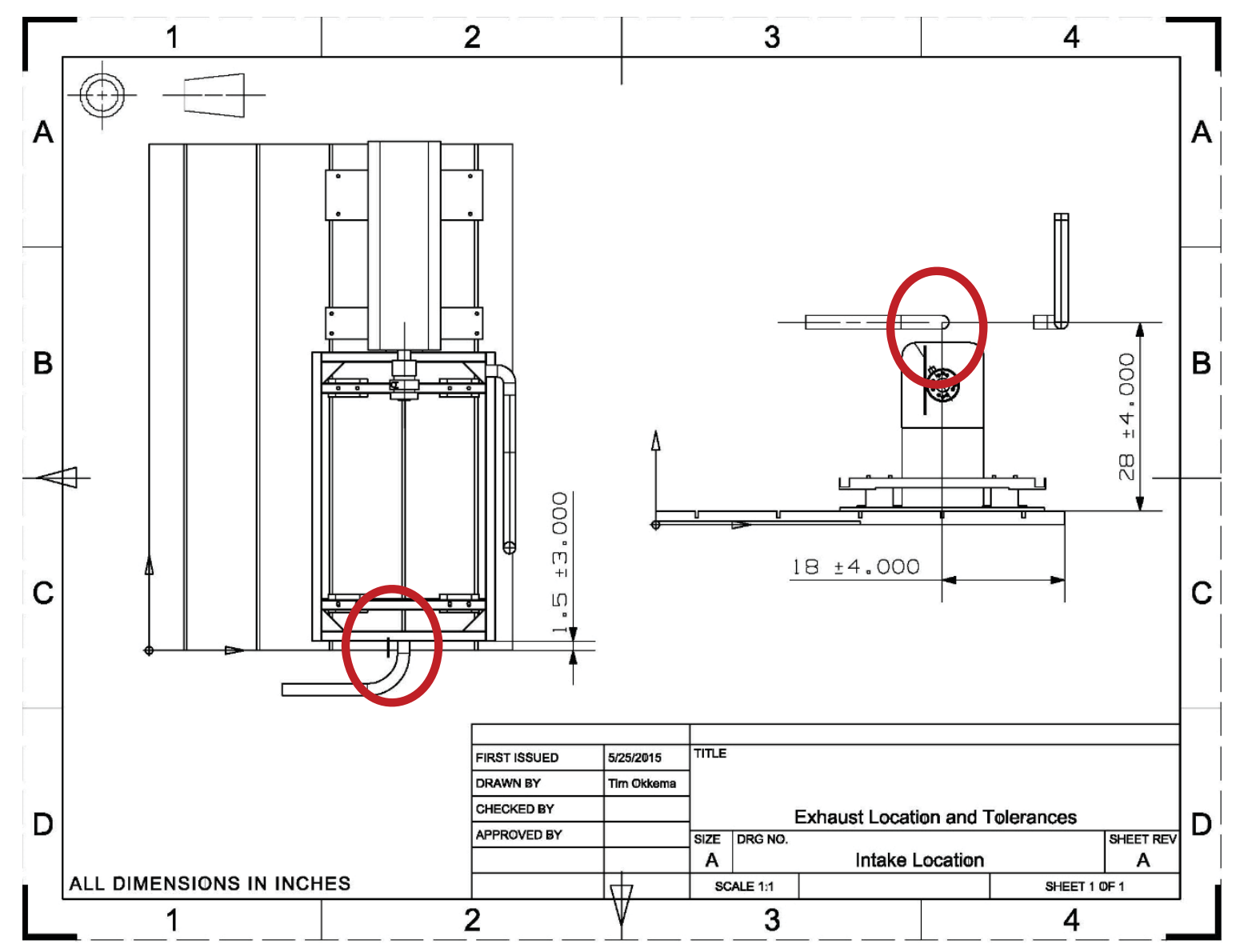

Figure 5-2: Intake Location 


\section{Exhaust System}

\subsection{Exhaust Design}

The exhaust system in this test cell has multiple options that can be connected to the engine. The overall piping is stainless steel and is two inches in diameter. It exits through a marmon flange on the outside of the test cell. This marmon flange was purchased from Detroit Flex [23]. In outdoor environments, this exits directly to atmosphere. When testing in this condition, the rear doors to the trailer should not be opened all the way, as the exhaust port on the outside of the test cell is blocked. This may lead to burning or discoloring of the graphics. When testing is done indoors, a ventilation system can be connected to this marmon flange. Figure 6-1 shows both a marmon flange and a V-band flange.

Inside the test cell there is a twenty four inch vertical section of tubing that is connected via marmon flanges, and can be disconnected and replaced with a muffler of the same length depending on whether the test requires sound deadening, or if a free flowing exhaust system is needed. Connection to the engine is done through a flexible tube with a two inch v-band flange purchased from AN-Fittings Direct [24]. Figure 6-2: Test Cell Exhaust System on the following page shows the exhaust as connected to the Yanmar diesel engine that will be covered in chapter 11 .

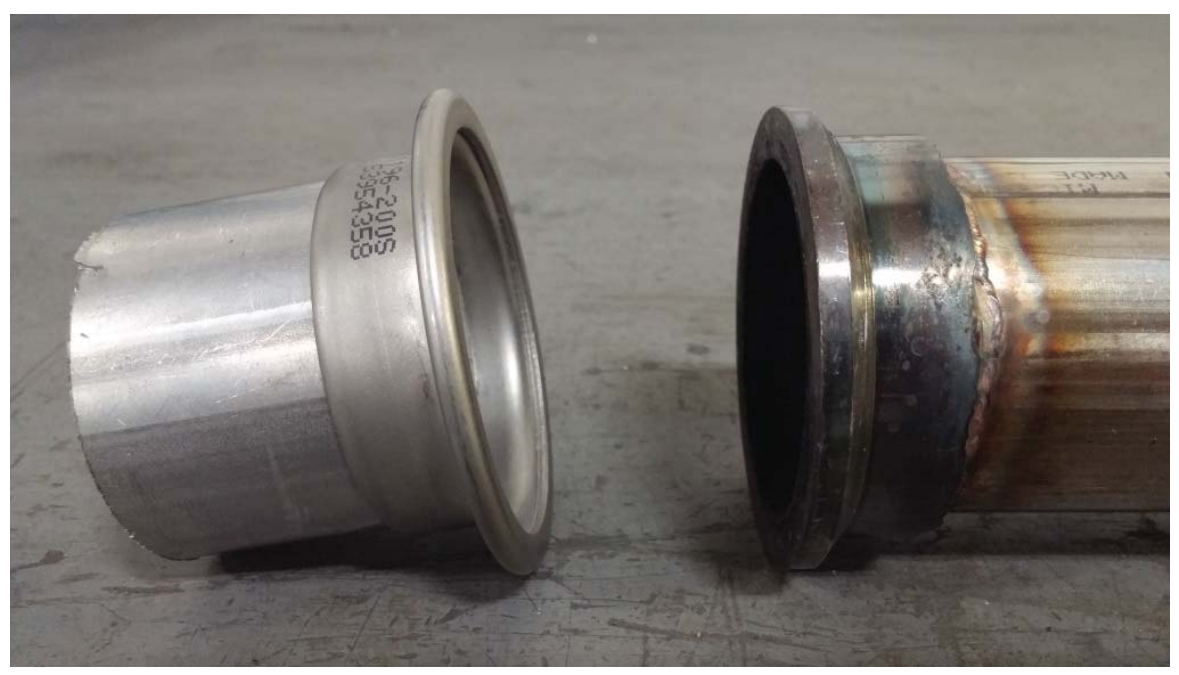

Figure 6-1: Left: Marmon Flange. Right: V-Band Flange 


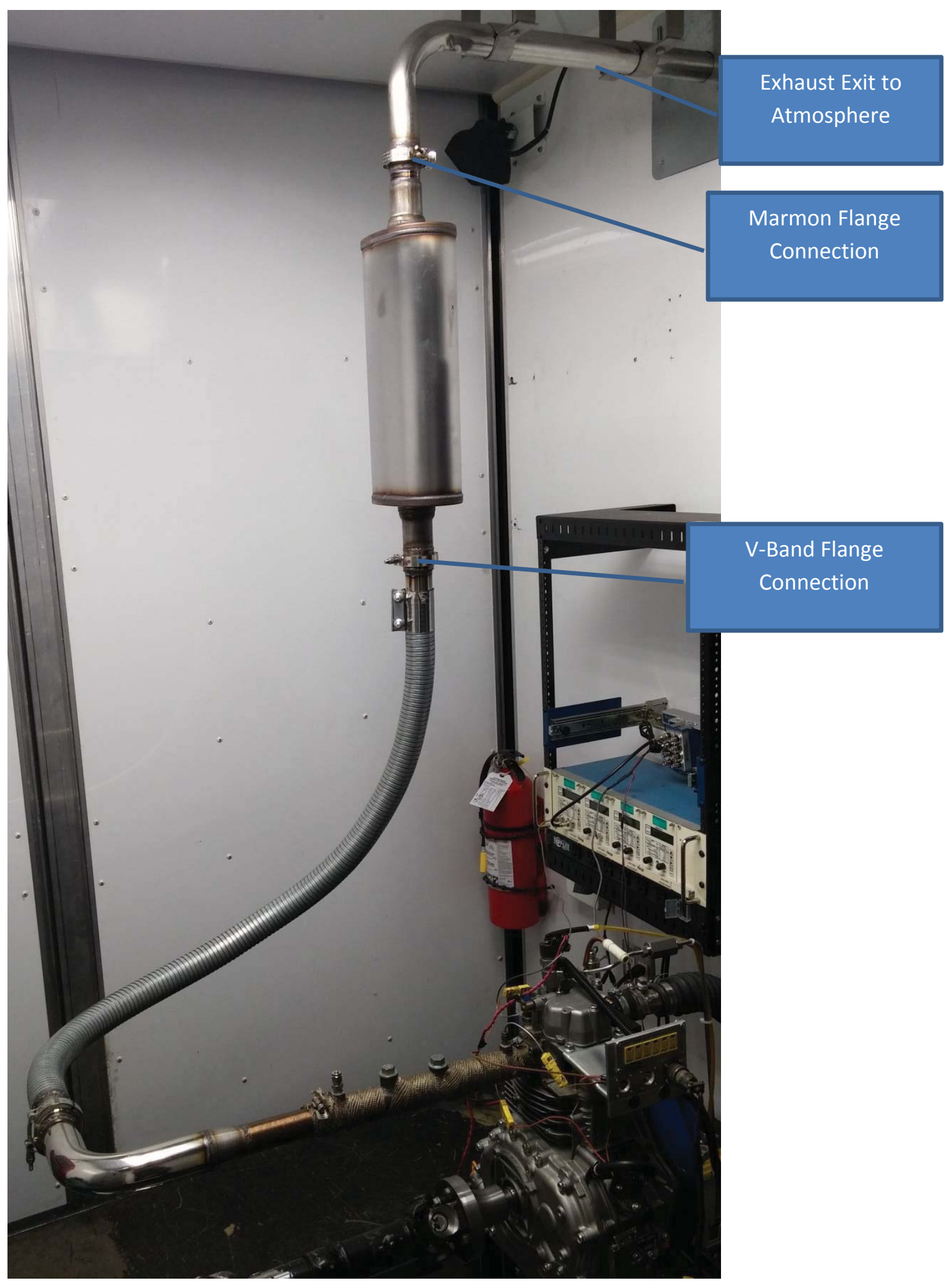

Figure 6-2: Test Cell Exhaust System 


\subsection{Exhaust Location}

The connection for the exhaust in the test cell is very flexible since most of the piping is done through flexible tubing. The connection location with dimensions is shown in Figure 6-3 along with tolerances for the connection location.

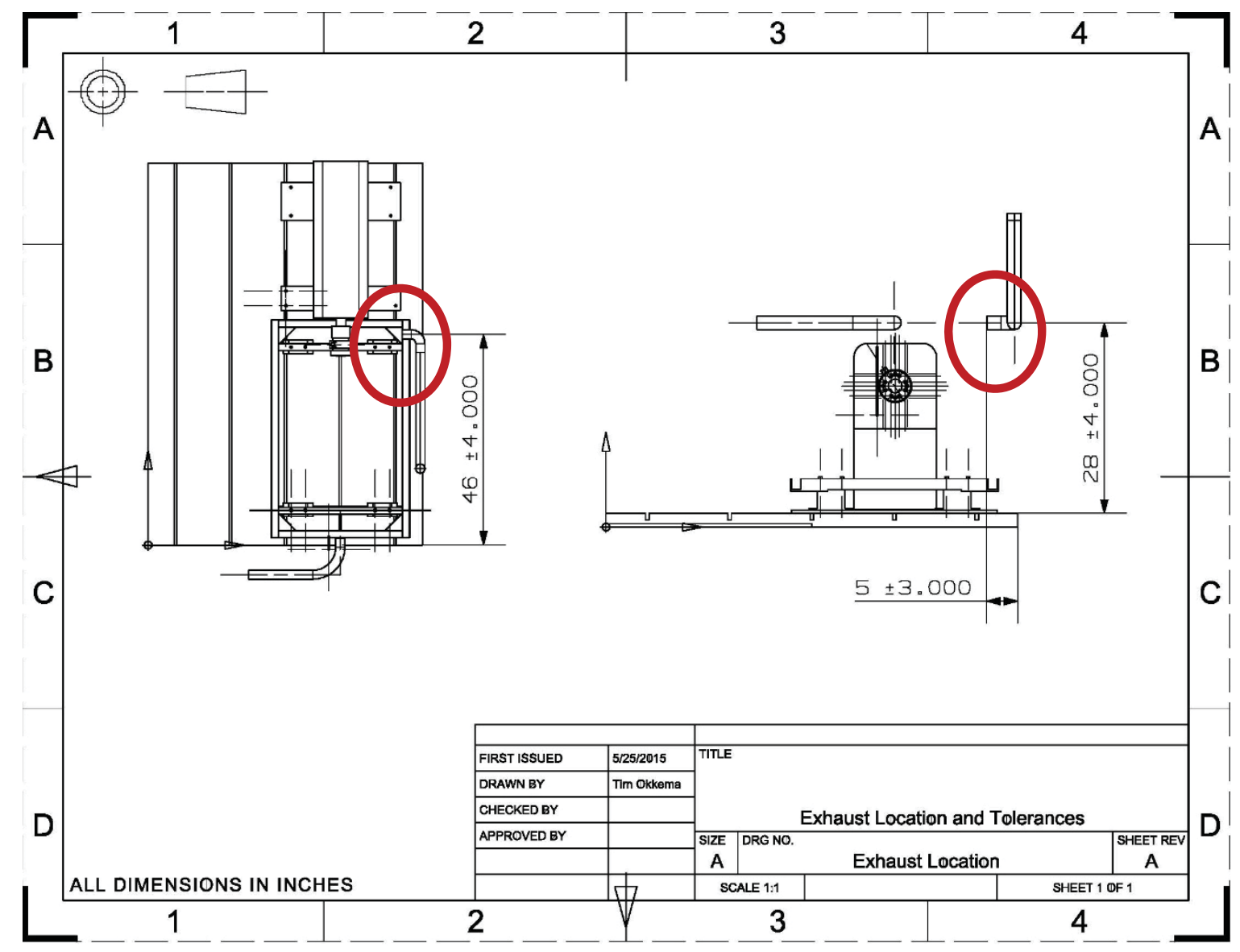

Figure 6-3: Exhaust Connection Location 


\section{Engine Pallet}

\subsection{Pallet Design}

The engine itself, along with any components specific to the engine to be tested, are mounted to a custom built pallet. This entire pallet will be removed from the test cell when changing to another engine. Each engine will have its own pallet, and will be mounted in such a way that it can easily be brought into the test cell and connected quickly. Therefore it was necessary to design the pallet in a way that can easily be re-created for future engine projects. It also needed to be simple to add components to, and easy to replace in the event of a failure. The chosen design was a solid Unistrut [25] with welded construction rather than a bolted configuration. The design is a rectangular frame with two cross pieces that are used to both stiffen the frame, and provide mounting locations to the bedplate. The frame was built as large as possible, while still allowing room to remove it from the test cell easily. The print below in Figure 7-1 shows dimensions of the pallet. In Table 7-1 is a list of part numbers, and strut channel lengths needed to build the pallet. Each of the 60 inch pieces are cut into two 27 inch pieces to make the four cross bars of the pallet. All parts were purchased from McMaster-Carr [20], however, any general electric supplier can be used to buy the strut channel. 


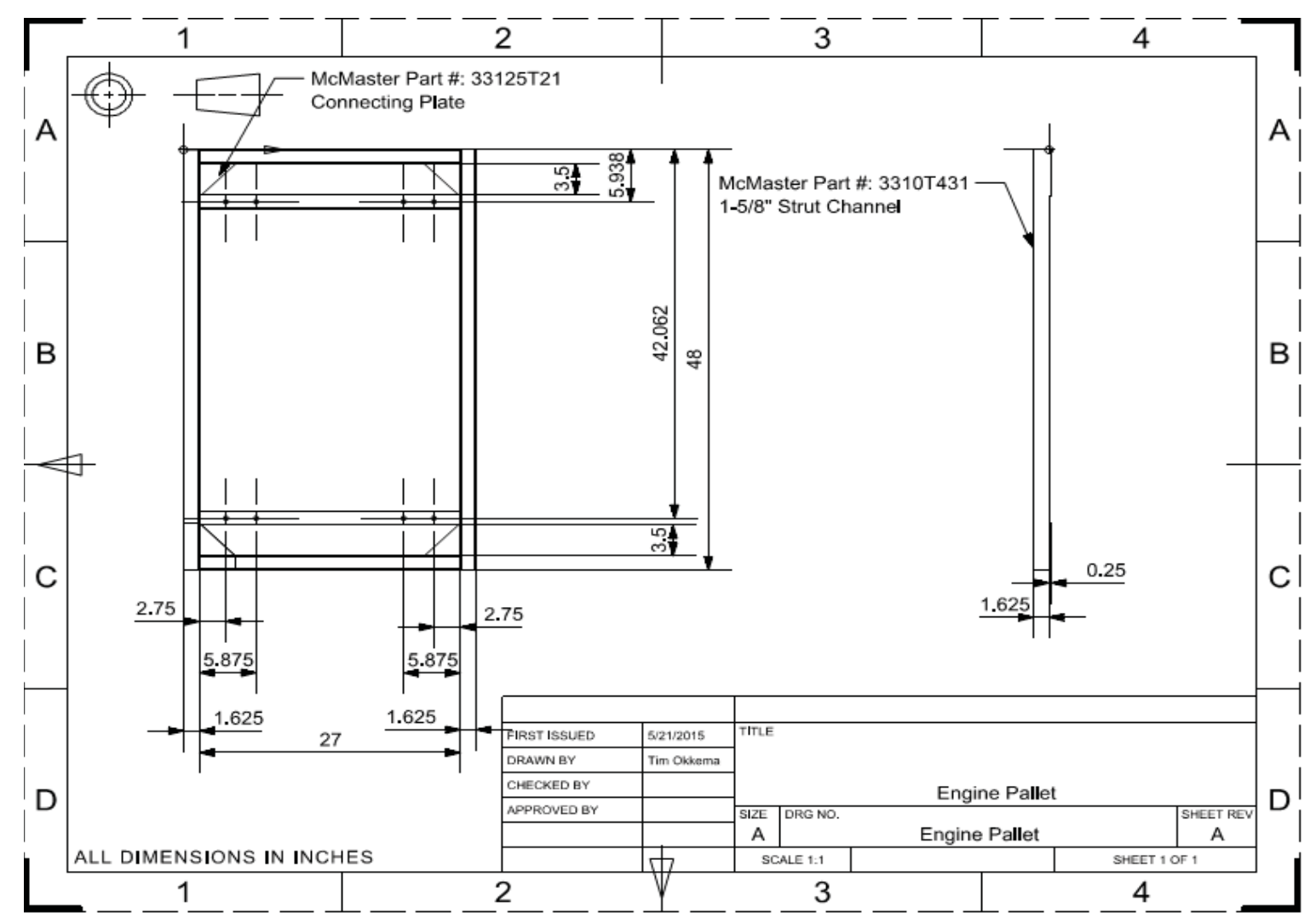

Figure 7-1: Engine Pallet

Table 7-1: Pallet Part Numbers and Lengths

\begin{tabular}{|c|c|c|c|c|}
\hline Part Name & Part Number & $\begin{array}{l}\text { Length } \\
\text { (inches) }\end{array}$ & Quantity & Supplier \\
\hline $\begin{array}{l}\text { Solid Unistrut Channel } 15 / 8 " \times 1 \\
5 / 8 "\end{array}$ & 3310T111 & 48 & 2 & $\begin{array}{l}\text { McMaster- } \\
\text { Carr }\end{array}$ \\
\hline $\begin{array}{l}\text { Solid Unistrut Channel } 15 / 8 " \text { x } 1 \\
5 / 8 "\end{array}$ & 3310T441 & 60 & 2 & $\begin{array}{l}\text { McMaster- } \\
\text { Carr }\end{array}$ \\
\hline Connecting Plate - Style 5 & $33125 T 21$ & $\mathrm{~N} / \mathrm{A}$ & 4 & $\begin{array}{l}\text { McMaster- } \\
\text { Carr }\end{array}$ \\
\hline
\end{tabular}

Permanent isolating mounts are used to fasten the pallet to the bedplate. The engine is then mounted to the pallet with no isolators. Because the pallet system is very universal, and intended to be used on everything from small single cylinder engines up to $75 \mathrm{hp}$ engines, mounting needed to be robust, but still provide dampening. Mounting is done through automatic transmission mounts from a two wheel drive, 
four cylinder 1999 Ford Ranger. These mounts were chosen because of their ease of availability, and they are a compact design that fits well with the design of the pallet. Each mount has two studs on the top. The studs are used as the locating pins when lowering an engine pallet onto the mounts. One mount is used in each of the four corners of the pallet. These mounts can be ordered from Summit Racing [26], or any general auto parts store. Figure 7-2 shows dimensions of the transmission mount used.

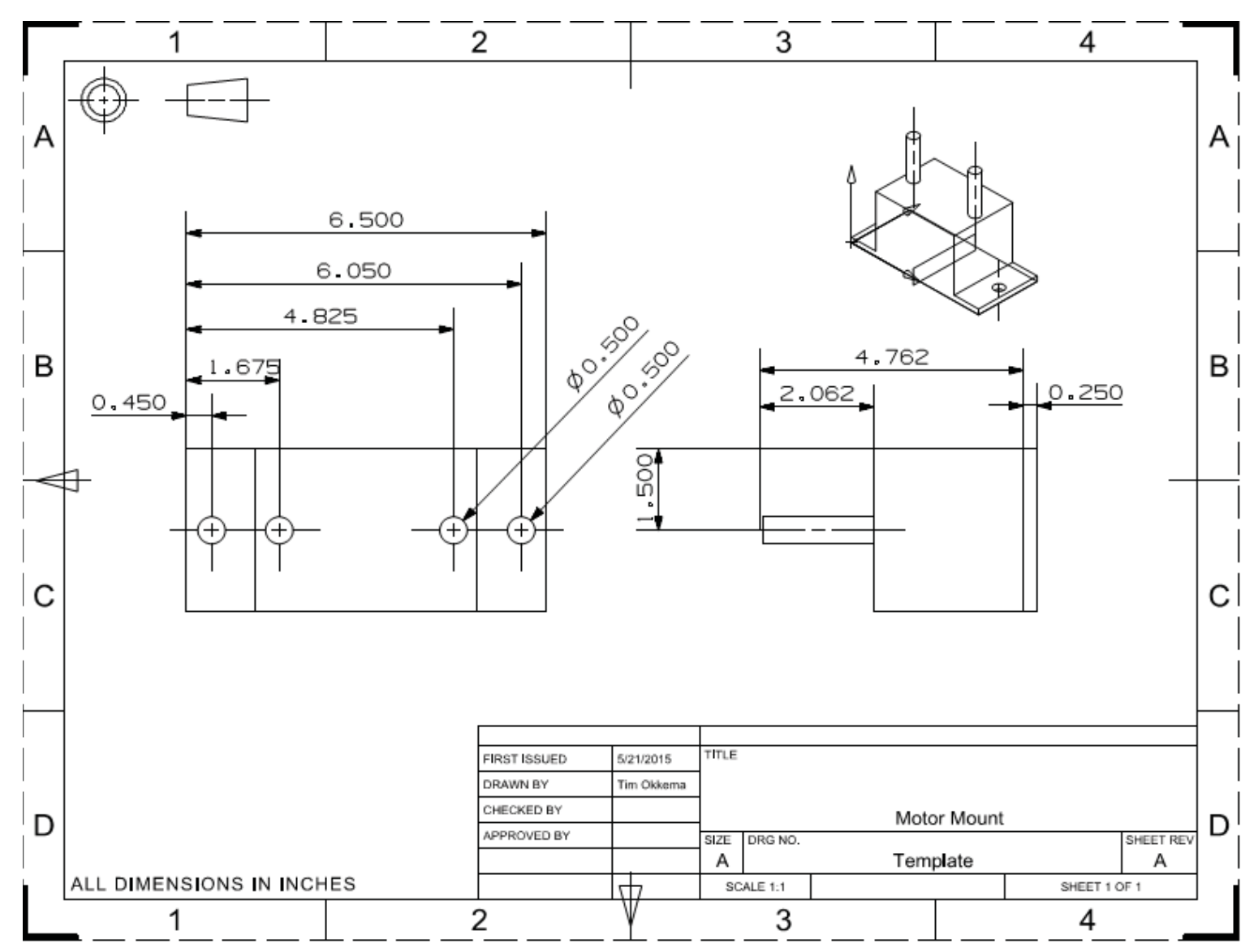

\section{Figure 7-2: Isolating Mounts}

Fastening the mounts to the bed plate of the test cell requires an adaptor. The bed plate has T-slots spaced 12" apart. Adaptor bars were made from steel and used to bolt the mounts to the bed plate. The adaptor bars bolt to three of the T slots and use 3/8"-16 flat head socket cap screws with an 82 degree bevel under the head so they 
can be recessed into the bar and mounted face down on the bed plate. Figure 7-3 is a print that shows the dimensions for the mounting holes.

The final position of the Isolating mounts and the relative location to the dyno hub is shown in Figure 8-6 in Chapter 8.

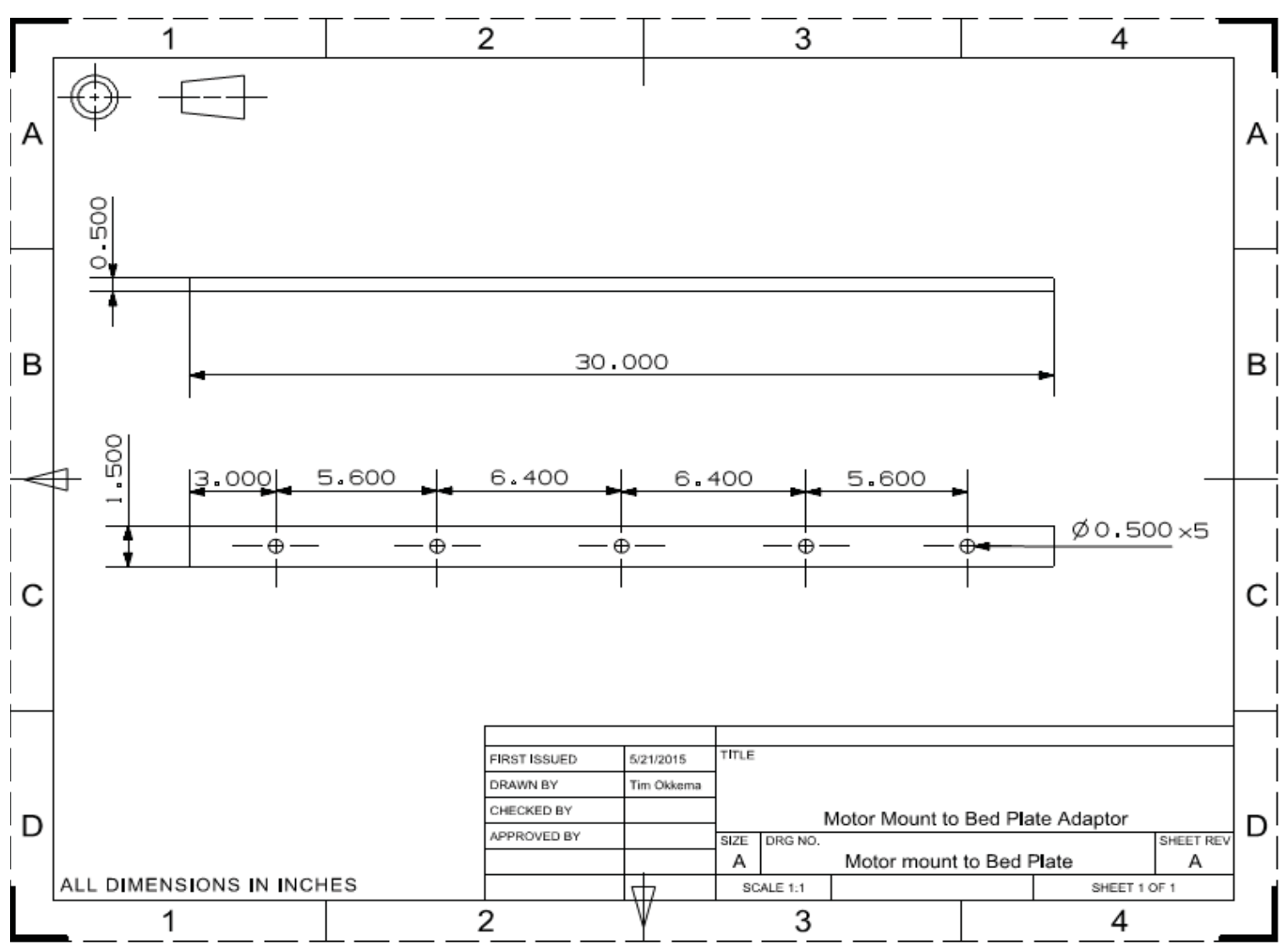

\section{Figure 7-3: Isolating Mounts to Bed Plate Adaptor}

Engines are mounted directly to the pallet. The isolators provide the dampening to the test cell bed plate. When mounting an engine that needs a large amount of spacing to bring the crankshaft to the dyno hub height, longer spacers should be used to prevent any rocking motion perpendicular to the engines crankshaft rotation line. This motion was noticed after the Yanmar covered in Chapter 11 was mounted on short spacers. It was assumed that there would be no forces in this direction, so it 
would be acceptable. Figure 7-4 shows the motion that the Yanmar engine experiences in the direction of the arrows shown. The mounts that could be lengthened in future applications are also referenced. 


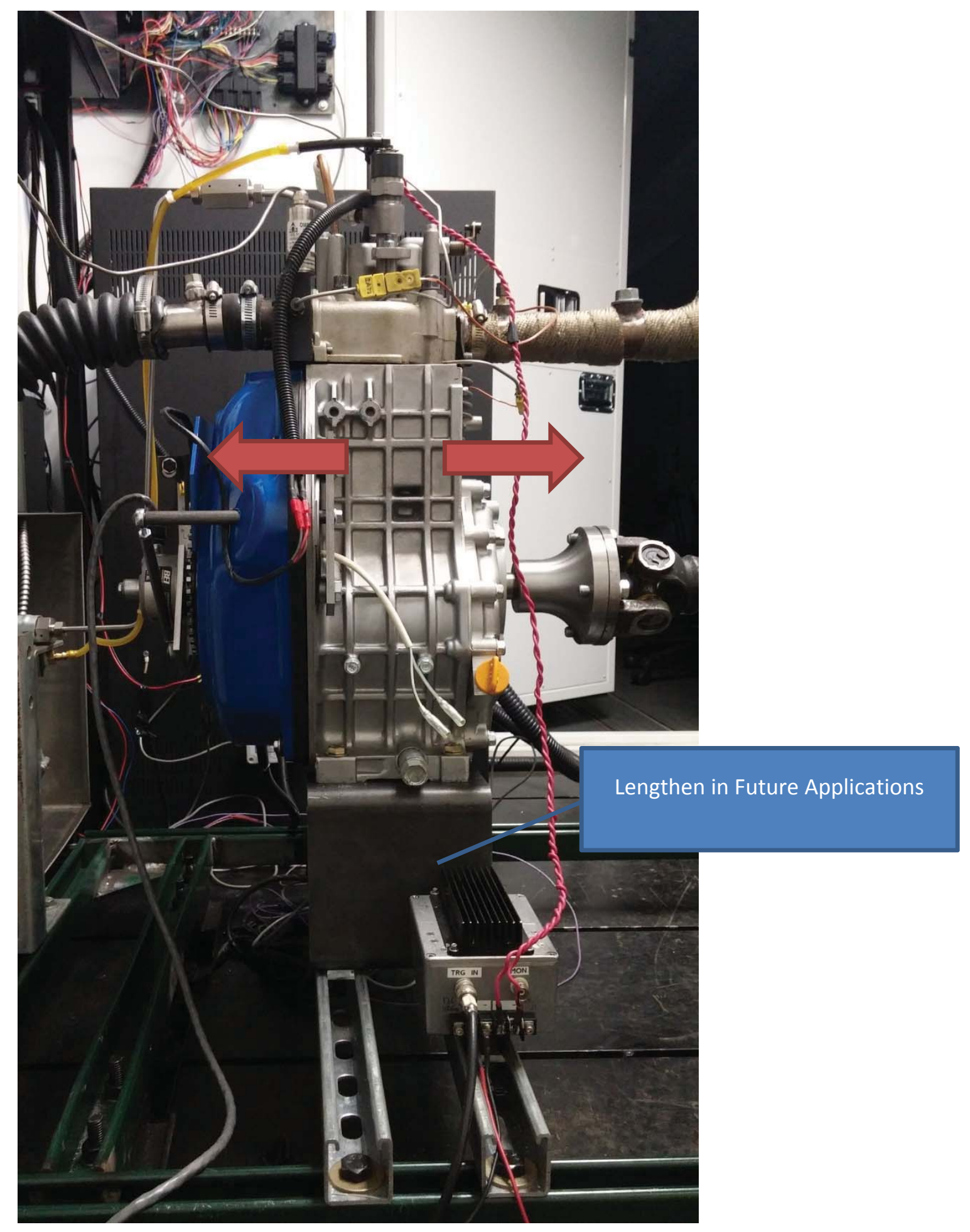

Figure 7-4: Yanmar Rocking Motion 


\section{Dynamometer and Shafting}

\subsection{Dynamometer Mounting}

To keep the test cell as universal as possible, modifications needed to be made to the dyno as well. To accommodate for larger engines, the dyno was elevated. The chosen height for this modification was 12 " from the original location. The original adaptor plates that were used to bolt the dyno to the bedplate were reused, and spacers were installed in between the adaptor plates and the dyno. Both spacers were 12 " x 8 " square tube with 1/4" wall thickness, and can be bought from many different material suppliers. Figure 8-1 shows a print of the front spacer block. Figure 8-2 shows a print of the rear spacer block.

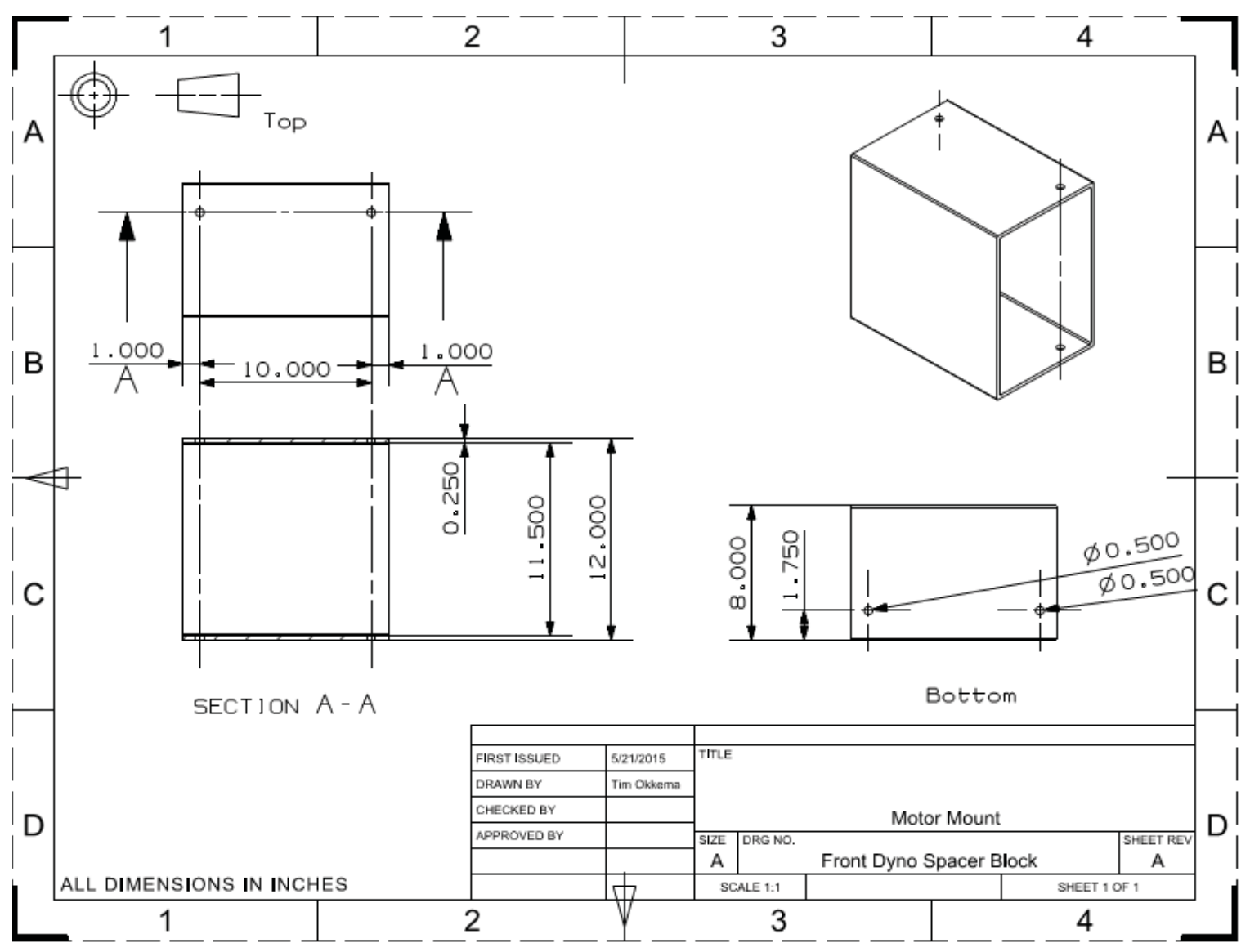

Figure 8-1: Front Dyno Spacer Block 


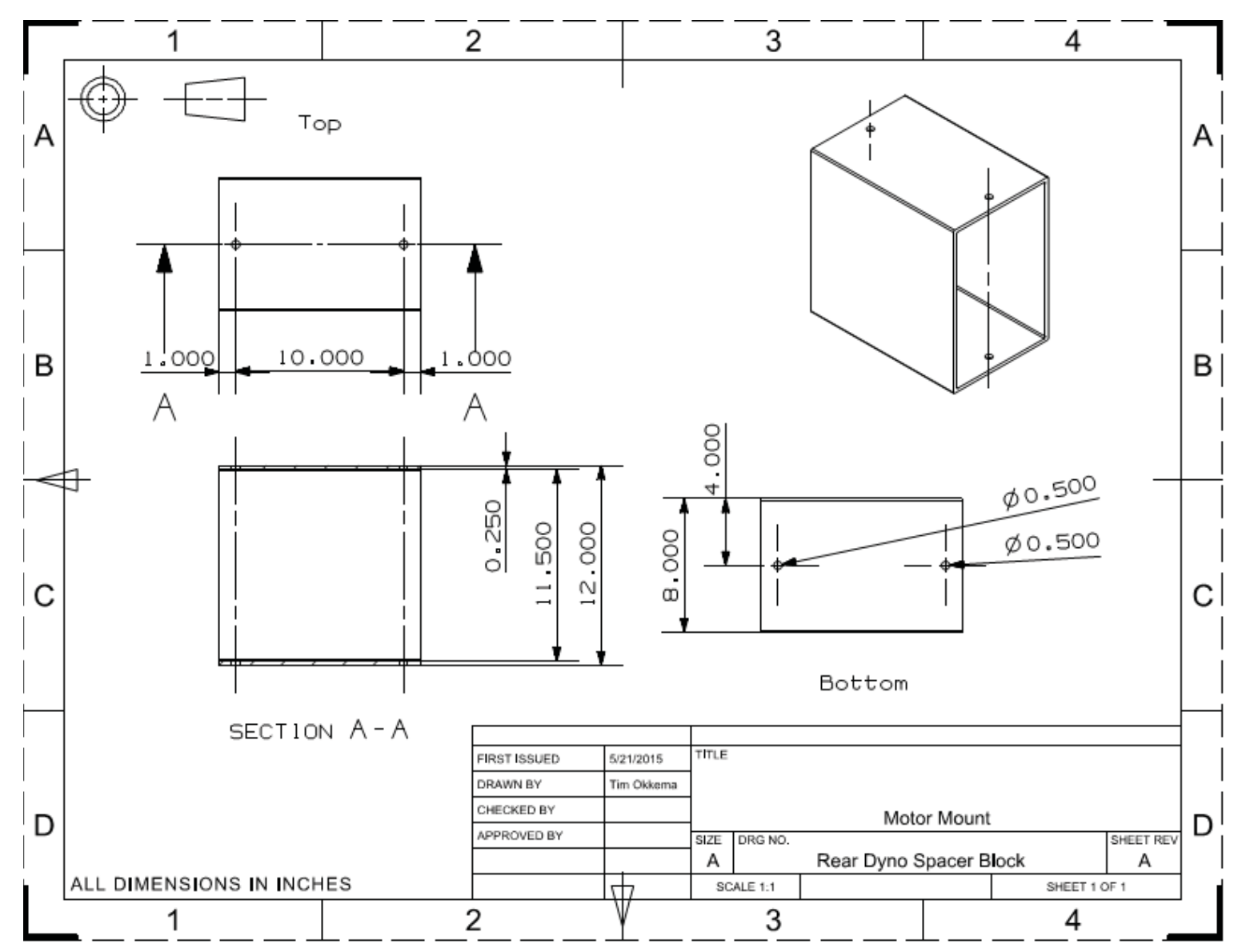

Figure 8-2: Rear Dyno Spacer Block

\subsection{Dynamometer Hub}

When mounting an engine in the test cell, the most critical part is alignment with the dyno hub itself. The crankshaft should be parallel with the dyno hub. When mounting the Yanmar diesel described in Chapter 11, it was found that simply aligning the hubs by eye caused no issues with vibrations. However, a simple device could be made that mounts to the hub and can be used to set parallelism between the hub on the powertrain and dyno more effectively. The Unistrut frame construction can allow for easy adjustment in the $\mathrm{X}$ and $\mathrm{Y}$ directions. Optimal driveshaft angle for a driveshaft with two universal joints is three degrees. The driveshaft has a slip joint in the center to account for engine vibrations and movement. These features can be seen in Figure 8-3 


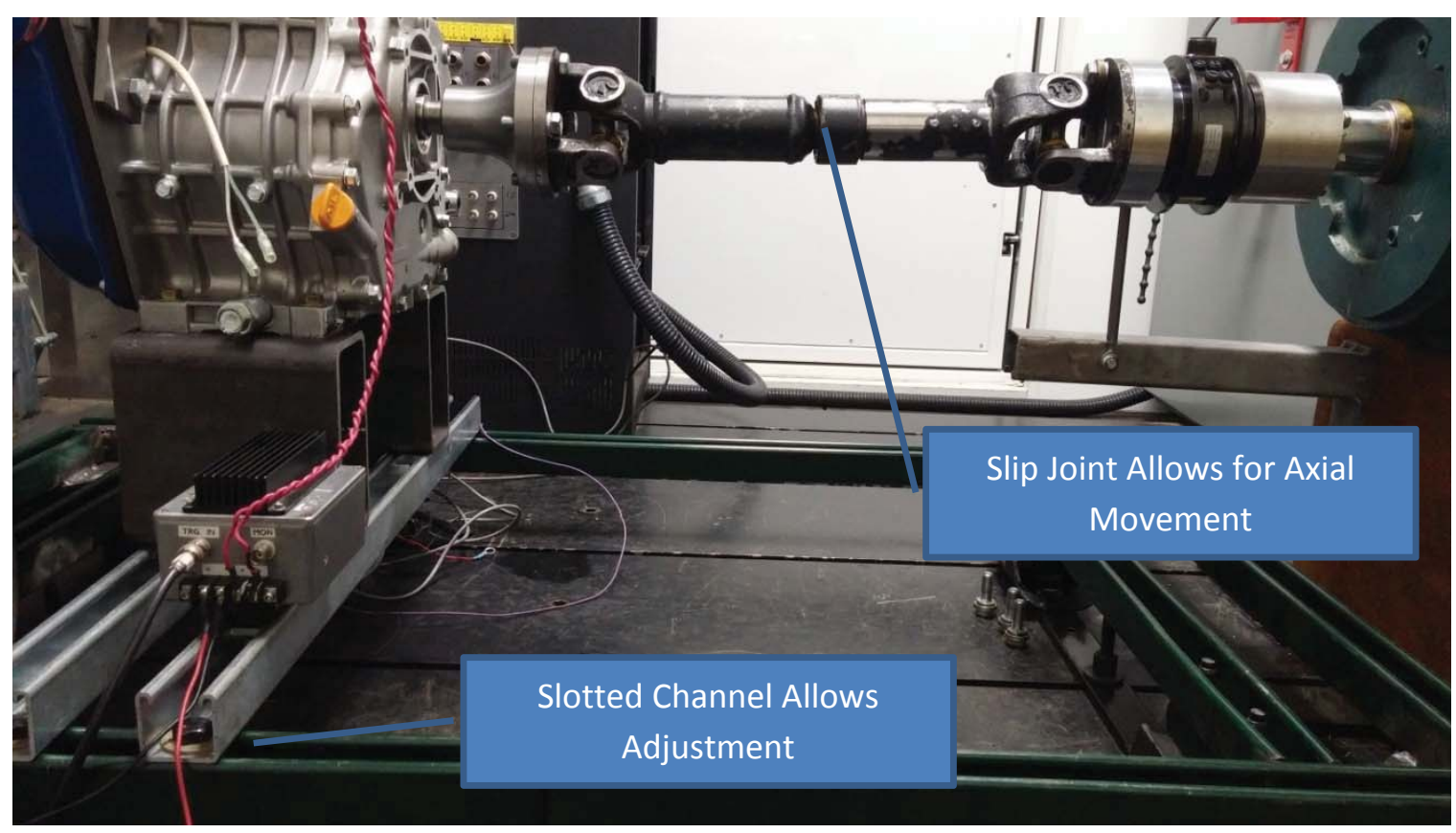

Figure 8-3: Driveshaft

The output shaft of the dyno and dimensions can be found on Baldors website in a full print of the dyno [27]. An adaptor is used to bolt the torque meter to this shaft, and is shown in the print in Figure 8-4. The torque meter used in the mobile lab test cell is a Honeywell 1228-10k, and is rated for 10,000 inch-lbs of torque [28]. A second adaptor flange bolts to the other side of the torque meter and is used to adapt to the bolt pattern on the driveshaft used. The print for this adaptor is shown in Figure 8-5. The hub location with reference to the mounting points on the pallet is shown in Figure 8-6. An assembled picture of this connection is shown in Figure 8-7.

The hub that connects the torque meter to the dyno is made with a shrink fit. The inner diameter is 2.123 ”, while the shaft of the dyno is 2.125 ". This creates a hub with zero run-out, and ensures that the hub will not slide off the shaft. The coefficient of expansion for aluminum is $12.3 * 10^{-6} \frac{\mathrm{inch}}{\mathrm{inch} *^{\circ} \mathrm{F}}$. To calculate the expansion of a shaft or hub based on temperature, Equation 8-1 is shown below. Aplha is the coefficient of expansion for the material, $d_{1}$ is the final diameter, $d_{0}$ is the initial diameter, and $d t$ is the change in temperature. 


\section{Equation 8-1: Expansion of a Shaft with Changing Temperature}

$$
d_{1}=d_{0} *(d t * \alpha+1)
$$

Based on this equation, the hub needs to be heated $77^{\circ} \mathrm{F}$ above room temperature for the inner diameter to be at least 2.125". This is well below any temperature that would impact the material properties of 6061 aluminum.

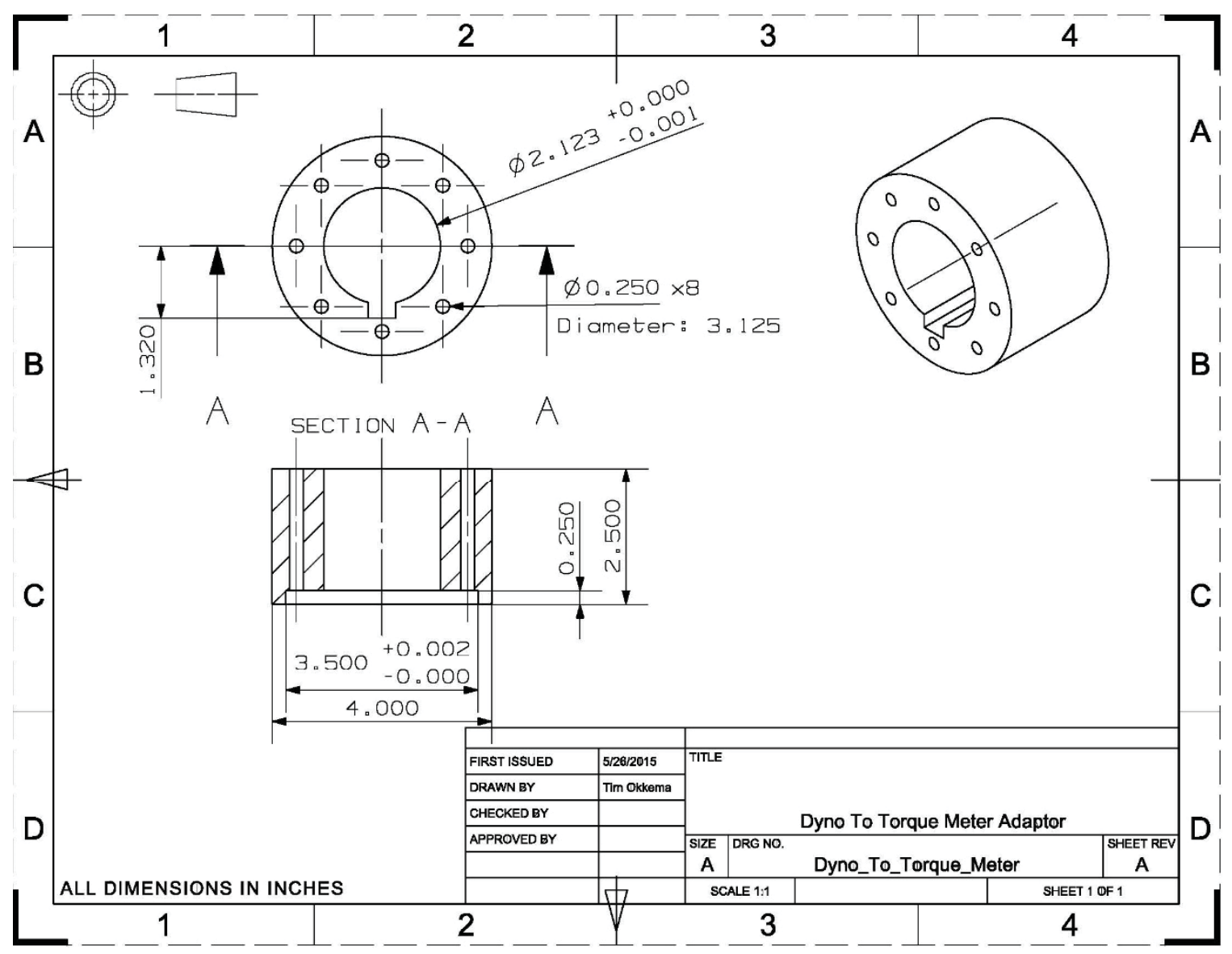

Figure 8-4: Dyno to Torque Meter Hub 


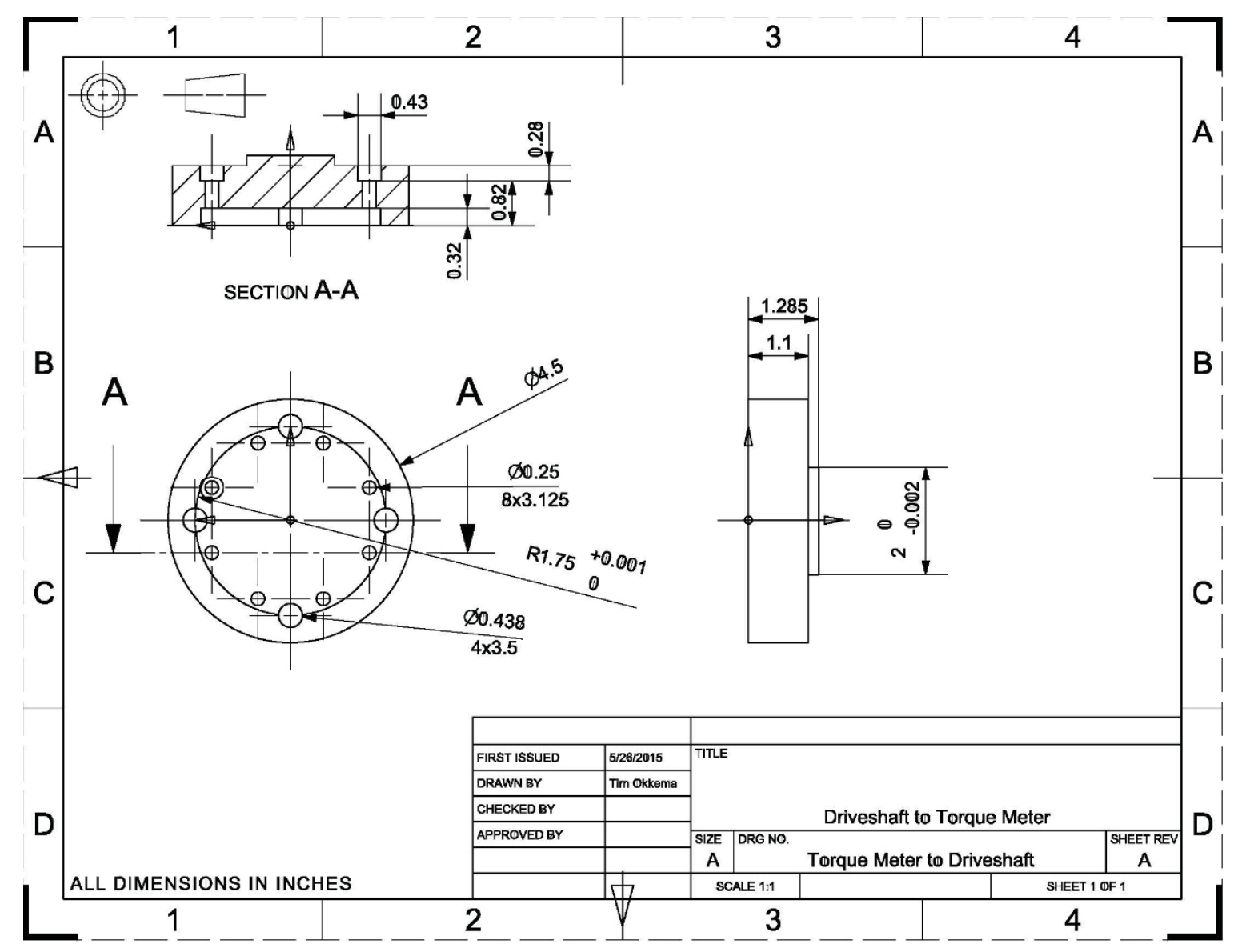

Figure 8-5: Driveshaft to Torque Meter Hub 


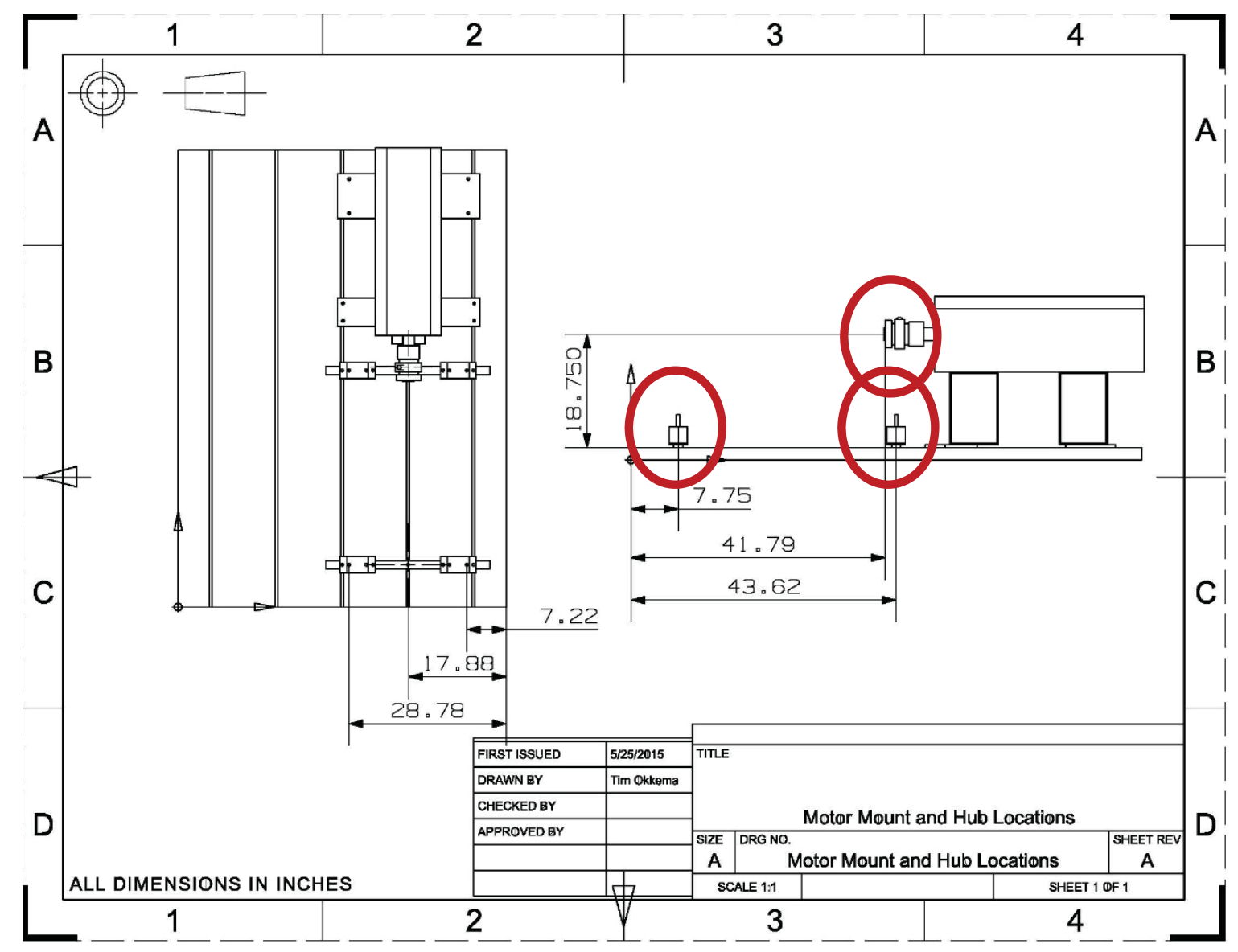

Figure 8-6: Dyno Hub Location and Isolating Mount Locations 


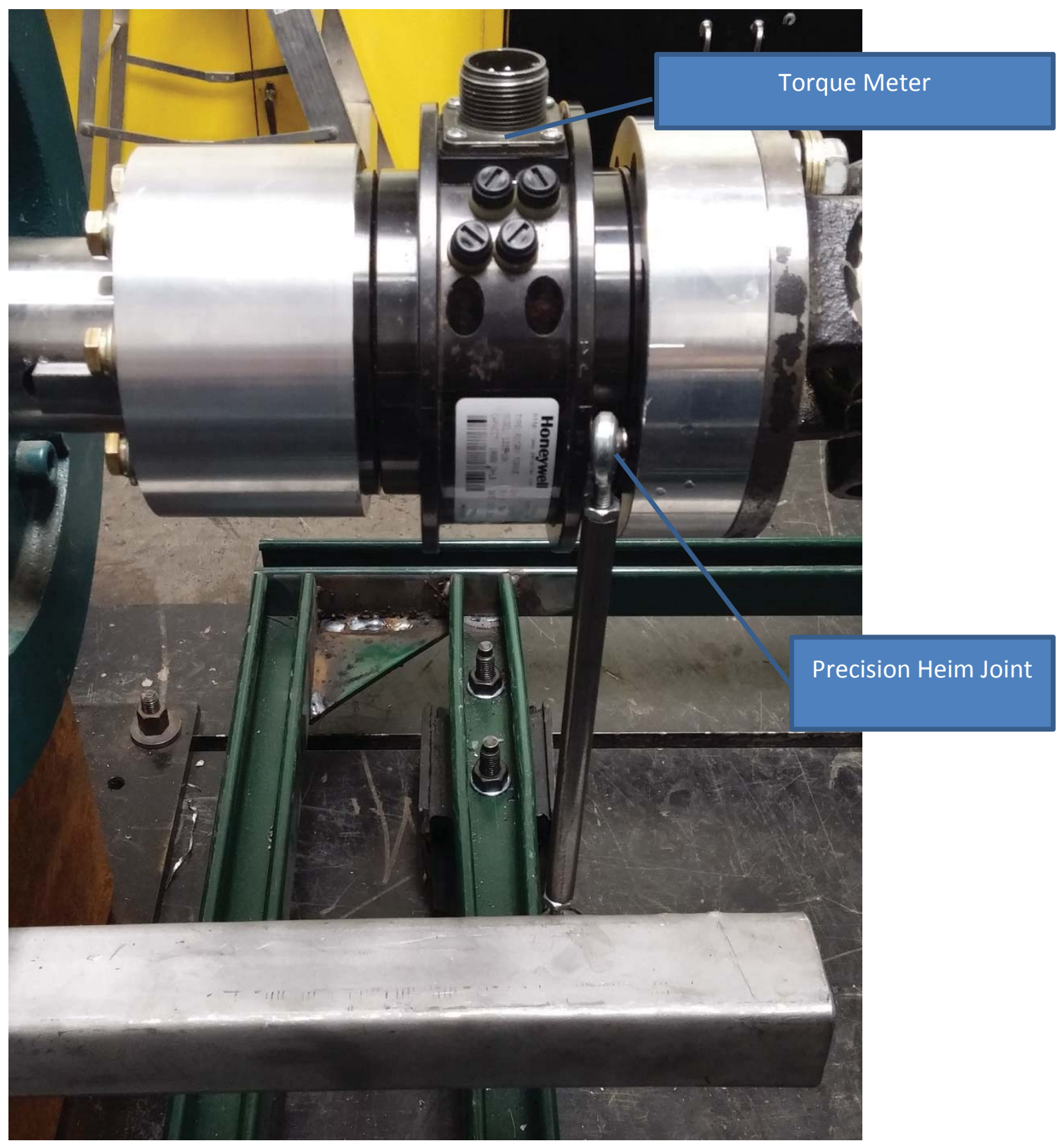

\section{Figure 8-7: Drive Shaft to Dyno Coupling}

The outer part of the torque meter remains stationary when the shaft is spinning. To hold the torque meter in place, a steel rod is used. On either end of the rod is a precision heim joint. The fixture used to mount this rod needs to be built solidly. There should be no movement in the mount when the shaft is spinning, as any 
movement would skew the measurements of the torque meter. The stiffer the mount is built, the higher the natural frequency. Any mechanical vibrations from running the engine should be well below the natural frequency of the mount. 


\section{Instrumentation}

Instrumentation is done through three main data acquisition (DAQ) boxes as mentioned in section 3.1. The DAQ used for general measurements and digital in/out signals is the PXI 1050. A National Instruments cDAQ is used for combustion analysis measurements. And the MotoTron controller is also used as a data acquisition device.

\subsection{PXI Cabinet}

This is a chassis built by National Instruments and is mounted in an enclosed standard 19" rack in the Mobile Lab test cell. The PXI is expandable with up to thirteen slots, and has a system bandwidth of $132 \mathrm{MB} / \mathrm{s}$. This DAQ provides up to twenty four thermocouple inputs, thirty two analog inputs with $24 \mathrm{~V}$ reference, four counter/timers, and twenty four digital inputs.

One of the most complex parts in engine integration into a test cell is the instrumentation connections. To simplify this process, connections are standardized in the Mobile Lab test cell. Although different applications might have unique measurement requirements, there will almost always be certain measurements that do not change between different engines. The PXI cabinet has a breakout panel with each connection labeled. This is shown in Figure 9-1. 


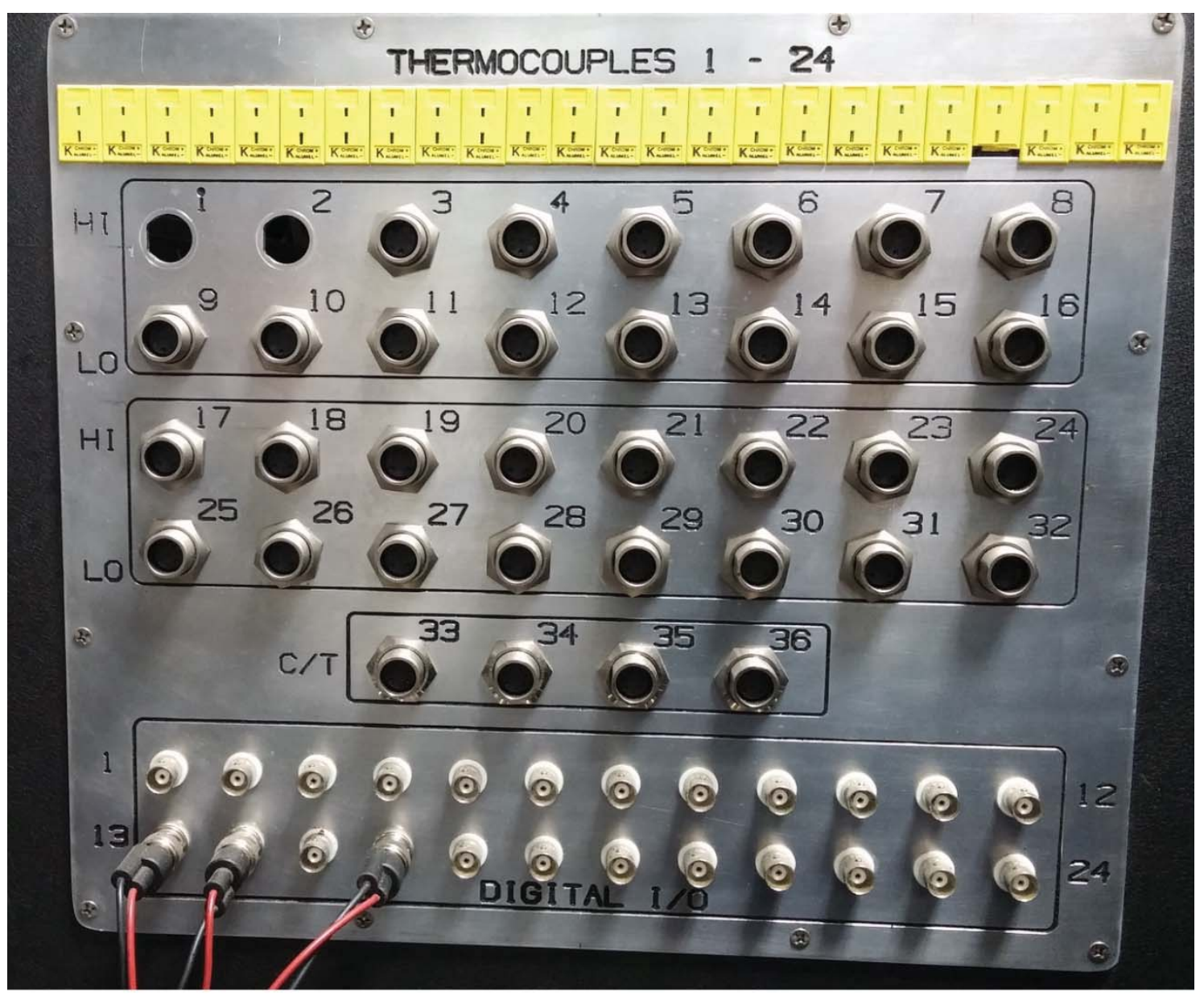

Figure 9-1: PXI Cabinet Breakout Panel

The first set of connections is thermocouples. In the Mobile Lab test cells, all thermocouples are K-type. Depending on the engine tested, and measurements required, the number of thermocouples needed may change greatly. In the case of the Yanmar engine discussed in chapter 11, only five thermocouple connections were necessary. In a four cylinder engine, with forced induction, many more thermocouples would likely be required. To standardize the thermocouple connections, a few assumptions were made about the points to be measured. The first assumption is that the max engine that would be installed in the test cell is a four cylinder. This means that up to four thermocouples would likely be used on the individual intake runners and up to four on the exhaust. But with any size engine, in general, only one oil 
temperature thermocouple would be needed. Other standard connections were made for dyno temperature, coolant temperature, and ambient cell temperature. Most of these connections will be used with every engine brought into the test cell, so this simplifies the process. Table 9-1 has a listing of all thermocouple inputs. When a user brings in a new engine, a loom of organized thermocouples can be quickly plugged into the breakout panel on the PXI cabinet.

Table 9-1: List of Thermocouple Connections

\begin{tabular}{|r|l|}
\hline \multicolumn{2}{|c|}{ Thermocouple } \\
\hline 1 & Fuel From Belly Box \\
\hline 2 & Return From Fuel Cooler \\
\hline 3 & Outlet to High Pressure Pump \\
\hline 4 & Air Filter Inlet \\
\hline 5 & Ambient Cell \\
\hline 6 & Intake Air \\
\hline 7 & Post Manifold EGT \\
\hline 8 & Oil Temperature \\
\hline 9 & Head Temperature \\
\hline 10 & Coolant Temperature \\
\hline 11 & EGT Cyl 1 \\
\hline 12 & EGT Cyl 2 \\
\hline 13 & EGT Cyl 3 \\
\hline 14 & EGT Cyl 4 \\
\hline 15 & Dyno Temperature \\
\hline 16 & User Defined \\
\hline 17 & User Defined \\
\hline 18 & User Defined \\
\hline 19 & User Defined \\
\hline 20 & User Defined \\
\hline 21 & User Defined \\
\hline 22 & User Defined \\
\hline 23 & User Defined \\
\hline 24 & User Defined \\
\hline & \\
\hline
\end{tabular}

Similar to the thermocouple breakout panel, there are labeled panels for analog connections and digital connectors. These are universal connections, and can be used for many different engine instrumentation applications. Because of this, many of the 
connections were left as user defined. Similar to the thermocouple table, Table 9-2 and Table 9-3 were made for standardized connections. In the current configuration, the PXI system is set up for differential measurement. This means that only the connections labeled "Hi" are in use. When bringing an engine in, a loom of organized connections is simply plugged into the breakout panel.

Table 9-2: List of Digital Inputs and Outputs

\begin{tabular}{|c|c|c|}
\hline \multicolumn{2}{|r|}{ Digital (In) } & Digital (Out) \\
\hline 1 & User Defined & \begin{tabular}{l|l}
13 & Front Tank Valve \\
\end{tabular} \\
\hline 2 & User Defined & 14 Rear Tank Valve \\
\hline 3 & User Defined & \begin{tabular}{l|l}
15 & High Pressure Pump Relay \\
\end{tabular} \\
\hline 4 & User Defined & \begin{tabular}{l|l}
16 & User Defined \\
\end{tabular} \\
\hline 5 & User Defined & 17 User Defined \\
\hline 6 & User Defined & 18 User Defined \\
\hline 7 & User Defined & 19 User Defined \\
\hline 8 & User Defined & \begin{tabular}{l|l}
20 & User Defined \\
\end{tabular} \\
\hline 9 & User Defined & 21 User Defined \\
\hline 10 & User Defined & 22 User Defined \\
\hline 11 & User Defined & \begin{tabular}{l|l}
23 & User Defined \\
\end{tabular} \\
\hline 12 & User Defined & \begin{tabular}{l|l}
24 & User Defined \\
\end{tabular} \\
\hline
\end{tabular}

Table 9-3: List of Analog Connections

\begin{tabular}{|r|l|r|l|}
\hline \multicolumn{2}{|c|}{ Analog Hi (2 Pin) } & \multicolumn{2}{|c|}{ Analog Hi(4 Pin) } \\
\hline 1 & $48 \mathrm{~V}$ Pack & 17 & Torque Meter \\
\hline 2 & $48 \mathrm{~V}$ Pack & 18 & Low Fuel Pressur \\
\hline 3 & Lambda & 19 & Fuel Flow \\
\hline 4 & User Defined & 20 & Oil Pressure \\
\hline 5 & User Defined & 21 & MAP \\
\hline 6 & User Defined & 22 & User Defined \\
\hline 7 & User Defined & 23 & User Defined \\
\hline 8 & Speed Feedback & 24 & User Defined \\
\hline
\end{tabular}

\subsection{Combustion Analysis}

In addition to the PXI cabinet, the Mobile Lab test cell uses another National Instruments chassis for combustion analysis measurements. The second chassis is a CompactDAQ 9188 (cDAQ), which supports up to eight expansion slots. Two cards 
are used in this chassis to support combustion analysis, an analog input (9215) card and a digitial input (9411) card.

To support combustion analysis, an in-cylinder pressure transducer is installed in the engine. The signal from the in-cylinder transducer passes through a PCB 443B102 charge amplifier before being sent to the analog card in the cDAQ chassis.

Combustion chamber volume measurement is done through crank angle measurement. A BEI H25 [29] encoder is installed on each engine entering the test cell. This encoder is then plugged into the serial card on the cDAQ chassis. When loading Micro Drivven Combustion Analysis Tool ( $\mu$ DCAT) combustion analysis software, the engine being used must have all specifications loaded into a profile. Further information on using $\mu$ DCAT can be found in the manual in [30]. Figure 9-2 shows an image of the tools used for combustion analysis.

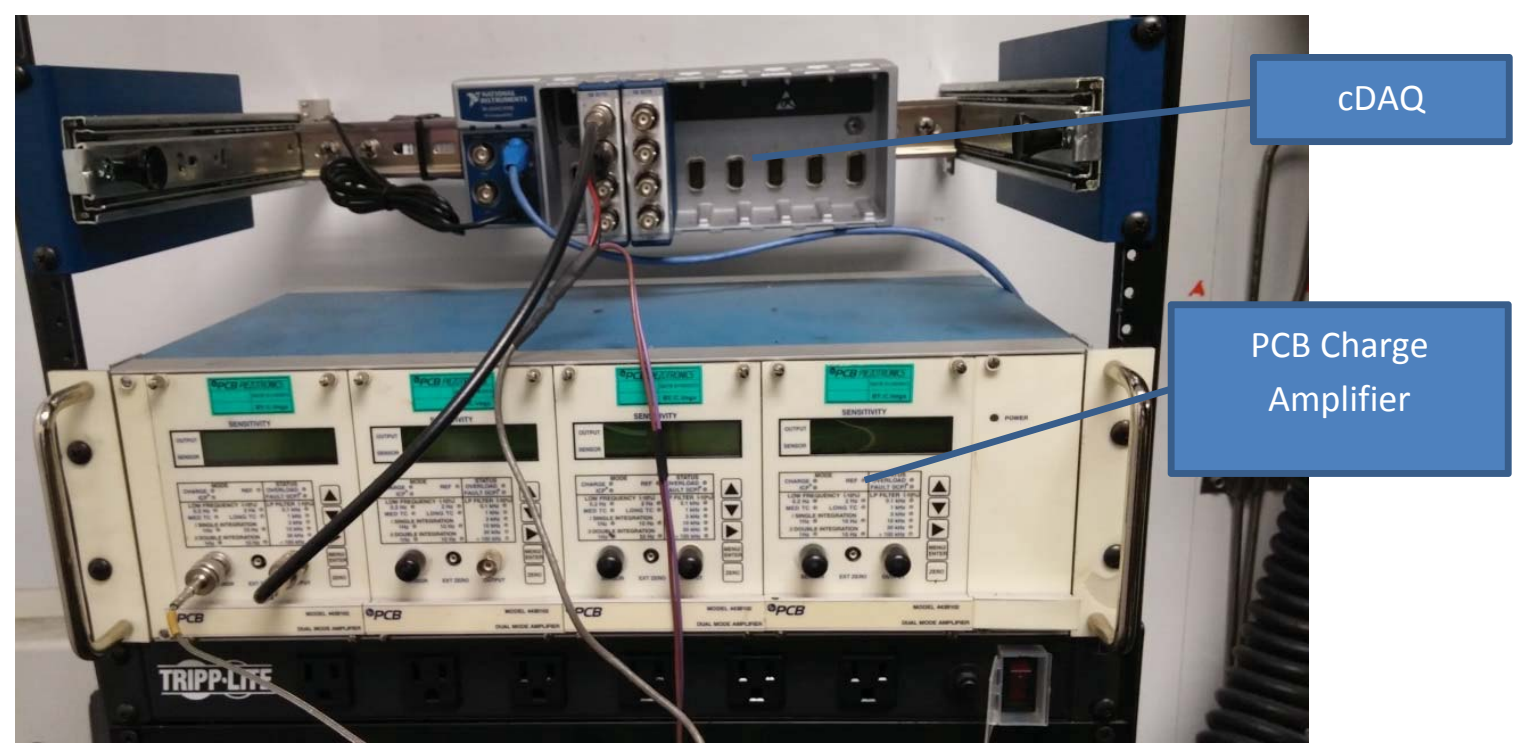

Figure 9-2: Combustion Analysis Tools

\subsection{MotoTron}

The final tool used for instrumentation is the MotoTron ECU used to control the engine. Engine sensors used to run the engine are wired into the MotroTron controller, and data is logged as the engine is running. The MotoTron ECU can 
provide a $5 \mathrm{~V}$ source for sensors that require it as well. Further details on the MotoTron ECU are covered in chapter 10. 


\section{Control System}

\subsection{MotoTron}

Currently, control is provided by a 112 pin MotoTron ECU. This allows full customized control of advanced engines. This ECU can support an eight cylinder engine with full OBD2 [31]. This allows for the development of advanced drivetrains in the Mobile Lab, such as a hybrid drivetrain that can be used in hybrid vehicle courses. This also allows set point control for operating engines that there is no calibration for. This would allow for SOI, spark, injection pressure, and other sweeps to be done to find optimal operating conditions.

Control strategies can be built in Mathworks Simulink software [32] using a custom development kit made by Woodward MCS for use with a MotoTron ECU. The software is called MotoHawk [33]. Using MotoHawk software, new control strategies can quickly be flashed to the MotoTron ECU. This makes for simple engine control changes when bringing in a new engine pallet. The engine is wired directly into screw terminal breakout rail as shown in Figure 10-1.

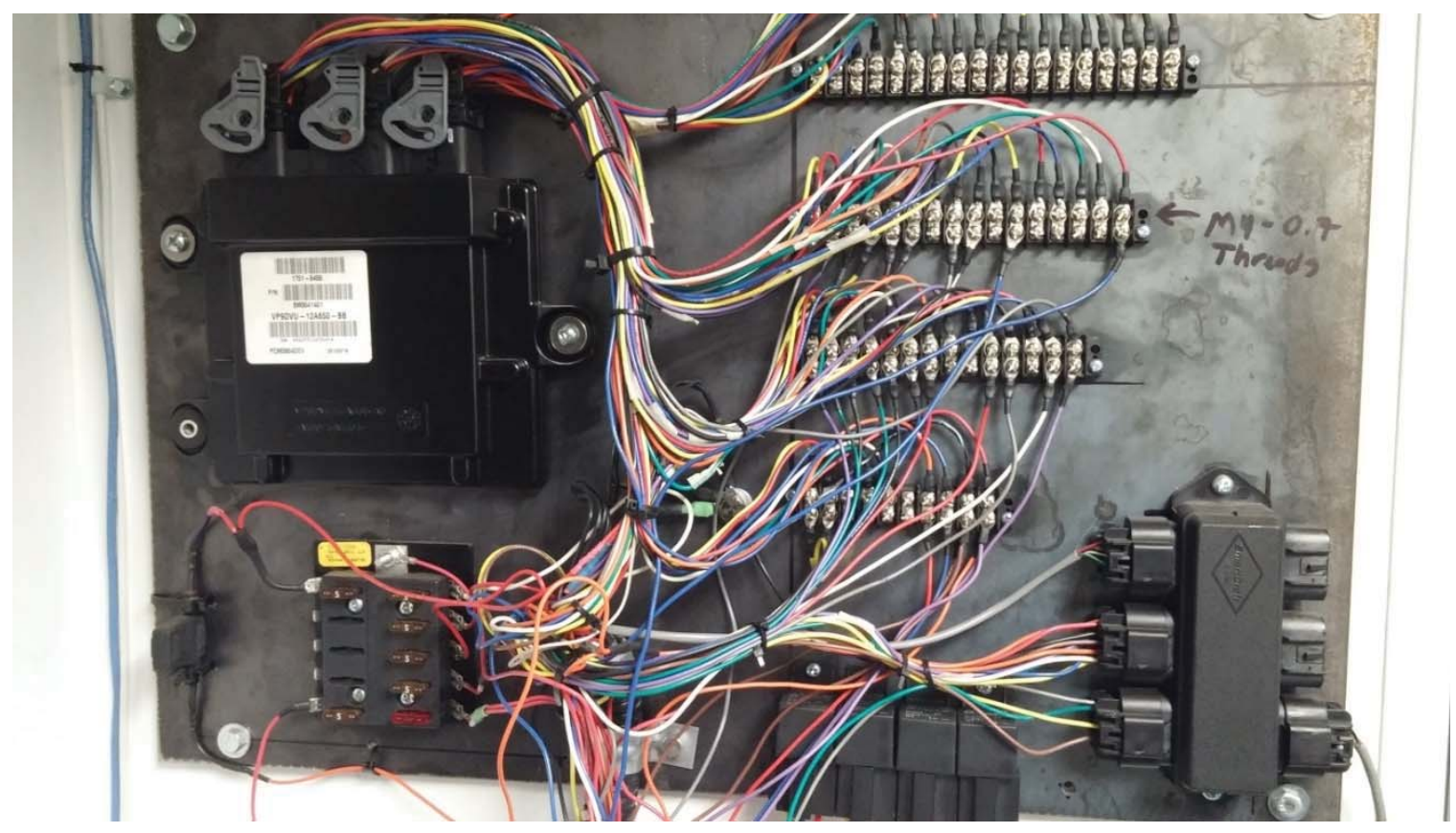

Figure 10-1: MotoTron Breakout Panel 


\section{Yanmar Engine Mapping}

In this chapter of the thesis, a Yanmar L100N single cylinder diesel engine is run using the Mobile Lab rear test cell. The engine is instrumented through the PXI cabinet, and control is done using the Mototron ECU. The common rail fuel injection system is used along with a Bosch injector to run the engine.

A BEI encoder was mounted to the crankshaft of the engine on the flywheel side to get volume measurements of the engine. An AVL in-cylinder pressure transducer is mounted as well. The transducer is recessed in the head with a straight port to the combustion chamber. The size of this port is unknown.

Using the new pallet system, the engine was mounted and attached to the dyno. Mounting to the bedplate was done using an engine pallet built to the specifications covered in chapter 7. Further details will be covered in the next section on mounting and shafting for the Yanmar engine.

\subsection{Mounting and Shafting}

The Yanmar engine was mounted to an engine pallet as described in this thesis. Using additional Unistrut channel, and spacer blocks, the output hub of the Yanmar was located to the same height as the dyno. The Yanmar output shaft was kept parallel with the dyno shaft, but offset slightly, to keep a few degrees of angle on the driveshaft so that the universal joints are kept in good shape. Figure 11-1 shows the mounting used on the Yanmar engine. 


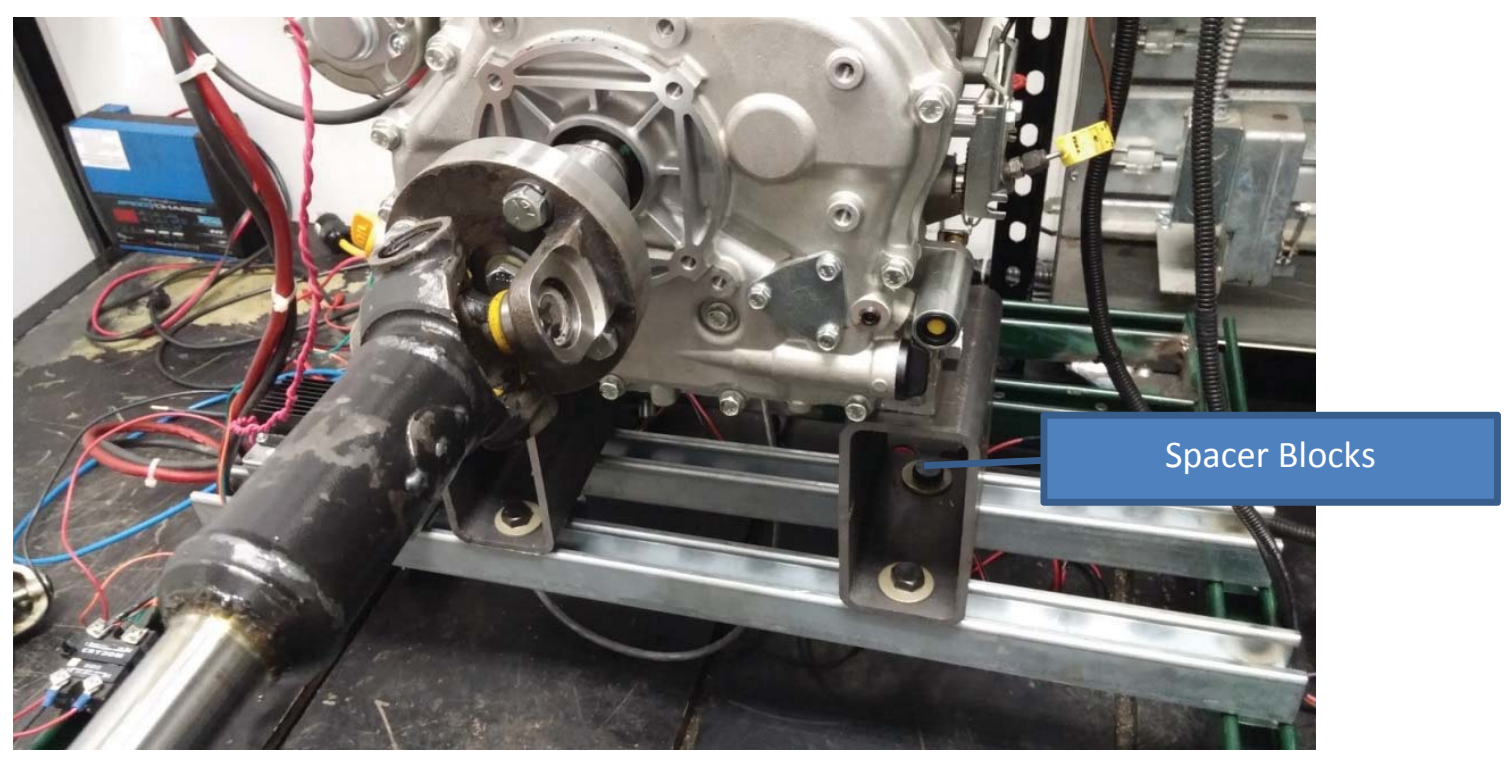

Figure 11-1: Yanmar Engine Mounting

This Yanmar engine was used in many different OEM applications, and because of this, multiple crankshaft options were available from the factory. This particular engine tested has a 1:10 tapered crankshaft. This means that for every 1 inch of length, the shaft tapers by 0.1 inches. To transmit torque through this attachment, the hub design needs to be the exact same taper so it contacts as much of the shaft as possible. The crankshaft is threaded, and a bolt is used to clamp the hub onto the end of the crankshaft. The hub also is threaded to a larger thread size so that a bolt can be threaded into the hub until it pushes against the crankshaft to unseat the hub from the taper. A draft of this hub design is shown in Figure 11-2. Figure 11-3 shows the finished hub, installed on the crankshaft. 


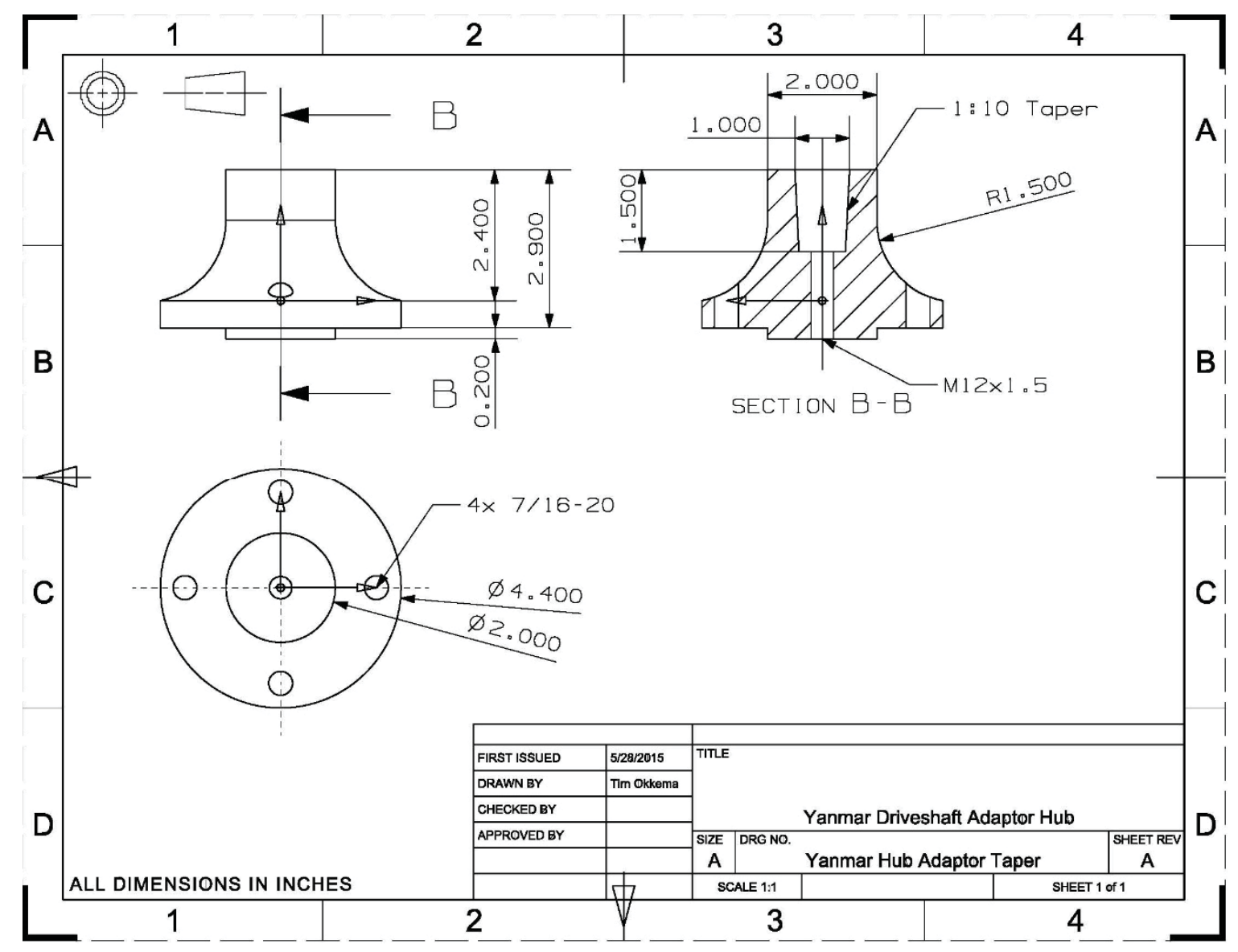

Figure 11-2: Yanmar to Driveshaft Hub 


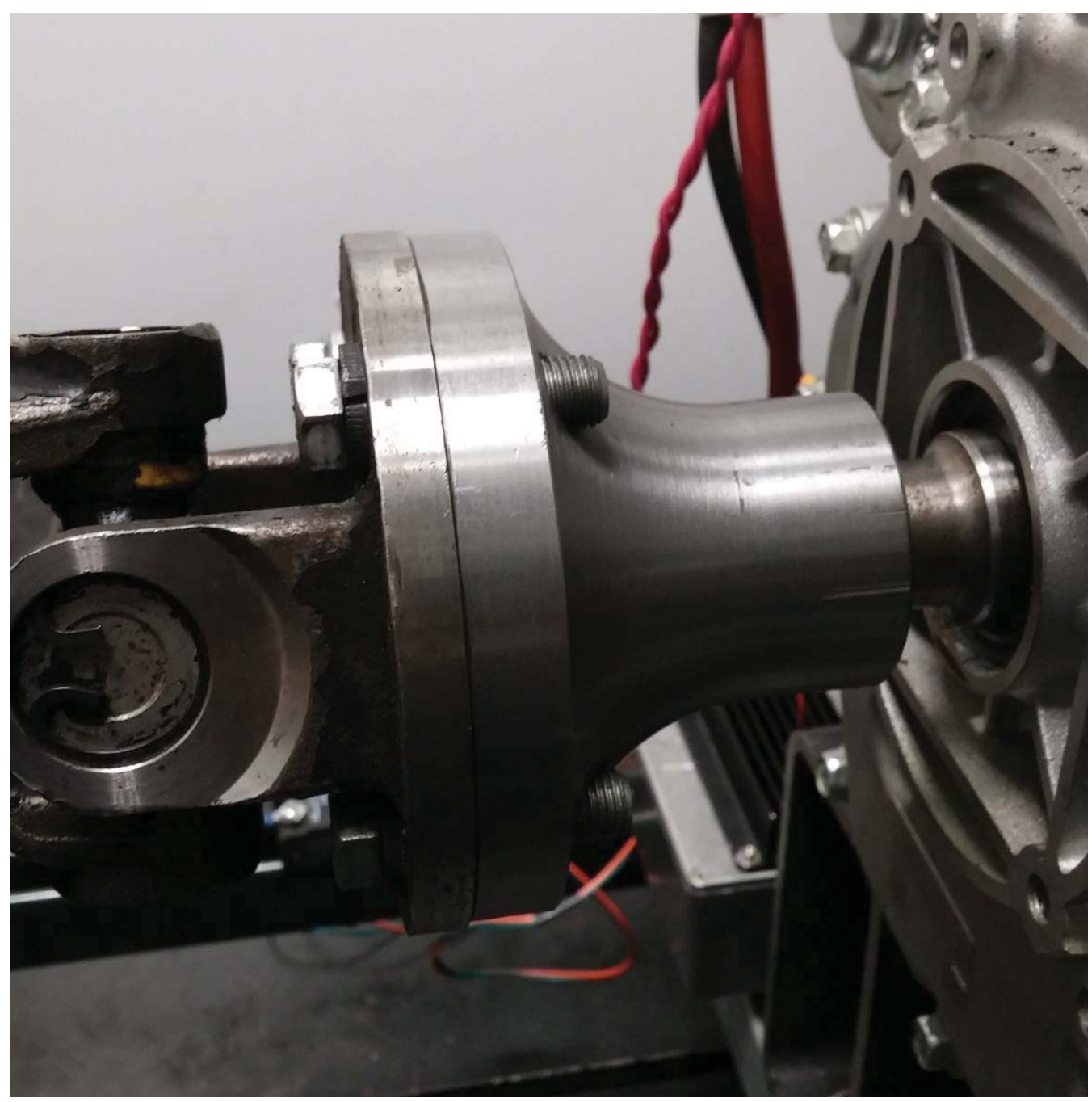

Figure 11-3: Finished Hub

\subsection{Yanmar L100 Engine Dimensions}

The Yanmar L100 is a single cylinder, direct injection, diesel engine. The original fuel system used a mechanical injector that has a small pump directly geared to the crankshaft. In the Mobile Lab test cell, the engine was run using the Bosch common rail injector mentioned in chapter 4 , connected to the high pressure fuel system. Table 11-1 lists the engine parameters. 
Table 11-1: Yanmar Engine Parameters

\begin{tabular}{|l|r|l|}
\hline \multicolumn{3}{|c|}{ Yanmar L100 } \\
\hline Bore & 8.6 & CM \\
\hline Stroke & 7.5 & CM \\
\hline Swept Volume & 0.43544 & Liters \\
\hline Clearance Volume & 21.5 & CC \\
\hline Compression Ratio & 20.253 & \\
\hline
\end{tabular}

\subsection{Yanmar Engine Mapping}

The original use for the Yanmar engine was in a generator setup, and the output was rated at 3600RPM. Using this as a basis, four speed (RPM) points were chosen to run the engine, with three load (NMEP) points at each speed. At each load point, a start of injection (SOI) sweep was done to find the optimal timing. Table 11-2 shows a matrix of the SOI sweeps that were performed. Using the Bosch injector covered in chapter 4, precise control of the Yanmar engine was difficult since the injector was designed for a larger engine. To maintain better control over NMEP, the fuel pressure was regulated to $35 \mathrm{MPa}$. For first attempt, the engine was run with the fuel pressure at 55MPa. At this pressure, there was very little control over NMEP. 
Table 11-2: SOI Test Matrix

\begin{tabular}{|c|c|c|c|c|c|c|c|c|c|c|}
\hline \multirow{3}{*}{\begin{tabular}{|l|} 
Speed \\
\\
NMEP[kPa] \\
\end{tabular}} & \multicolumn{10}{|c|}{1200 RPM } \\
\hline & \multicolumn{10}{|c|}{ SOI (BTDC) } \\
\hline & & & & & & & & & & \\
\hline \begin{tabular}{|l|l}
+2 \\
\end{tabular} & 21 & 18 & 15 & 12 & 9 & 6 & 3 & 0 & -1 & \\
\hline 260 & 21 & 18 & 15 & 12 & 9 & 6 & 3 & 0 & -3 & \\
\hline 500 & 21 & 18 & 15 & 12 & 9 & 6 & 3 & 0 & -3 & -5 \\
\hline \multirow[t]{2}{*}{ Speed } & \multicolumn{10}{|c|}{2000 RPM } \\
\hline & \multicolumn{10}{|c|}{ SOI (BTDC) } \\
\hline \multicolumn{11}{|l|}{ NMEP[kPa] } \\
\hline 160 & 20 & 17 & 14 & 11 & 8 & 5 & 4 & & & \\
\hline 260 & 20 & 17 & 14 & 11 & 8 & 5 & 3 & & & \\
\hline 500 & 20 & 17 & 14 & 11 & 8 & 5 & 2 & 1 & & \\
\hline \multirow[t]{2}{*}{ Speed } & \multicolumn{10}{|c|}{2800 RPM } \\
\hline & \multicolumn{10}{|c|}{ SOI (BTDC) } \\
\hline \multicolumn{11}{|l|}{ NMEP[kPa] } \\
\hline 160 & 25 & 22 & 19 & 16 & 13 & 10 & 9 & & & \\
\hline 260 & 25 & 22 & 19 & 16 & 13 & 10 & 7 & 6 & & \\
\hline 500 & 25 & 22 & 19 & 16 & 13 & 10 & 7 & 6 & & \\
\hline \multirow[t]{2}{*}{ Speed } & \multicolumn{10}{|c|}{3600 RPM } \\
\hline & \multicolumn{10}{|c|}{ SOI (BTDC) } \\
\hline \multicolumn{11}{|l|}{ NMEP[kPa] } \\
\hline 160 & 29 & 2 & 23 & 20 & 17 & 15 & 13 & 11 & & \\
\hline 260 & 29 & 26 & 23 & 20 & 17 & 15 & 13 & 12 & & \\
\hline 500 & 29 & 26 & 23 & 20 & 17 & 14 & 11 & & & \\
\hline
\end{tabular}

After running the Yanmar engine in the test cell, the results were compared to the OEM efficiency and torque curves [34]. It was found that at low speeds, the Yanmar running the Bosch injector produced similar torque numbers. However, the brake specific fuel consumption (BSFC) was larger when using the Bosch injector. The BSFC graphs that resulted from the SOI sweep are shown in Figure 11-4 and Figure 11-5. The only published data for the Yanmar L100V was at full load, which is different than the tests run here. The $500 \mathrm{kPa}$ load is close to full load for the Yanmar, but is still not the same as the load the published data is using.

A look at the exhaust gas while running shows that the engine is running very rich, and there is a large amount of unburnt fuel going into the exhaust. The exhaust is a grey-white color. Because the injector was designed for a much different engine, it is likely spraying too much fuel in the cylinder that cannot be properly combusted in the 
small Yanmar engine. And because the spray pattern differences of the Bosch injector in relation to the OEM injector is unknown, it is possible that large amounts of fuel are contacting the piston or cylinder walls directly. This would cause condensation of the fuel, and result in the white exhaust smoke that has been observed.
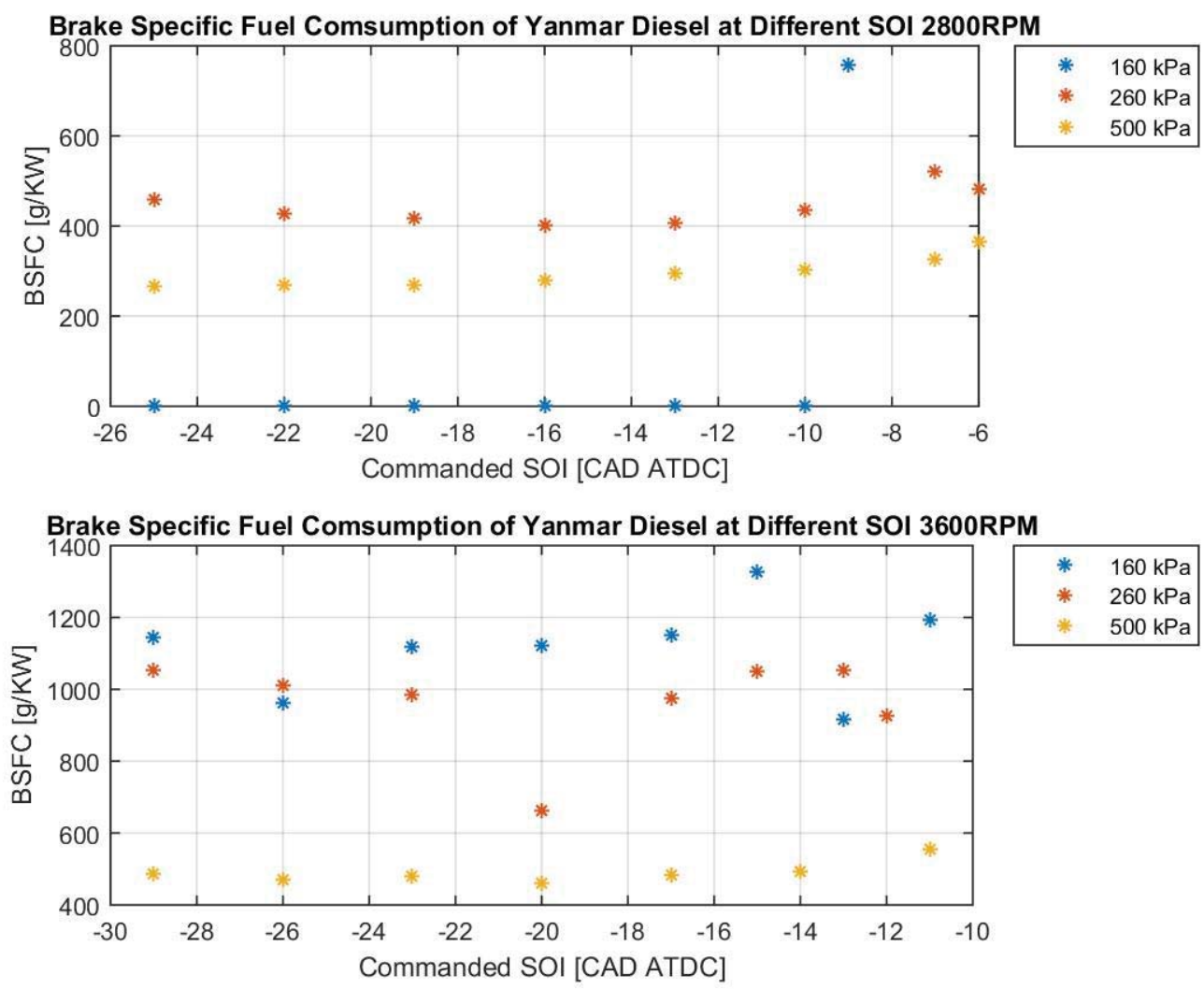

Figure 11-4: High Speed BSFC of Yanmar SOI Sweep 

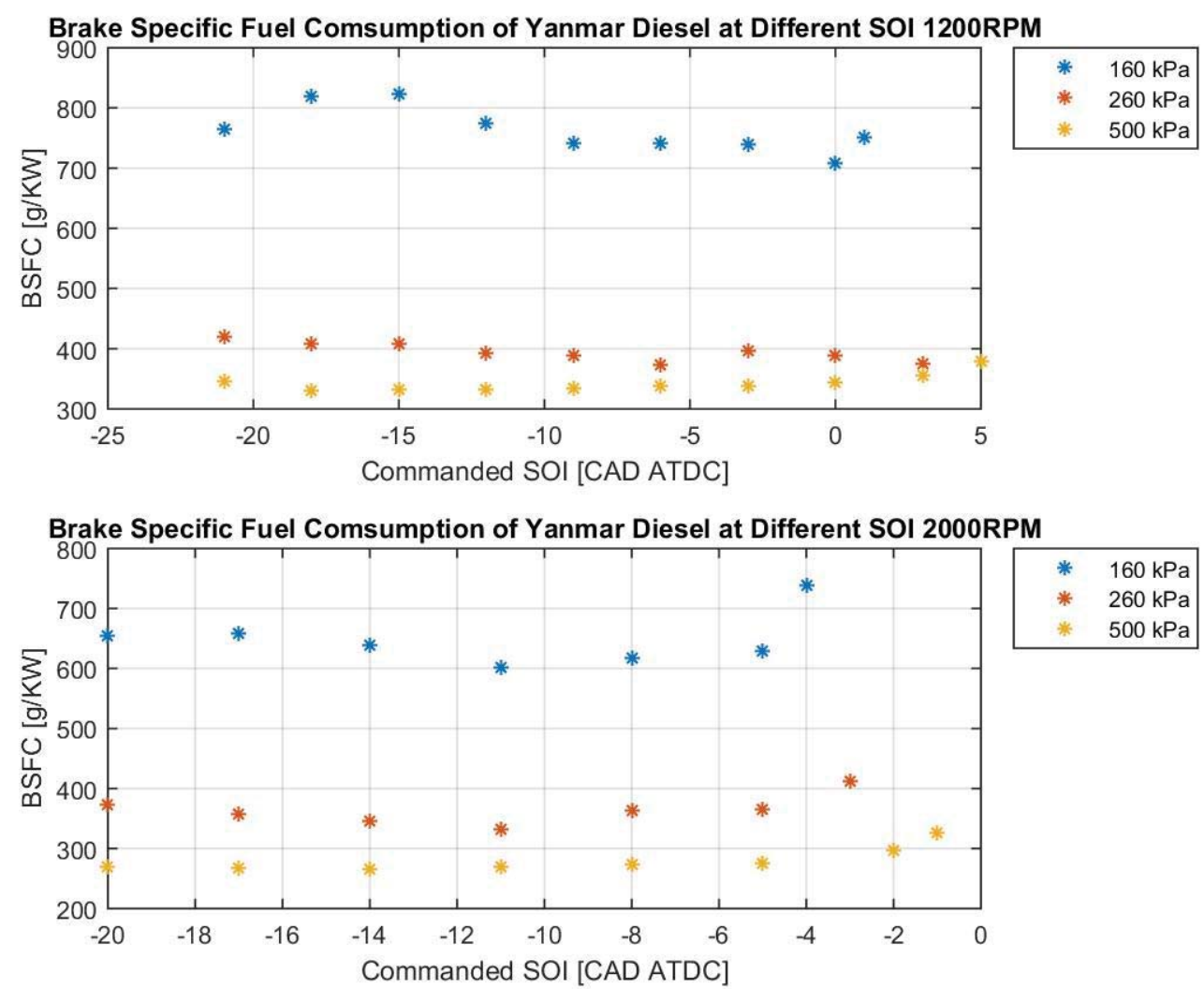

Figure 11-5: Low Speed BSFC of Yanmar SOI Sweep

After performing the SOI sweep, many of the results did not show clear trends as predicted. The goal was to find an optimal SOI timing for each speed and load point. Likely because of the inefficiencies found with the Bosch injector in the Yanmar, SOI played a smaller role in overall efficiency than estimated.

Looking at the thermal efficiencies of the engine over the range of SOI, a downward trend can be seen as the SOI approaches piston top dead center. Figure 11-6 and Figure 11-7 show the indicated thermal efficiencies across the SOI sweep. As seen in the 2800 RPM sweep at 160kpa, the efficiency drops significantly as the SOI is changed from 10 degrees before top dead center (BTDC) to 9 degrees BTDC. The same trend can be seen in most of the SOI sweeps. A downward hook at the end of the sweep can be observed. At 1200RPM, these trends are not as clear at the $160 \mathrm{kPa}$ and $260 \mathrm{kPa}$ loads. 

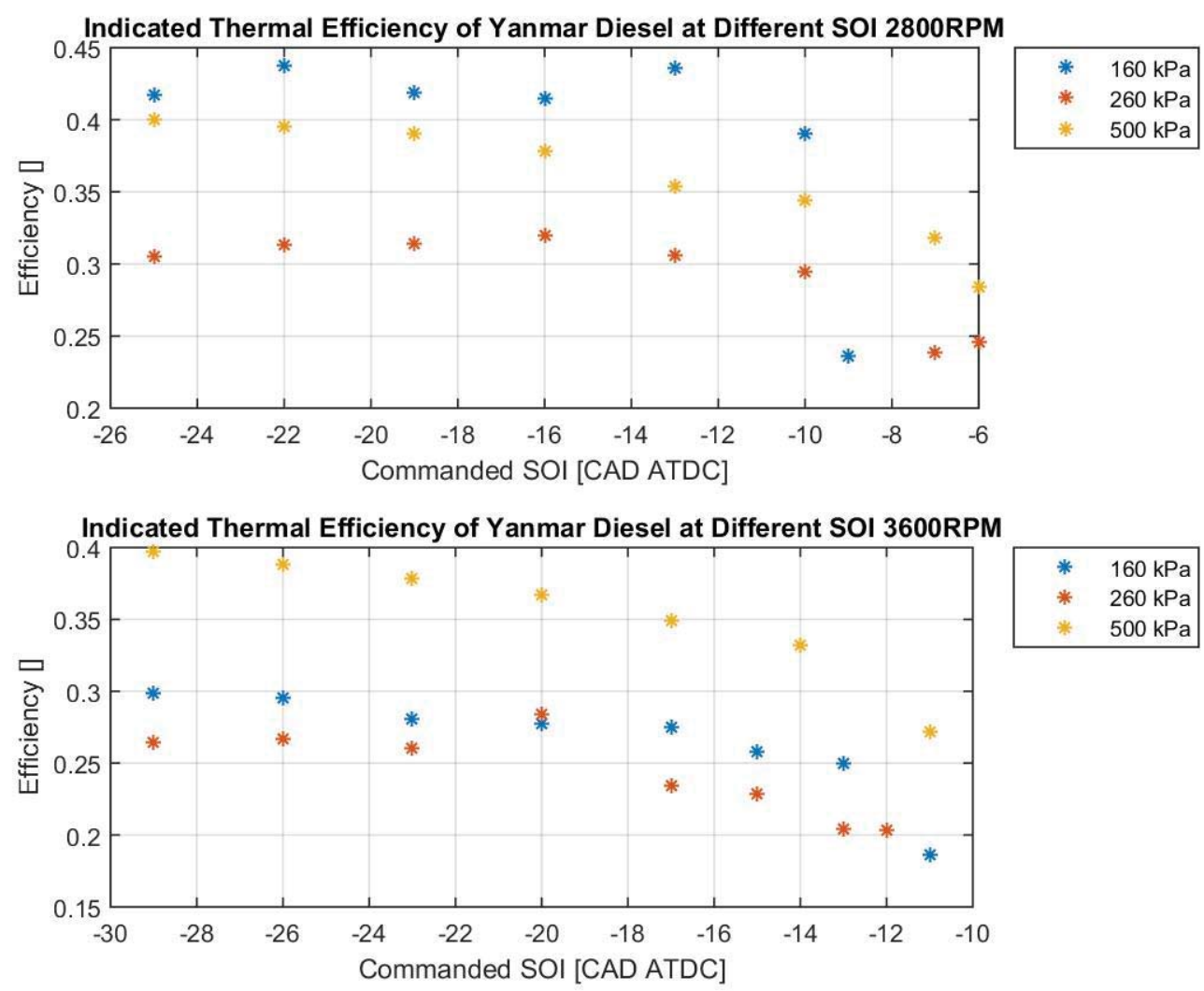

Figure 11-6: Indicated Thermal Efficiency at High Speeds 

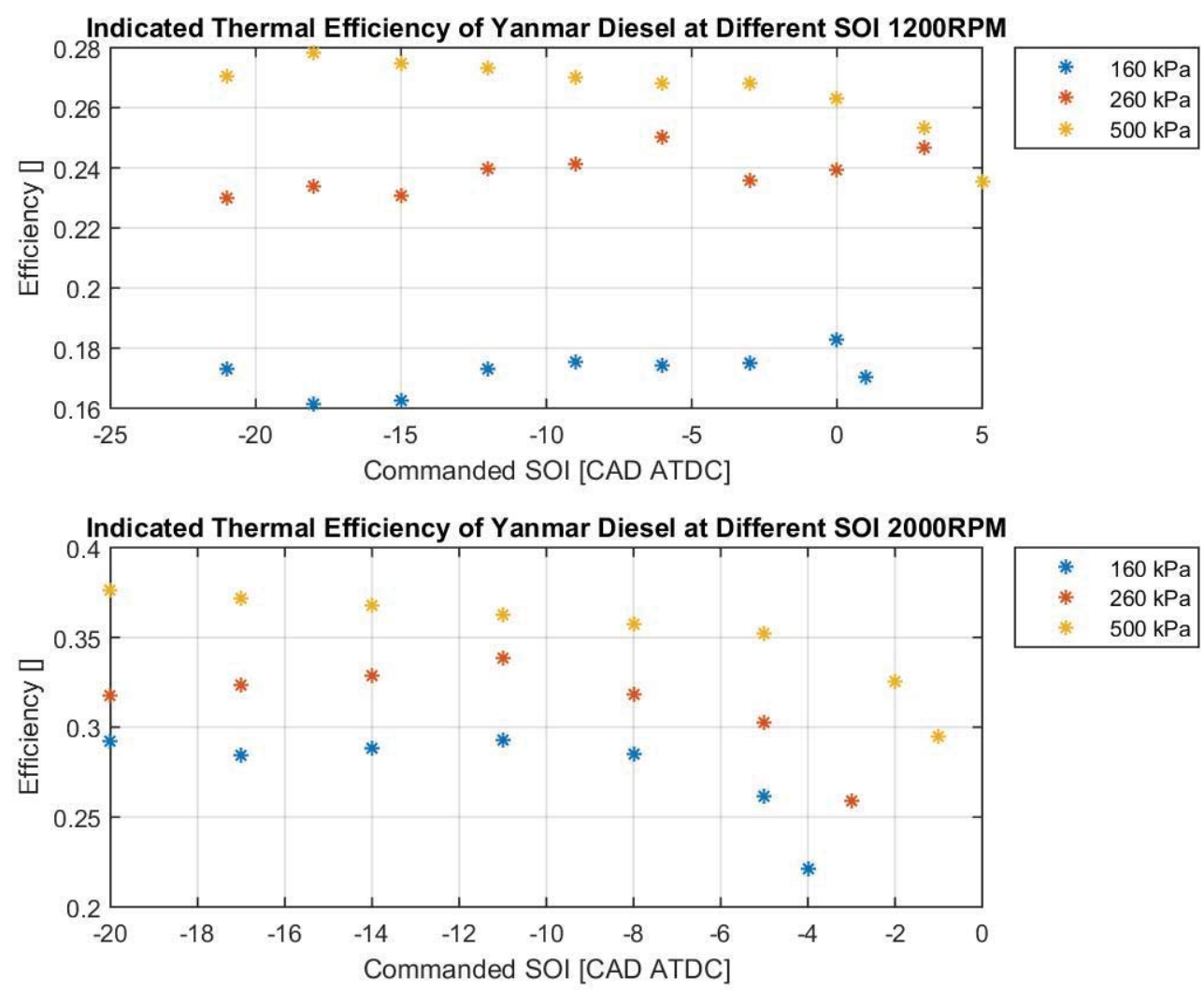

Figure 11-7: Indicated Thermal Efficiency at Low Speeds

As the SOI is moved closer to TDC, more unburnt fuel is pushed out the exhaust port. This can be seen in the exhaust gas temperatures (EGTs). This becomes more evident at higher loads, as the EGTs increase drastically as the SOI is moved closer to TDC. Figure 11-8 and Figure 11-9 show the effects of SOI on EGTs. These plots show a clear upward hook at the end of the SOI sweep as EGTs greatly increased. 

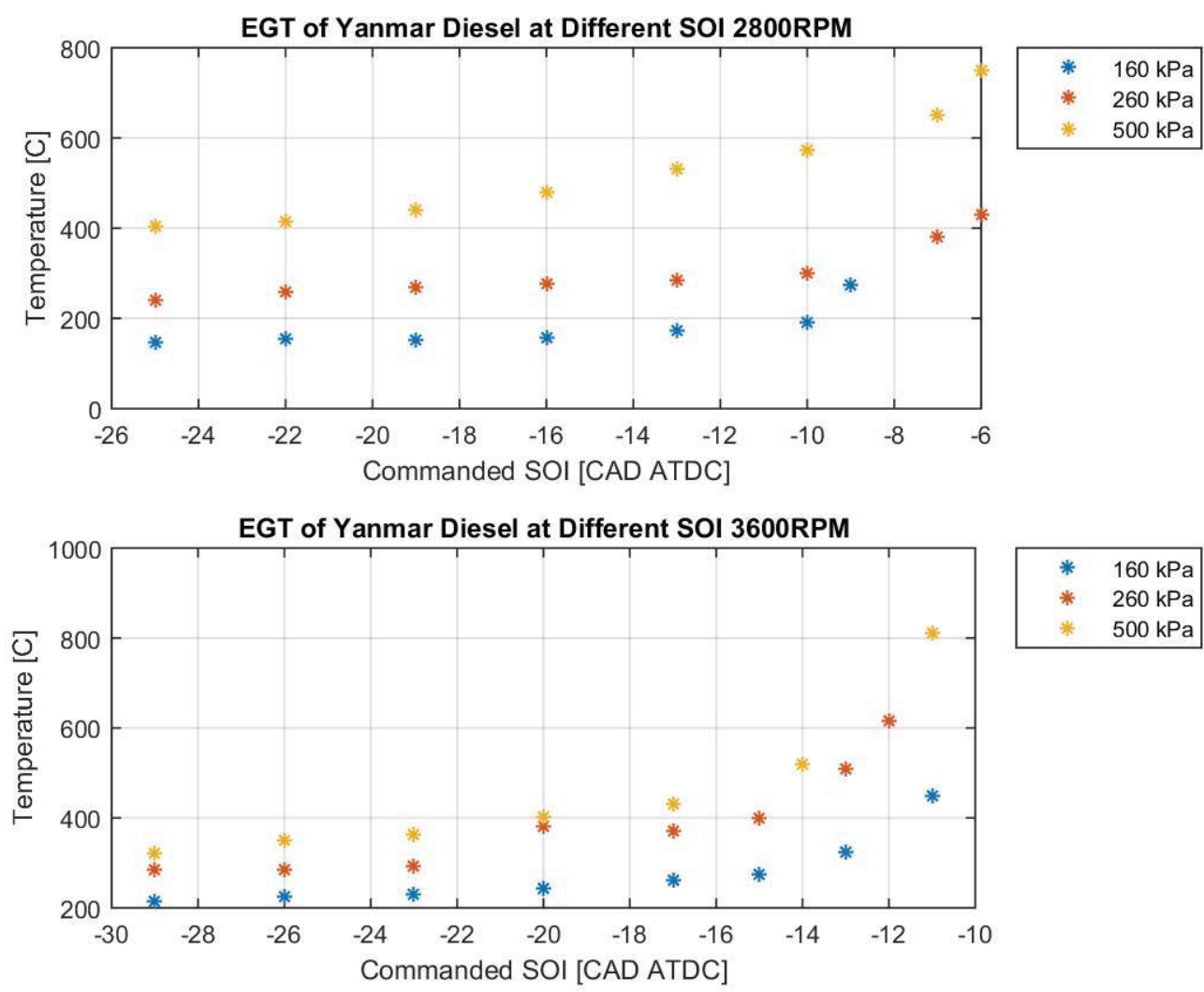

* $160 \mathrm{kPa}$

* $260 \mathrm{kPa}$ $500 \mathrm{kPa}$

Figure 11-8: High Speed EGTs 

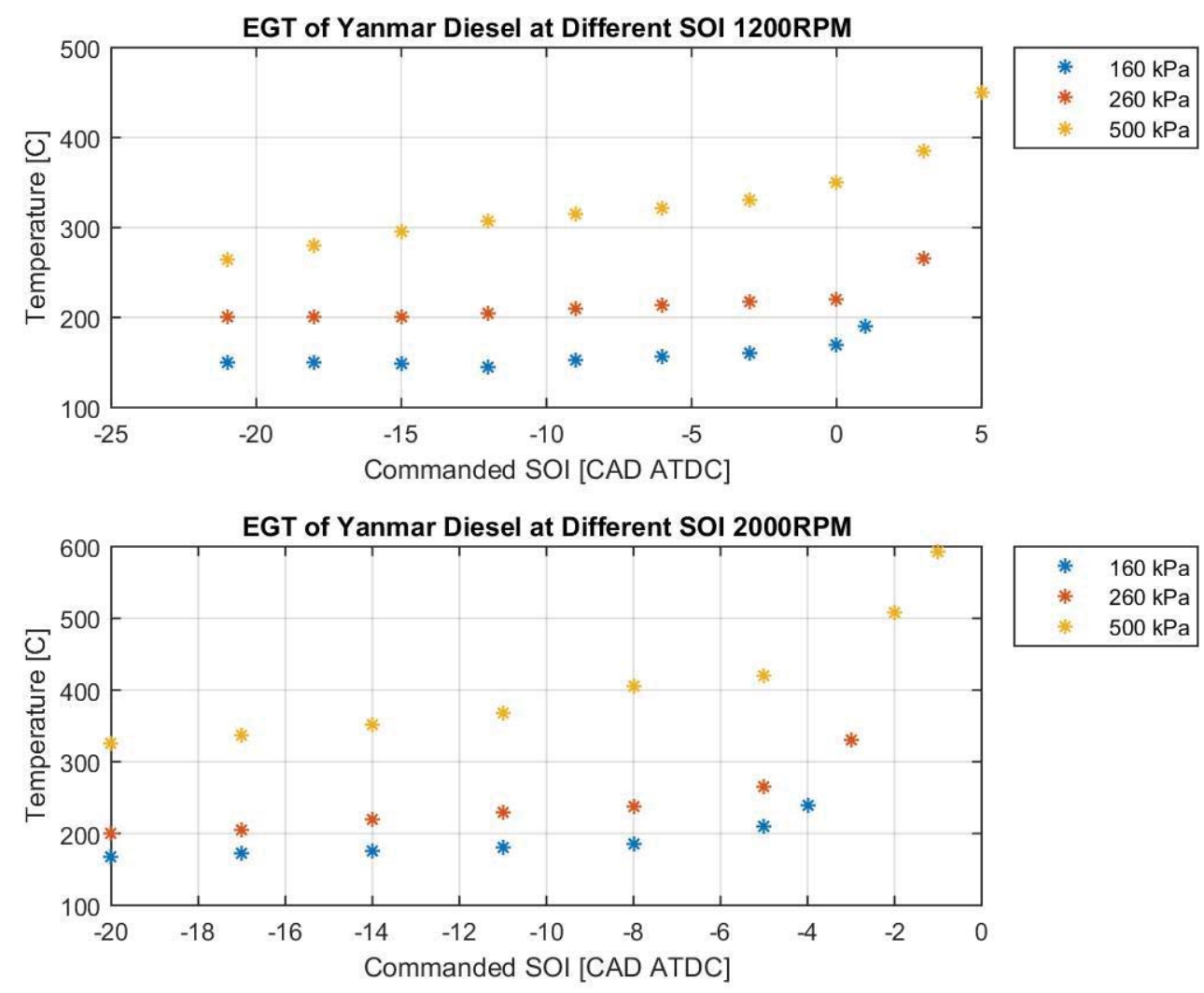

\section{Figure 11-9: Low Speed EGTs}

Looking at the coefficient of variance (CoV) at the different points along the SOI sweep indicates that the engine is not running great. The CoV is very high. This is possibly because fuel is pooling on the cylinder walls or on the piston and firing inconsistently. Or because of an injector that is not optimally spraying, the engine doesn't fire on every cycle. It was found after testing, that fluctuations in fuel pressure as the engine was running caused large changes in NMEP. Keeping the pressure constant between injections is critical in keeping the NMEP the same between cycles. These results can be seen in Figure 11-10 and Figure 11-11. 

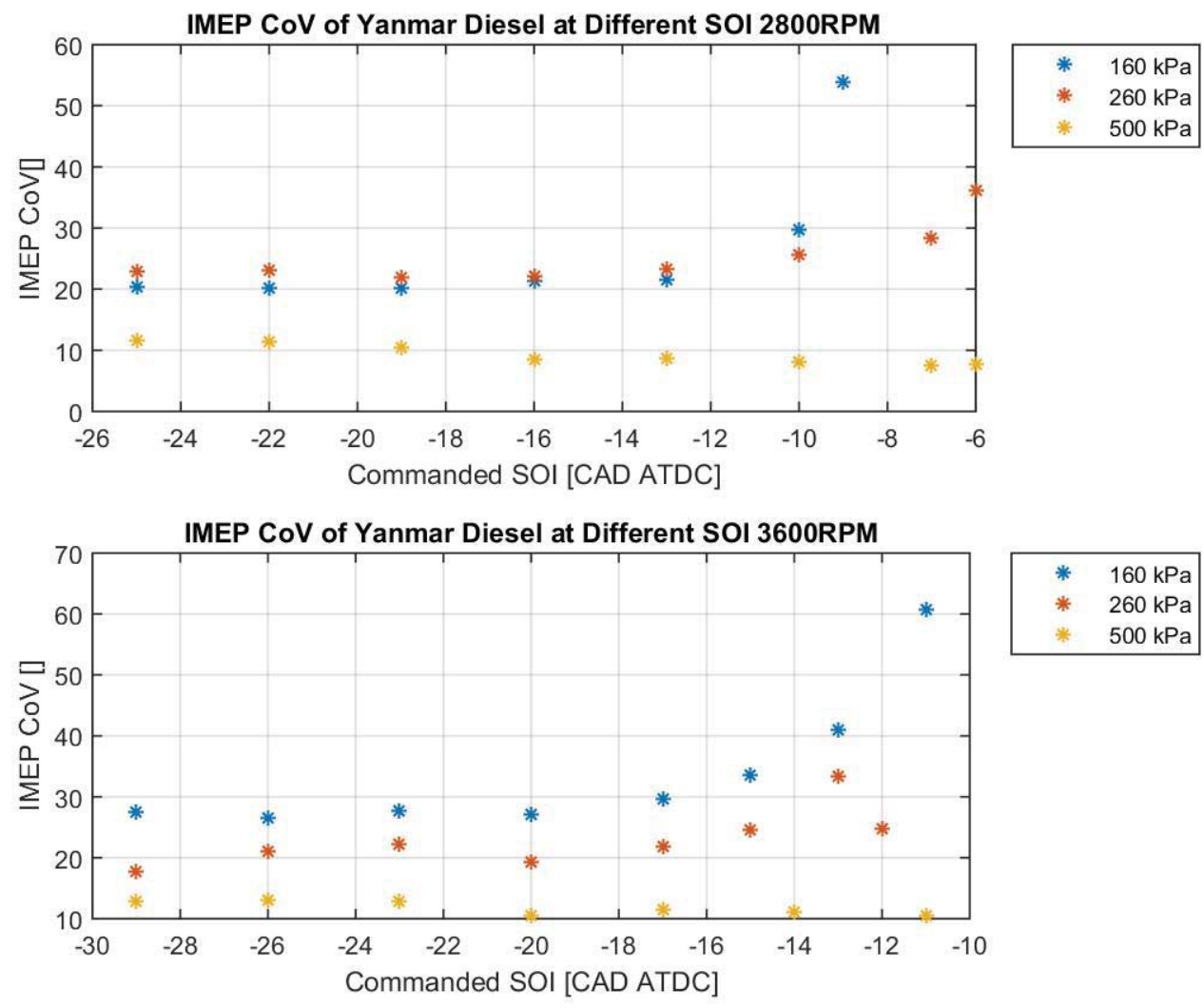

Figure 11-10: CoV of IMEP High Speed 

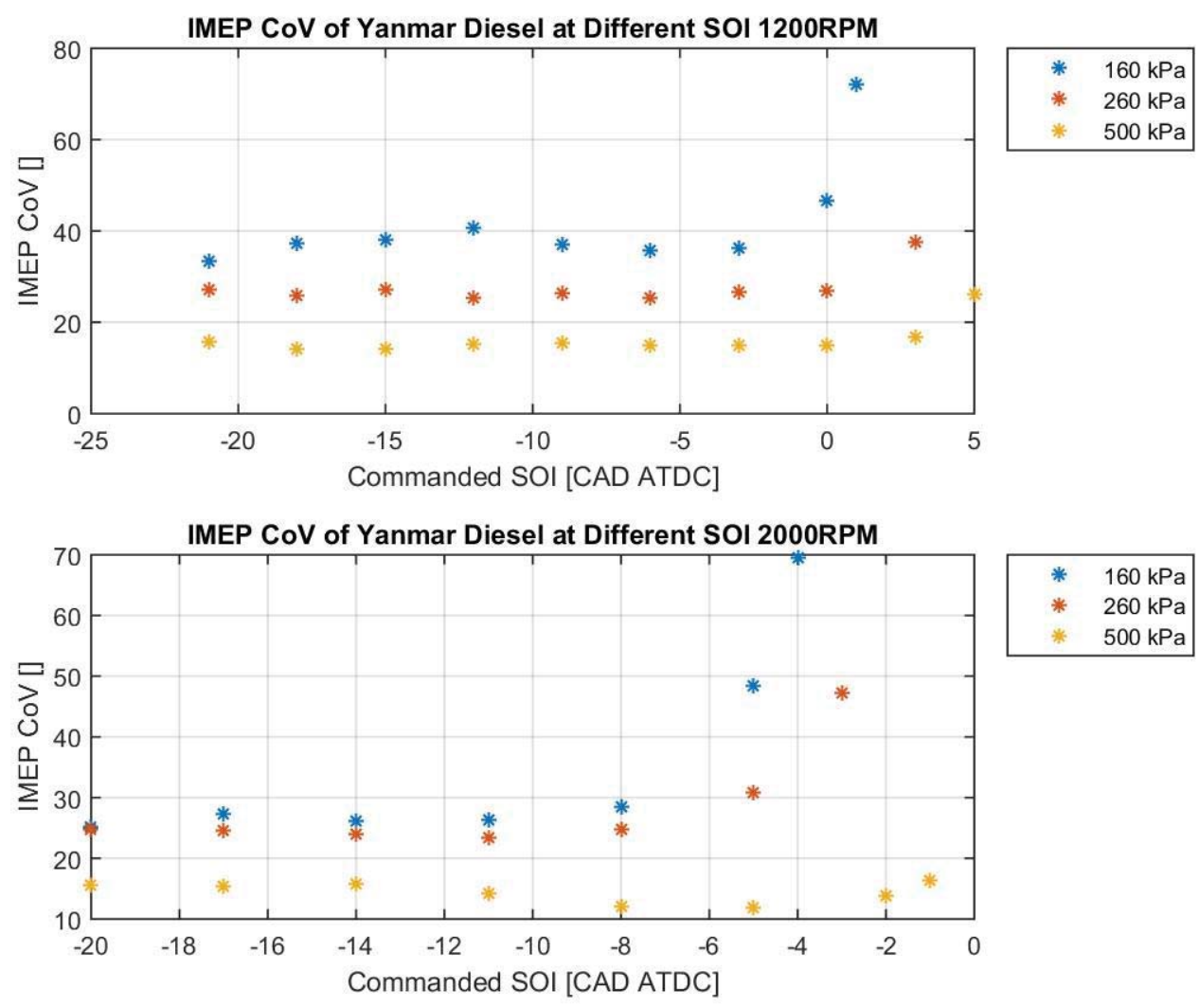

Figure 11-11: CoV of IMEP Low Speed

\subsection{Conclusions}

The Yanmar engine was run using the systems designed and covered in this Thesis. Although the engine did not run as efficiently as it did with a mechanical injector, it was able to run at multiple speed and load points. The engine tested all of the different subsystems installed in the Mobile Lab test cell. In the future, this engine configuration can be used to teach a course on diesel engines using the rear test cell. The modular fuel system allows for many different parameter sweeps to be performed on the Yanmar diesel that would not be possible with a mechanical injection system. 


\section{Future Work}

In the future, modifications could be made to improve the system designs explained in this thesis. These improvements are recommended, but not necessary for the functionality of the test cell.

The first improvement could be in creating a jig that is built to the specifications described in the cad drawing. This could be used by a researcher to locate the engine on the pallet outside the test cell. Once the engine was aligned to the jig, it would be set to be placed in the test cell, and will be aligned to the hub and all subsystems.

Two devices could be built to assist in working with the common rail injectors. The first devices would be a flow bench that would allow a researcher to measure how much fuel is flowing through an injector at different pressures. This would help with matching an injector to an engine properly.

The second injector device that would be beneficial is a backflow device. This device could be connected to the low pressure fuel system at the AERB building. The pressure would be applied to the nozzle of the injector, and would push any debris clogging the injector back out through the inlet. A function generator would be used to trigger the injector.

For running smaller engines, a smaller injector could be made that would flow less fuel. This would help with efficiently running small engines such as the Yanmar L100V that was tested as a part of this thesis. Having a better suited injector may have helped keep BSFC and COV of NMEP numbers better. The diagrams in Figure 12-1 and Figure 12-2 are the spray patterns of the OEM Yanmar L100V injector vs and the currently installed Bosch injector described in 4.6, with seven orifice diameters of $0.139 \mathrm{~mm}$. It is recommended that an injector tip with holes between 0.090 and $0.100 \mathrm{~mm}$ be installed with the same spray pattern as the OEM L100V injector. The OEM injector has five orifice diameters of $0.16 \mathrm{~mm}$. Measurement was done using gauge pins. 


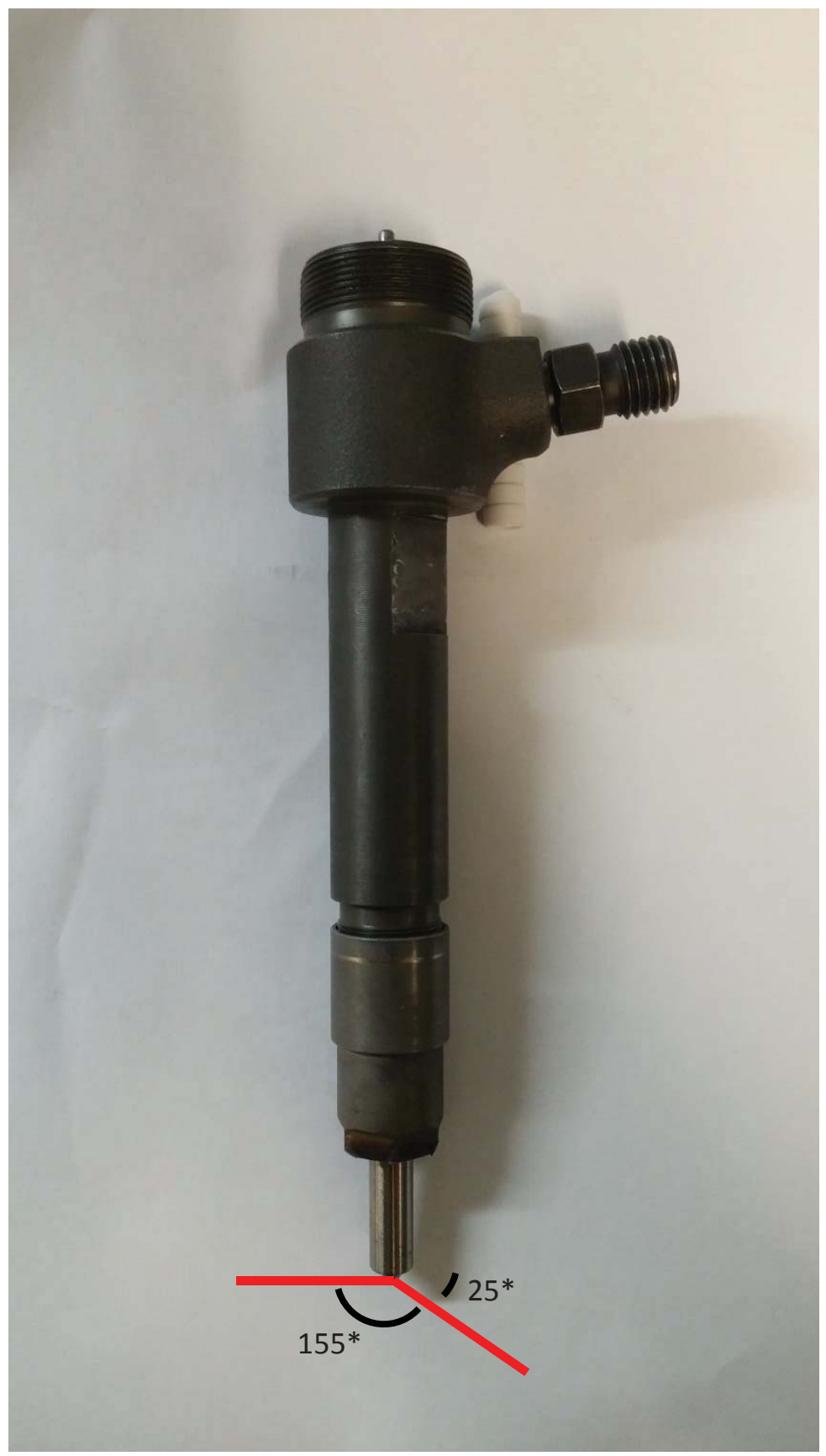

Figure 12-1: Bosch 7 Hole Common Rail Injector Spray Angle 


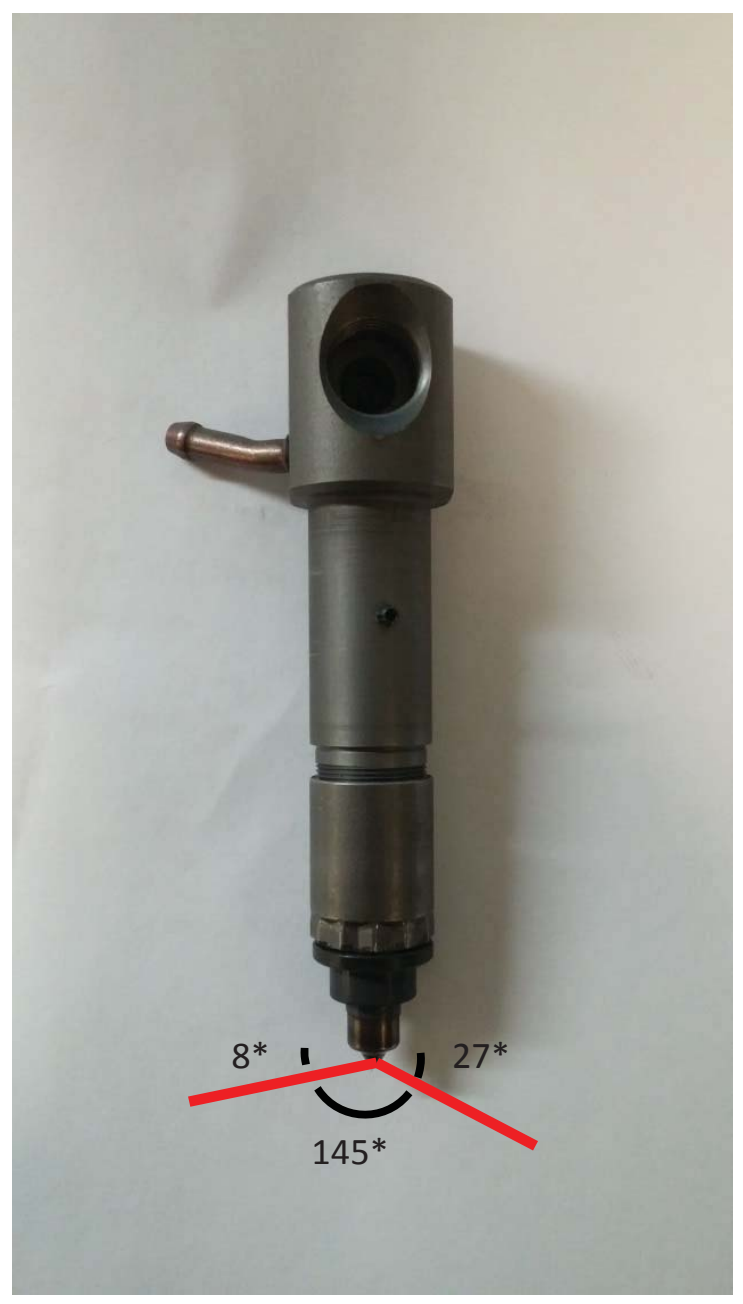

\section{Figure 12-2: Yanmar L100V 5 Hole OEM Injector Spray Angle}

In addition to injector modifications, a new injector driver box is recommended. The current injector driver box sends a saturation signal. The Bosch injector installed should be operated with a peak and hold signal instead. The current trigger signal and the current trace can be seen in Figure 12-3 and Figure 12-4. These 1200 data points were taken with an oscilloscope using a current clamp. As seen, the amperage sent to the injector is a constant 40 amps. This amperage is higher than an injector of this type should see. Using the driver box at this high of amperage can damage the solenoid. 


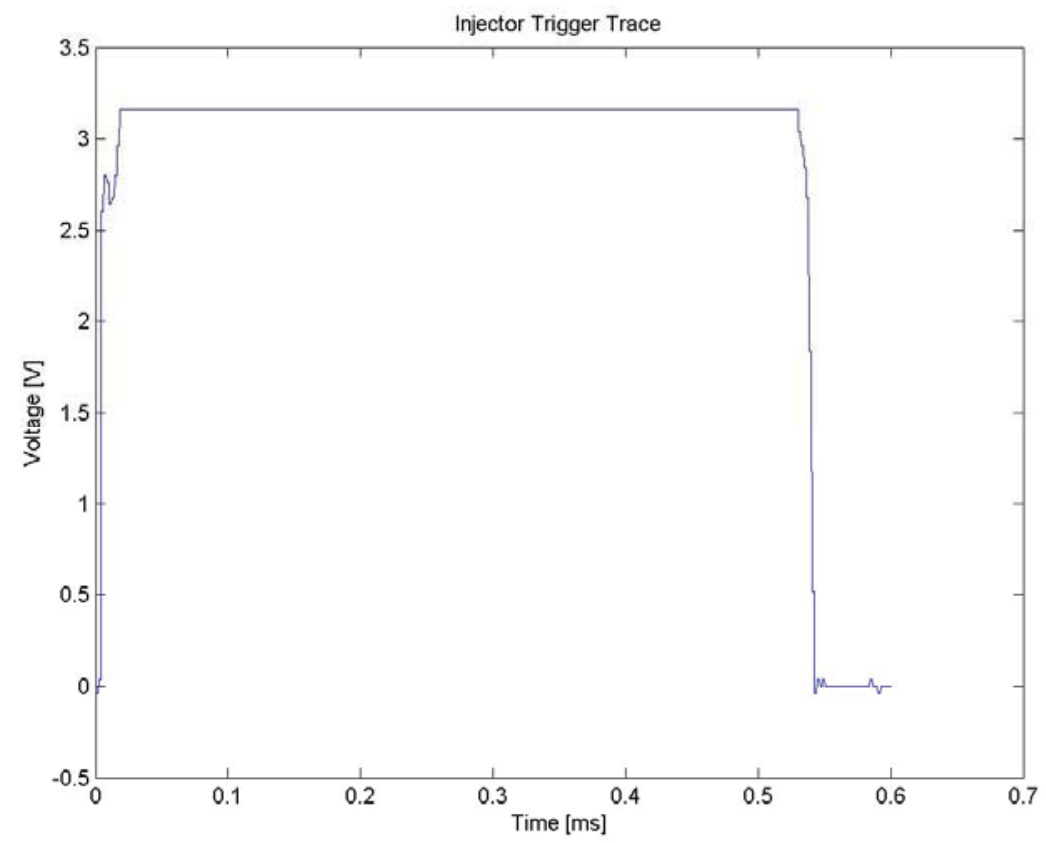

Figure 12-3: Injector Trigger Trace

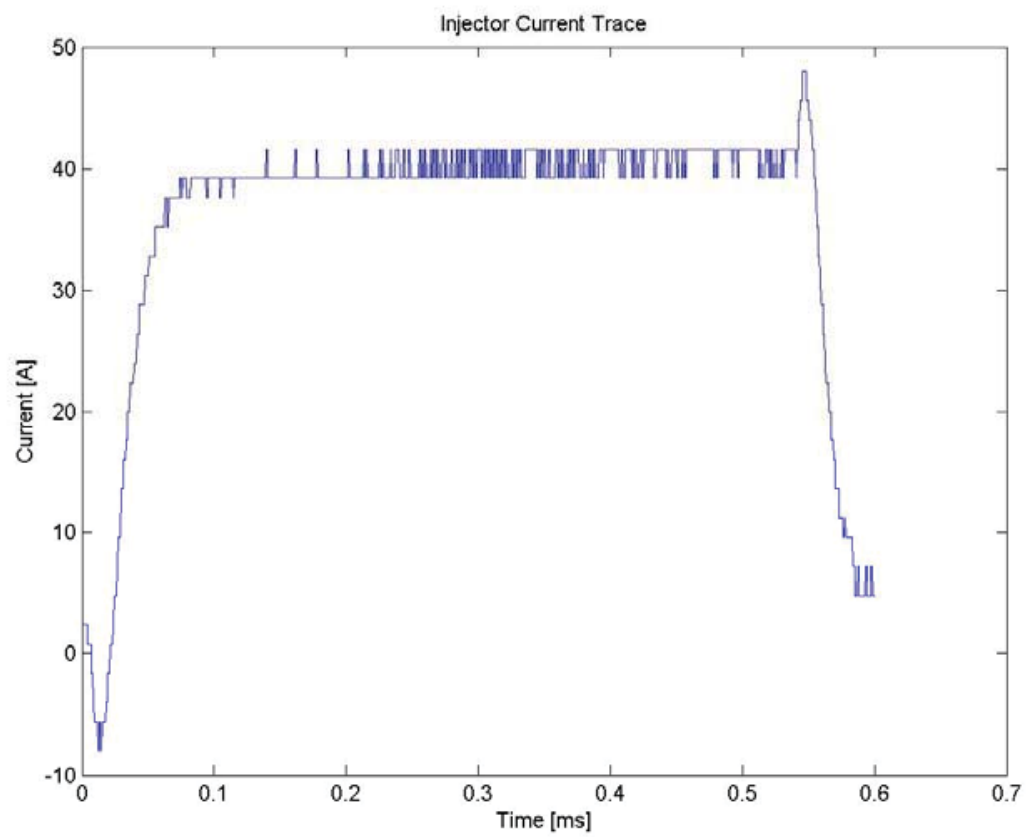

Figure 12-4: Injector Current Trace 
Although a five gas emissions analyzer would not fit in the Mobile Lab test cell, smaller devices could be implemented that would allow measurement of $\mathrm{NOx}, \mathrm{O} 2$, and CO2. An OEM type of NOx sensor that is CAN-based would be sufficient. These devices could be installed in the removable section of the exhaust system.

Currently, the engine control signals are hardwired into the MotoTron unit on the wall. This could be improved by integrating these signals into a universal breakout panel, similar to that used on the PXI cabinet. As well as this, creating a table that identifies all the connections that are currently broken out on the MotoTron wall mounted plate would be beneficial. This would help prevent researchers from mistakenly connecting to the wrong pin.

Finally, the high pressure fuel system could be refined. Changing the four pole AC motor for a twelve pole AC motor would reduce the speed to 600 RPM. Additionally, a variable speed drive could be added that would allow a user to simply turn a dial to set the optimal pump speed. With a lower speed motor, the motor could be couple directly to the high pressure fuel pump. This would help reduce noise from the pump drive box as well. In addition, looking at Figure 12-5 and Figure 12-6, it was found that although the pump supplies sufficient fuel flow, the injector pulses are much faster than the pressure pulses from the pump. This could account for the pressure drops between cycles. Running the pump at a higher speed might be the best option to reduce these pressure drops between engine cycles. This could also help to decrease the coefficient of variance of IMEP seen on the Yanmar L100V engine. 


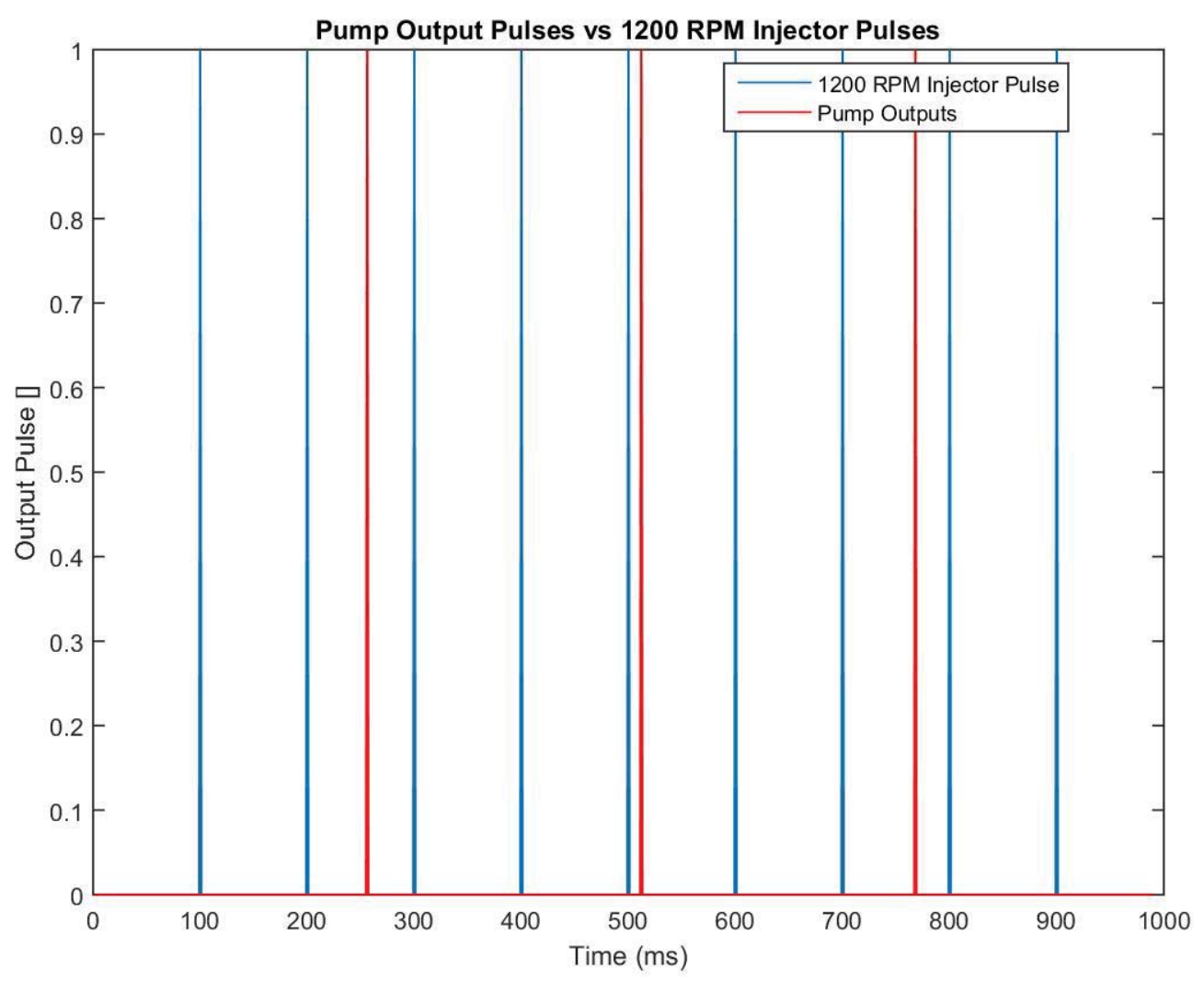

Figure 12-5: 1200RPM Injector Pulses vs High Pressure Pump Pulses 


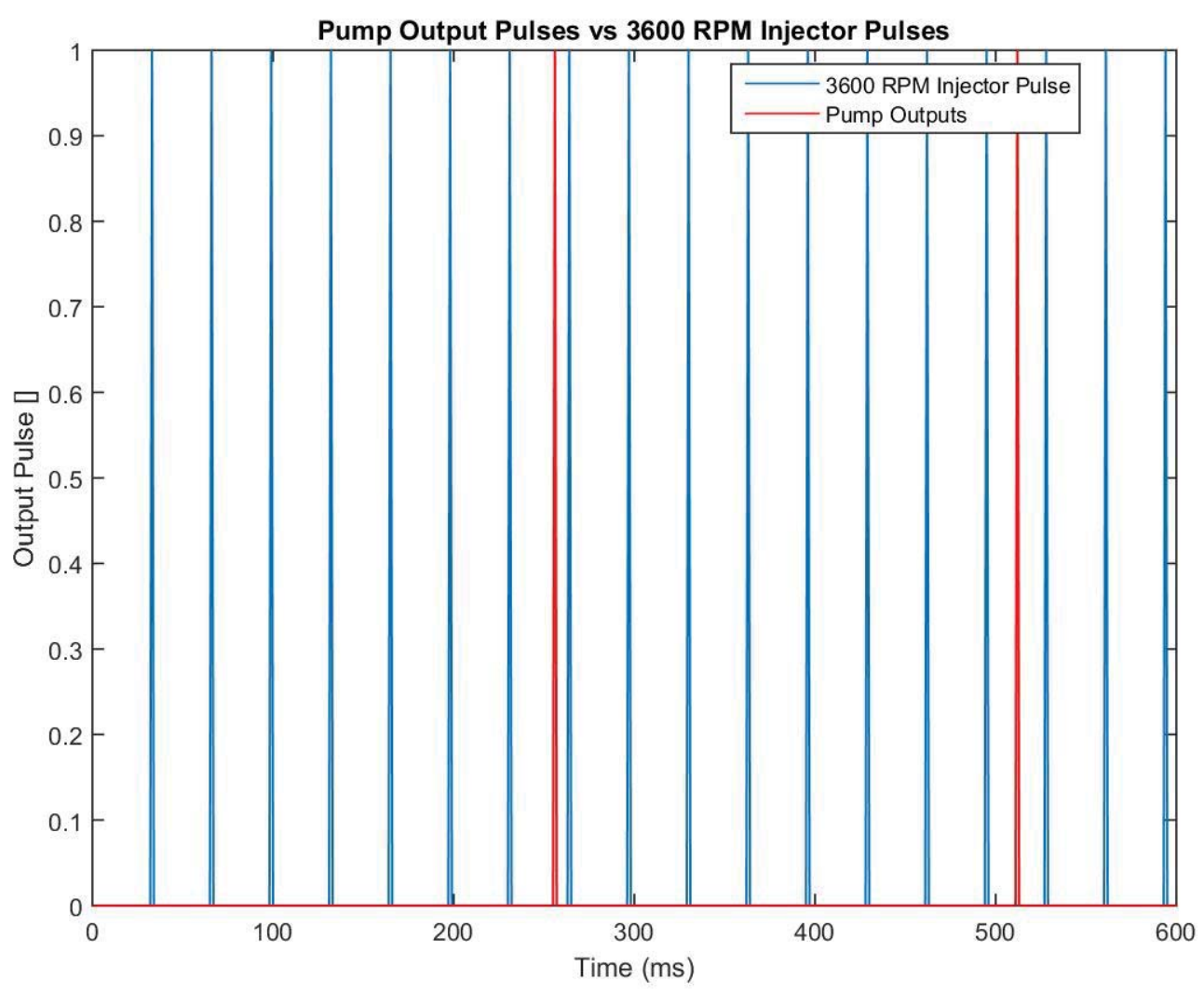

Figure 12-6: 3600RPM Injector Pulses vs High Pressure Pump Pulses 


\section{References}

[1] K. Buchholz, "New GM Center Focuses on Powertrains," 11 August 2008. [Online]. Available: http://articles.sae.org/3718/.

[2] T. F. Sondey, "Engine Delivery System". US Patent US5600059, 4 February 1997.

[3] T. F. Sondey, "Modular Fluid Manifold System". United States of America Patent US5629476, 13 May 1997.

[4] T. F. Sondey, "Modular Engine Delivery Apparatus". United States of America Patent US6591665, 15 July 2003.

[5] F. KKIENZL and M. Wetzel, "Pallet System Comprising a Setup Pallet and a Setup Pallet Receptacle". United States of America Patent US8448930, 28 May 2013.

[6] "IDBRPM25754," Baldor Electric, [Online]. Available: http://www.baldor.com/catalog/IDBRPM25754. [Accessed May 2015].

[7] D. Corporation, "Denso Injection Pump Service Manual," [Online]. Available: http://steldiesel.ru/files/crdensoservismanual.pdf. [Accessed January 2015].

[8] "Common Rail Injection," Bosch Auto Parts, [Online]. Available: http://de.boschautomotive.com/en/parts/parts_and_accessories/motor_and_sytems/diesel/common_r ail_injection/common_rail_diesel_motorsys_parts. [Accessed May 2015].

[9] C. Performance, "E-Rod Crate Engine Control System," [Online]. Available: http://www.chevrolet.com/content/dam/Chevrolet/northamerica/usa/nscwebsite/en/H ome/Vehicles/Performance/Catalog_Download/02_pdfs/Is3-and-lc9-e-rod-crate-enginecontrol-system-40tooth-and-17tooth.pdf. [Accessed May 2015].

[10] Parker, "Fuel Filtration Systems," [Online]. Available: http://www.parker.com/literature/Racor/Racor_Fuel_Filtration__Fuel_Filtration_Products_-_7529.pdf. [Accessed May 2015].

[11] "Turbine Flometer - FTO Specs," [Online]. Available: http://www.ftimeters.com/products/turbine_flowmeters/fto_series.htm. 
[12] "Canton Racing CM Fuel Filters," [Online]. Available:

http://www.summitracing.com/parts/ctr-25-909/overview/. [Accessed August 2014].

[13] Denso, "Service Manual," September 2007. [Online]. Available:

http://steldiesel.ru/files/crdensoservismanual.pdf. [Accessed July 2014].

[14] "Columbus Diesel Supply Company," [Online]. Available:

http://columbusdieselsupply.com/performanceproducts.html. [Accessed June 2014].

[15] "Hydraulic Hose," McMaster Carr, [Online]. Available:

http://www.mcmaster.com/\#general-purpose-hose/=x2xex0. [Accessed May 2015].

[16] "Spir Star," [Online]. Available: http://www.spirstar.de/en/home. [Accessed May 2015].

[17] H. P. Equipment, "High Pressure Valves, Fittings, and Tubing," [Online]. Available: http://www.highpressure.com/pdfs/section/hp.pdf. [Accessed May 2015].

[18] "High Pressure Equipment Company," [Online]. Available: http://www.highpressure.com/. [Accessed May 2015].

[19] Baldor, "Baldor Motors and Drives," [Online]. Available: http://www.baldor.com/Shared/pdf/NEMA.pdf. [Accessed May 2015].

[20] "McMaster-Carr," [Online]. Available: http://www.mcmaster.com/\#. [Accessed May 2015].

[21] "Gates 420H100 PowerGrip Timing Belt, Heavy," [Online]. Available: http://www.amazon.com/Gates-420H100-PowerGrip-Timing-Length/dp/B00CMHS8LM. [Accessed June 2014].

[22] "Diesel Jones," [Online]. Available: http://www.dieseljones.co.uk/.

[23] "Detroit Flex Defense," [Online]. Available: https://detroitflexdefense.com/. [Accessed May 2015].

[24] "AN Fittings Direct," [Online]. Available: https://www.anfittingsdirect.com/. [Accessed May 2015].

[25] "Unistrut US," Unistrut, [Online]. Available: http://www.unistrut.us/. [Accessed May 2015]. 
[26] "FORD RANGER Anchor Industries Transmission Mounts 2639," Summit Racing Equipment, [Online]. Available: http://www.summitracing.com/parts/ani2639/overview/make/ford/model/ranger. [Accessed January 2015].

[27] "Baldor," [Online]. Available: https://www.baldorvip.com/servlet/productInfoPacket/IDBRPM25754.pdf. [Accessed May 2015].

[28] "1228-10K," [Online]. Available: https://measurementsensors.honeywell.com/pages/Product.aspx?pid=122810K\&cat=Honeywell\&CategoryQUICKSHIPDELIVERY-TORQUE.

[29] "Express Encoders," [Online]. Available: http://www.beisensors.com/pdfs/HS25-opticalincremental-encoder.pdf. [Accessed May 2015].

[30] National Instruments, "DRIVVEN," January 2010. [Online]. Available: http://www.ni.com/pdf/manuals/uDCAT_UM.pdf. [Accessed May 2015].

[31] "Modules," Woodward MCS, [Online]. Available: http://mcs.woodward.com/support/wiki/index.php?title=Modules. [Accessed May 2015].

[32] "Simulink," MathWorks, [Online]. Available: http://www.mathworks.com/products/simulink/. [Accessed May 2015].

[33] "MotoHawk," Woodward MCS, [Online]. Available: http://mcs.woodward.com/support/wiki/index.php?title=MotoHawk. [Accessed may 2015].

[34] "Yanmar L100V," [Online]. Available: http://bellpower.com/uploads/yanmar_industrial_power_units/561_26.pdf. [Accessed 13 July 2015].

[35] "Industrial Engines," [Online]. Available: http://us.yanmar.com/products/industrialengines/air-cooled/epa-certified/I-v-series/I100v/. [Accessed August 2014].

[36] "Bosch 047-090 90 Degree Fuel Injector Return Line Fitting," [Online]. Available: http://dirtyhookerdiesel.com/i-16697914-bosch-047-090-90-degree-fuel-injector-returnline-fitting-leak-back-l-fitting.html.

[37] "MSC Industrial," [Online]. Available: http://www.mscdirect.com/product/details/04254389. [Accessed August 2014]. 
[38] DENSO Develops a New Diesel Common Rail System With the World's Highest Injection Pressure, Denso, 2013. 